$$
\begin{aligned}
& \text { UNIVERSIDADE DE SÃO PAULO } \\
& \text { INSTITUTO DE RELAÇÕES INTERNACIONAIS }
\end{aligned}
$$

JONATAS TORRESAN MARCELINO

\title{
Opinião Pública, Política Externa e Redes Sociais no Brasil
}




\section{JONATAS TORRESAN MARCELINO}

\section{Opinião Pública, Política Externa e Redes Sociais no Brasil}

Tese apresentada ao Programa de Pós-Graduação em Relações Internacionais do Instituto de Relações Internacionais da Universidade de São Paulo, para a obtenção do título de Doutor em Ciências.

Orientador: Prof. Dr. Leandro Piquet Carneiro

\section{Versão corrigida}

A versão original se encontra disponível na Biblioteca do Instituto de Relações Internacionais. 
Autorizo a reprodução e divulgação total ou parcial deste trabalho, por qualquer meio convencional ou eletrônico, para fins de estudo e pesquisa, desde que citada a fonte.

Catalogação na publicação Serviço de Biblioteca e Documentação

Instituto de Relações Internacionais da Universidade de São Paulo

Marcelino, Jonatas Torresan

Opinião pública, política externa e redes sociais no Brasil / Jonatas

Torresan Marcelino / Jonatas Torresan Marcelino ; orientador: Leandro Piquet. - São Paulo, 2020.

$139 \mathrm{p}$.

Tese (Doutorado) - Instituto de Relações Internacionais. Universidade de São Paulo, São Paulo, 2020.

1. Opinião pública 2. Política externa 3 . Facebook 4. Redes sociais 5. Brasil I. Piquet, Leandro, orient. II. Título.

$\mathrm{CDD}-303.380981$ 
Nome: TORRESAN-MARCELINO, Jonatas

Título: Opinião Pública, Política Externa e Redes Sociais no Brasil

Tese apresentada ao Instituto de Relações Internacionais da Universidade de São Paulo para obtenção do título de Doutor em Ciências.

Aprovado em:

Banca Examinadora

Prof. Dr.

Instituição:

Julgamento:

Profa. Dra.

Instituição:

Julgamento:

Prof.Dr.

Instituição:

Julgamento: 
Para Davi, Fernanda e Gisele 


\section{AGRADECIMENTOS}

Para Leandro, pela orientação atenciosa, pelas correções de rota, pelas novas ideias, pelos incentivos, conselhos e, sobretudo, por tornar essa jornada de pesquisa mais agradável. Obrigado por tudo!

Para Gisele, minha companheira de todas as horas, pelo apoio incondicional até o fim.

Para meus pais, Davi e Fernanda, professores de toda a vida. Por me ensinarem a valorizar o conhecimento, os livros e as coisas que realmente importam na vida.

Para a minha família, pelo afeto e apoio em todas as horas: Daniel, Monike, Sophie, Antonieta, Denise, Bernadete, Renata, Virgínia, Tiago, Vergílio, Rosana e Amanda.

Aos meus amigos: Alberto, Alex, Armando, Bruno, Carmen, Cristina, Enio, Gabriela, Giovanni, João Francisco, Juliana, Juliano, Larissa, Leandro, Liliane, Luiz Augusto, Mônica, Natalie, Pablo, Pedro, Pércio, Rafael, Renan, Roberto, Saulo, Silvio e Tiago. Vocês são muito queridos e fundamentais na minha vida.

Aos professores, funcionários e colegas da USP: obrigado pela convivência e pelas conversas enriquecedoras. Agradeço em especial ao professor Feliciano e à professora Janina, pelas contribuições em diferentes fases da pesquisa. 
TORRESAN-MARCELINO, Jonatas. Opinião Pública, Política Externa e Redes Sociais no Brasil. 2020. 146f. Tese (Doutorado em Ciências) - Instituto de Relações Internacionais, Universidade de São Paulo, São Paulo, 2020.

RESUMO: A tese Opinião Pública, Política Externa e Redes Sociais no Brasil tem o objetivo de discutir as dinâmicas da opinião pública e da política externa a partir da difusão da internet e das redes sociais no País. O primeiro capítulo aborda as mudanças ocorridas no marco cronológico de 2010 a 2020 e a evolução de posicionamentos do público nas surveys de As Américas e O Mundo (2010, 2014, 2018). O segundo capítulo apresenta uma pesquisa exploratória, cujo objetivo é a discussão de quais são os principais atalhos cognitivos utilizados pela opinião pública brasileira para se conectar a política internacional no Facebook. A investigação tem como base de dados redes de páginas do Facebook organizadas em grafos. Foram construídas 59 redes bilaterais entre o Brasil e países dos cinco continentes. A questão de pesquisa é: Quais são os clusters mais importantes nas redes bilaterais do Brasil com cada um dos 59 países selecionados? A Hipótese é a de que os clusters de Governo/Política e de Mídias não são os principais atalhos cognitivos, como o foram no Século XX. O terceiro capítulo analisa a visão da opinião pública brasileira a respeito de dez países na survey As Américas e O Mundo em perspectiva comparada com dez redes bilaterais no Facebook. As questões de pesquisa são: Q2) O uso do Facebook pelos respondentes gera alterações significativas nas percepções a respeito dos dez países em questão? Q3) A opinião positiva acerca de um país está correlacionada ao tamanho de sua rede bilateral?; Q4) A opinião negativa acerca de um país está correlacionada ao tamanho de sua rede bilateral? As hipóteses são: H2) O uso do Facebook altera positivamente as percepções de Amizade, Sociedade, Rivalidade e Ameaça dos respondentes a respeito dos dez países pesquisados; H3) Quanto mais positiva é a opinião a respeito de um país, mais volumosa (nós) e conectada (arestas) tende a ser a sua rede bilateral; H4) Quanto mais negativa a opinião a respeito de um país, menos volumosa (nós) e conectada (arestas) tende a ser a sua rede bilateral.

PALAVRAS-CHAVE: Opinião Pública, Política Externa, Facebook, Redes Sociais, Brasil 
TORRESAN-MARCELINO, Jonatas. Public Opinion, Foreign Policy and Social Networks in Brazil. 2020. 139p. Thesis (Doctorate in Sciences) - Institute of International Relations, University of São Paulo, São Paulo, 2020.

ABSTRACT | The thesis Public Opinion, Foreign Policy and Social Networks in Brazil aims to discuss the dynamics between public opinion and foreign policy in the midst of internet and social network diffusion in Brazil. The first chapter discusses the changes in Brazilian public opinion from 2010 to 2020 based on the survey The Americas and The World, conducted in Brazil by the University of São Paulo in 2010, 2014 and 2018. The second chapter presents an exploratory research that investigates which are the main cognitive shortcuts accessed by the Brazilians on Facebook to connect to international politics and related topics. The research is based on 59 bilateral networks organized in graphs. Data from Facebook was extracted using the Netvizz app. The Facebook pages are related to foreign policy, public diplomacy, culture and other subjects, from Brazil and 59 selected countries. The first research question is: "Q1) Which are the most important clusters on the 59 bilateral networks?" The hypothesis is: "H1) The Governmental/Politics and Media clusters are not the main cognitive shortcuts on foreign policy, as they were in the 20th century". The third chapter aims to analyze Brazilian public opinion of ten countries in comparison to bilateral network pages on Facebook. The database of the public opinion survey comes from The Americas and the World. Both data sets are from 2018. The networks were also built with a bilateral strategy, containing pages from Brazil and each one of these ten countries: Argentina, China, Cuba, India, Japan, Mexico, Russia, South Africa, the United States and Venezuela. The selected question from the survey was "How would you describe Brazil's relationship with the following countries: Friendship, Society, Rivalry or Threat?" The research questions are "Q2) Being a Facebook user changes the perception of each one of the ten countries?" "Q3) Does a positive opinion about a country correlate to the size of its bilateral network?", and "Q4) Does a negative opinion of another country correlate to the size of its bilateral network?" The hypotheses are "H2) Being a Facebook user positively influences the Brazilians' opinions on Friendship, Society and Rivalry of each one of the ten countries" "H3) The more positive an opinion of another country, the larger and more connected the bilateral network will be," and "H4) The more negative an opinion of another country, the smaller and less connected the bilateral network will be."

KEYWORDS: Public Opinion, Foreign Policy, Facebook, Social Networks, Brazil 


\section{SUMÁRIO}

INTRODUÇÃO. .11

1. OPINIÃO PÚBLICA E POLÍTICA EXTERNA NO BRASIL: DINÂMICAS DO

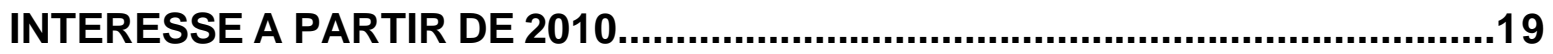

1.1 UM BREVE HISTÓRICO DAS ATITUDES POLÍTICAS PARA TEMAS INTERNACIONAIS NO PÓS-GUERRA .19

1.2 AS NOVAS VARIÁVEIS NO DEBATE: A INTERNET E AS REDES SOCIAIS .22

1.3 AS AMÉRICAS E O MUNDO | UM PANORAMA $(2010,2014,2018) \ldots \ldots \ldots \ldots \ldots . . .26$

1.3.1 POSICIONAMENTOS ESTÁVEIS NA POLARIZAÇÃO......................27

1.3.2 POSICIONAMENTOS ALTERADOS NA POLARIZAÇÃO...................30

1.4 OS ATALHOS COGNITIVOS: OS CAMINHOS PARA ACESSAR OS TEMAS INTERNACIONAIS MUDARAM? .35

\section{INTERESSES INTERNACIONAIS EM REDE: QUAIS OS ATALHOS PARA} TEMAS DISTANTES. . .49

2.1 AS REDES SOCIAIS E A DIVERSIFICAÇÃO DE ATORES NO CENÁRIO INTERNACIONAL. 49

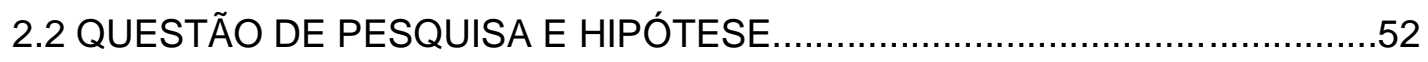

2.3 MÉTODOS E CONSTRUÇÃO DA BASE DE DADOS ...................................53

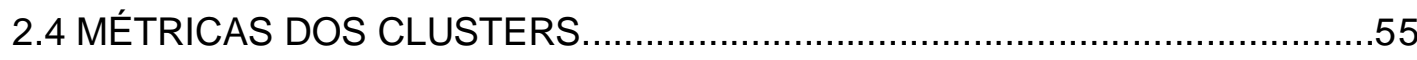

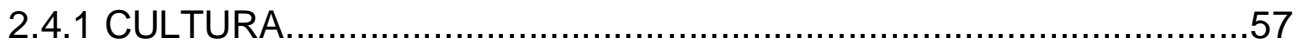

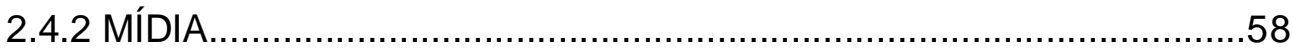

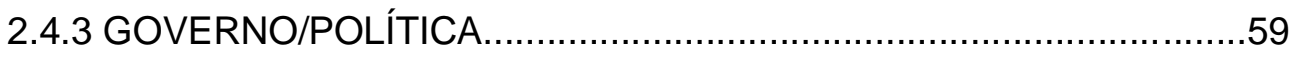

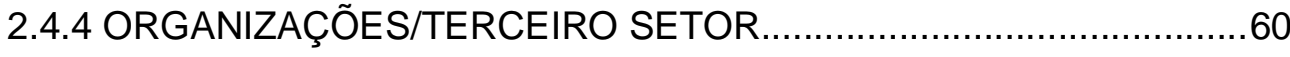

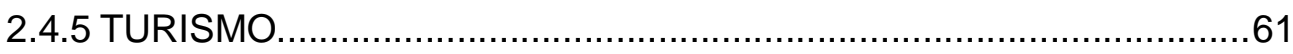

2.4.6 EDUCAÇÃO

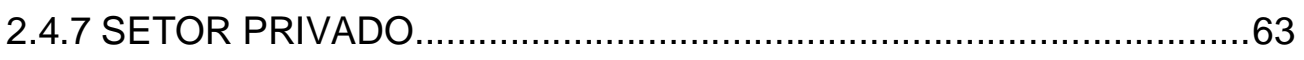

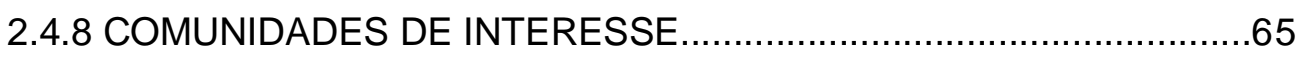

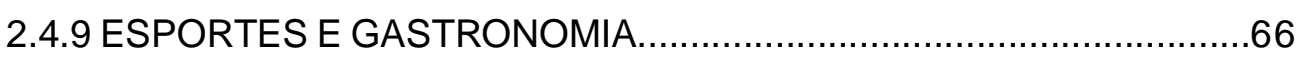

2.5 CARACTERÍSTICAS COMUNS ENTRE AS REDES A PARTIR DAS 
MÉTRICAS: UMA PROPOSTA DE TIPOLOGIA

2.6 AS REDES E A DIVERSIFICAÇÃO DE ATORES NAS RELAÇÕES INTERNACIONAIS

3. INTERESSES EM REDE: DEZ RELAÇÕES BILATERAIS DO BRASIL NA VISÃO DOS BRASILEIROS CONECTADOS..................................................79

3.1 AS RELAÇÕES DO BRASIL COM DEZ PAÍSES, SEGUNDO O PÚBLICO.....79 3.2 O USO DO FACEBOOK $E$ AS RELAÇÕES COM PAÍSES. 83

3.3 OS INTERESSES EM REDE NO FACEBOOK: DEZ PAÍSES EM RELAÇÃO COM O BRASIL. .84

3.4 QUE TIPOS DE NÓS TÊM PREDOMINÂNCIA EM CADA UMA DAS REDES BILATERAIS?.

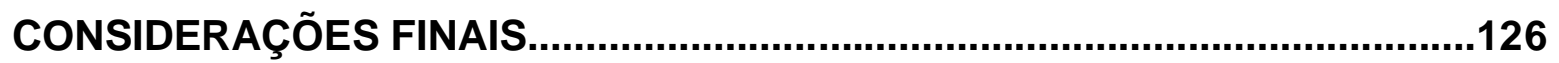

REFERÊNCIAS BIBLIOGRÁFICAS.......................................................132

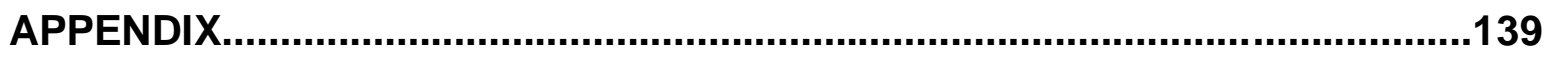




\section{INTRODUÇÃO}

A conjuntura internacional nas primeiras duas décadas do Século XXI apresenta duas frentes importantes de transformação: a primeira frente diz respeito às consequências políticas relacionadas à alternância de prosperidade econômica (2000-2007) e a recessão desencadeada pela Crise do Subprime (2008); a segunda frente de transformação é provocada pela ampla difusão do acesso à internet e às redes sociais em escala global, fator de impacto para o comportamento político de governos e da opinião pública na década de 2010. Ambas frentes de transformação se influenciariam mutuamente na medida em que os processos mencionados se aprofundaram.

Esses processos têm impactos significativos tanto na América Latina quanto no Brasil. Em primeiro lugar, é importante observar que, devido aos atentados terroristas de 11 de setembro de 2001 e à forte ascensão da China como potência mundial, os focos principais da política externa dos Estados Unidos estão no Oriente Médio ${ }^{1}$ e na Ásia, e não na América Latina. A China, por sua vez, diversifica o seu leque de atuação em política externa na medida em que expande a sua influência política e econômica mundial. Nesse período dos anos 2000, a América Latina avança economicamente movida pelo boom das commodities, influenciado pela ascensão chinesa, e adota uma posição mais autônoma em sua política externa.

A difusão de políticas redistributivas na região leva partidos governistas de centroesquerda a se fortalecerem com altas taxas de aprovação ${ }^{2}$ nos primeiros anos do Século XXI. Outro motor desse período de crescimento na América Latina é a expansão do consumo. $O$ crescimento do consumo viabilizou a expansão das redes sociais no Brasil em particular, possibilitada pela ampliação do acesso à internet e

\footnotetext{
${ }^{1}$ Desde 2001, Estados Unidos se envolveram em guerras no Afeganistão (2001-2017), Iraque (2003-2011) e Síria (2011-2020)

2 De acordo com dados do Latinobarómetro (2003-2010), as taxas de aprovação dos governos de centro-esquerda superaram os $60 \%$ na Argentina $(2003,2006)$, no Brasil $(2003,2006,2008,2009$, 2010), Chile (2004, 2005, 2006, 2009), Equador (2007, 2008), Uruguai (2005-2010) e Venezuela (2005-2007)
} 
a computadores pessoais. O acesso à internet no País era de $20,9 \%{ }^{3}$ dos domicílios em 2005, número que saltou para 46,5\% em 2011. Com relação ao número de computadores pessoais, a cifra passou de 12,6\% em 2001 para 46,4\% em 2012.

Em um período no qual os smartphones ainda não eram parte do cotidiano da população, o Orkut se tornou a rede social favorita dos brasileiros a partir de 2005. Vinculado ao então emergente Google, tornou-se amplamente difundido principalmente entre os jovens de regiões metropolitanas e de municípios acima de 100 mil habitantes. No seu auge, em 2008, a rede social chegou a ter mais de 40 milhões de usuários no País. O reinado do Orkut no País durou até 2012, quando o Facebook ${ }^{4}$ ultrapassou o concorrente em número de perfis: 36,1 milhões contra 34,4 milhões.

Em 2010, os smartphones com acesso às redes sociais se difundem, devido à extensa influência do iPhone no mercado de telefonia móvel internacional. Em 2010, o Facebook já apresentava 500 milhões de perfis no mundo, dos quais 100 milhões acessavam a rede via smartphone. Com mais mobilidade nas redes sociais, expansão da infraestrutura de telefonia móvel e uma conjuntura de estagnação econômica após a Crise do Subprime nos EUA (2008), estão dadas as condições para o uso político que se daria logo no início da década dos anos 2010.

Em 2010, ocorre uma crise diplomática de grandes proporções. A ONG Wikileaks, sediada na Suécia, vaza mais de 90 mil documentos confidenciais das Forças Armadas dos Estados Unidos referentes ao período de 2004 a 2009, revelando violações de direitos humanos praticadas em ações militares de combate ao terrorismo no Oriente Médio. O Caso Wikileaks teve grande impacto nos mecanismos de controle social via internet e o vazamento de dados sigilosos de governos e corporações poderosas provocou grande pressão para a quebra de

\footnotetext{
${ }^{3}$ PNAD, IBGE (Série Histórica 2001-2016)

${ }^{4}$ Em 2017, o Brasil estava entre os cinco países com mais usuários de Facebook em números absolutos, com 139 milhões de perfis. O número equivale a mais da metade da população do País, que é de 207,6 milhões.
} 
sigilos dos ativistas envolvidos e incidentes internacionais, como o refúgio de Julian Assange - líder da organização - na Embaixada do Equador em Londres (Malini e Antoun, 2012).

O ano de 2013 revelou-se como um marco nesse sentido, com a diversificação das fontes de ameaças para os Estados e grandes corporações. Edward Snowden, analista da National Security Agency (NSA), e Glenn Greenwald, repórter do diário londrino The Guardian, revelaram que 35 líderes mundiais foram grampeados pelos Estados Unidos, incluindo Dilma Rousseff, Angela Merkel e François Hollande. Além do extenso impacto dos vazamentos da NSA em 2013, as redes assumem o protagonismo em movimentos políticos em diferentes continentes.

Recuero e colegas (2015) apontam que a rápida propagação das redes sociais como ferramentas de protestos se deve à presença marginal de mediadores políticos tradicionais nos movimentos, por conta da grande descentralização de pautas e atores envolvidos. Se o Facebook havia se consolidado como a rede social hegemônica em 2012, ultrapassando a casa do 1 bilhão de usuários mundiais, é o Twitter o primeiro ator-chave em protestos no Brasil, Egito, Espanha, Estados Unidos e Turquia, entre os anos de 2011 e 2014.

Dentre as principais razões para o protagonismo do Twitter em protestos no início dos anos 2010, estão a facilidade de seleção e difusão de notícias, discursos e narrativas políticas, em especial por influenciadores independentes de veículos tradicionais. Outro ponto importante são os precedentes: desde os anos 2000, já eram registrados diversos casos internacionais de uso do Twitter em países com restrições nas comunicações, tanto por razões de censura política quanto por suspensão temporária em ataques terroristas: Índia (2008), Irã (2009) e o próprio Egito (2011) são os principais exemplos (Meraz e Papacharissi, 2013).

No entanto, o Twitter não é somente protagonista em crises políticas: ele também é ferramenta de influenciadores no dia a dia da política internacional. Após a vitória 
de Barack Obama ${ }^{5}$ nas eleições presidenciais dos Estados Unidos em 2008, a primeira com grande impacto do uso de redes sociais, o uso das redes por autoridades políticas se tornou paulatinamente inerente aos cargos, e ainda mais relevante a depender do peso geopolítico dos perfis. A agência de relações públicas Burson-Marsteller conduziu estudos anuais sobre o impacto das redes sociais nas relações internacionais entre 2012 e 2017.

O número de governos e líderes mundiais com conta na rede social saltou de 125 em 2012 para 178 em 2017. Enquanto presidente dos Estados Unidos, Barack Obama liderou no número de seguidores no Twitter de 2012 a 2016. O Papa Francisco ocupou a segunda colocação de 2013 a 2016, assumindo a liderança na análise em 2017, a frente de Donald Trump. Narendra Modi, primeiro-ministro da Índia, esteve entre os cinco perfis mais seguidos do Twitter desde 2014, geralmente na terceira colocação. Recep Tayyip Erdogan, presidente turco, alternou a quarta colocação com o perfil institucional da Casa Branca. Na América Latina, Dilma Rousseff esteve entre os cinco perfis mais seguidos entre 2012 e 2015. Além de Rousseff, Cristina Kirchner (Argentina), Juan Manuel Santos (Colômbia), Enrique Peña Nieto (México) e Nicolás Maduro (Venezuela) também ocuparam com frequência o posto dos cinco líderes mais seguidos na plataforma na região.

Apesar de não tão populares nas redes como os perfis dos líderes políticos, os organismos multilaterais e organizações não-governamentais também apresentaram crescimento importante no número de seguidores no Twitter. Em 2013, cinco perfis ultrapassaram a casa do 1 milhão: UNICEF, ONU, Fórum Econômico de Davos, ACNUR e WWF. Entre 2015 e 2017, outros seis perfis também chegaram a essa marca: OMS, UNESCO, Human Rights Watch, Greenpeace, Organização Europeia para a Pesquisa Nuclear (CERN) e o Banco Mundial. Outro dado relevante diz respeito ao número de representações ou representantes diplomáticos presentes na rede social. Em 2014, 3.500 eram ativos e oito países apresentavam mais de 100 perfis: Reino Unido, Polônia, Israel, Suécia,

${ }^{5}$ Barack Obama foi o primeiro líder mundial a aderir ao Twitter, em março de 2007. 
Canadá, Rússia, França e Estados Unidos. Esse número ultrapassou a marca dos 4.100 em 2015 e 100 perfis dobraram o número de seguidores.

A investigação da Burson-Marsteller também levantou dados do comportamento dos líderes políticos internacionais no Facebook, rede social selecionada para esta investigação. De acordo com o estudo, 169 governos marcavam presença na rede social em 2016 e 2017, incluindo 87 chefes de Estado, 82 primeiros-ministros e 51 ministros de relações exteriores. O número de países presentes se manteve estável nos dois levantamentos, mas o número de likes $^{6}$ nas páginas cresceu de forma significativa: eram 230 milhões em 2016 e passaram a ser 311 milhões em 2017.

Em 2016, os líderes mais seguidos no Facebook eram, pela ordem: Barack Obama (EUA), Narendra Modi (Índia), Recep Tayyip Erdogan (Turquia), Joko Widodo (Indonésia), Abdel Fattah el-Sisi (Egito), Rainha Rania (Jordânia), Enrique Peña Nieto (México) e Noynoy Aquino (Filipinas). Em 2017, Modi assume a liderança do ranking com o fim do mandato de Obama e Donald Trump assume a segunda colocação. Noynoy Aquino deixa de figurar entre os mais seguidos, posição assumida por Samdech Hun Sen, primeiro-ministro do Camboja.

Como visto, as redes sociais ganharam grande centralidade no debate político internacional nesse marco cronológico e se tornaram um espaço da crescente polarização da política doméstica no Brasil, iniciada nas Jornadas de Junho (2013), aprofundada em duas eleições presidenciais $(2014,2018)$ e no impeachment de Dilma Rousseff (2016). Nesse cenário de polarização, convivem atores forjados em ambientes políticos online e offline, que projetam diferentes formas de comportamento no ambiente no qual a política externa e a política internacional se desenvolvem.

\footnotetext{
${ }^{6}$ Em 2017, os likes no Facebook implicavam necessariamente em seguir (follow) a página. Posteriormente, a rede social permite que os usuários façam distinção entre ambas as formas de conexão
} 
A tese Opinião Pública, Política Externa e Redes Sociais no Brasil busca explorar quais são os efeitos da ampliação do acesso às redes sociais e da polarização política nos comportamentos do público brasileiro em relação a temas externos. Essa investigação discutirá essa problemática a partir do conceito de atalhos cognitivos, utilizado na literatura de ciência política e relações internacionais para a compreensão dos caminhos utilizados pelos eleitores para a decodificação de temas políticos complexos. As duas bases de dados utilizadas na pesquisa são três rodadas da survey As Américas e O Mundo, conduzidas no Brasil pela Universidade de São Paulo (USP) e 59 redes de páginas do Facebook, que contemplam fanpages de política externa e internacional, diplomacia pública e temas relacionados. No total, 33.468 páginas integram as 59 redes bilaterais, construídas entre o Brasil e países selecionados dos cinco continentes.

O primeiro capítulo, Opinião Pública e Política Externa no Brasil: Dinâmicas do Interesse a Partir da Década de 2010, tem o objetivo de contextualizar as dinâmicas da opinião pública e da política externa a partir da difusão da internet e das redes sociais no Brasil. As mudanças ocorridas no marco cronológico de 2010 a 2020 contemplam: a) ampliação do acesso à internet; b) ampliação do acesso às redes sociais; c) ampliação da polarização na política doméstica; d) estabilidade na atenção a notícias internacionais. Após esse debate, será abordada a evolução de posicionamentos dos brasileiros na survey As Américas e O Mundo, em um painel considerando as três rodadas e o cenário de polarização doméstica. Por fim, será discutido o conceito de atalhos cognitivos. Esse debate tem o objetivo de abordar os alicerces do conceito original dos atalhos cognitivos - concebido em uma conjuntura de domínio da mídia offline - e as mudanças de contexto geradas pela difusão da internet, das redes sociais e das alterações nos cenários de política doméstica e internacional.

O segundo capítulo, Interesses Internacionais em Rede: Quais os Atalhos para Temas Distantes, é uma pesquisa exploratória, cujo foco é a discussão de quais são os principais atalhos cognitivos utilizados pela opinião pública brasileira para se 
conectar a política externa e internacional no Facebook, a rede social mais popular no Brasil. A investigação tem como base de dados redes de páginas da rede social organizadas e analisadas em grafos no software Gephi. Foram construídas 59 redes bilaterais entre o Brasil e países dos cinco continentes. A questão de pesquisa é: Q1) Quais são os clusters mais importantes nas redes bilaterais do Brasil com cada um dos 59 países selecionados? A hipótese é a de que: H1) Os clusters de Governo/Política e de Mídias não são mais os principais atalhos cognitivos, como o foram no Século XX, em um contexto offline. As métricas serão discutidas por duas vias: dados das redes comparados por dez clusters qualitativos e por uma proposta de tipologia das redes com base nas métricas consideradas em seu conjunto.

O terceiro capítulo, Interesses em Rede: Dez Relações Bilaterais do Brasil na Visão dos Brasileiros Conectados, analisará a visão da opinião pública brasileira a respeito de dez países na survey As Américas e O Mundo em perspectiva comparada com dez redes bilaterais no Facebook. Os países a serem analisados são Argentina, África do Sul, China, Cuba, Estados Unidos, Índia, Japão, México, Rússia e Venezuela. A pergunta selecionada da survey foi: Como você descreveria a relação do Brasil com os seguintes países: Amizade, Sociedade, Rivalidade ou Ameaça? As questões de pesquisa são: Q2) O uso do Facebook pelos respondentes gera alterações significativas nas percepções a respeito dos dez países em questão? Q3) A opinião positiva acerca de um país está correlacionada ao tamanho de sua rede bilateral?; Q4) A opinião negativa acerca de um país está correlacionada ao tamanho de sua rede bilateral? As hipóteses são: H2) O uso do Facebook altera positivamente as percepções de Amizade, Sociedade, Rivalidade e Ameaça dos respondentes a respeito dos dez países pesquisados; H3) Quanto mais positiva é a opinião a respeito de um país, mais volumosa (nós) e conectada (arestas) tende a ser a sua rede bilateral; H4) Quanto mais negativa a opinião a respeito de um país, menos volumosa (nós) e conectada (arestas) tende a ser a sua rede bilateral.

Os três capítulos, em conjunto com esta introdução e com as considerações finais, têm o objetivo de apresentar uma contribuição sobre fatores e consequências na ampliação da presença online do público e dos diferentes atores nas relações 
internacionais do Brasil. Essa ampliação de presença é exemplificada em 59 redes de diferentes portes, clusters e métricas, testados em dez estudos de caso. Defendo que, apesar da polarização política influenciada pelas redes sociais, o uso do Facebook altera positivamente a imagem dos brasileiros a respeito de outros países; e que essa alteração é refletida no volume de páginas e de conexões em uma rede bilateral. 


\section{OPINIÃO PÚBLICA E POLÍTICA EXTERNA NO BRASIL: DINÂMICAS DO INTERESSE A PARTIR DA DÉCADA DE 2010}

\subsection{UM BREVE HISTÓRICO DAS ATITUDES POLÍTICAS PARA TEMAS INTERNACIONAIS NO PÓS-GUERRA}

O arcabouço estruturado na ciência política a respeito das atitudes individuais nas democracias liberais na segunda metade do Século XX pavimentou o caminho para a construção de uma literatura mais diversificada, que também abarcou o comportamento da opinião pública para a política externa. Nesse sentido, existem alguns marcos importantes para conhecermos o debate. A primeira e central questão nesse sentido foi levantada por Almond (1950): A população tem interesse em conhecer os temas de política externa? O cientista político sustenta que a opinião pública não apresenta conhecimento aprofundado e coerente a respeito de temas internacionais e que também que reage de forma volátil e pontual a issues estrangeiros.

Almond afirma que os interessados em relações internacionais podem ser divididos em quatro grupos ${ }^{7}$ : as elites políticas, burocráticas, de grupos de interesse e da comunicação. Os debates travados entre essas elites são acompanhados pelo attentive public, composto no geral por indivíduos com maior grau de instrução e que são a audiência estável dos debates travados pelas elites mencionadas. De acordo com o autor, a opinião pública apenas se mobiliza em questões de política externa em casos de guerras.

A obra de Almond, concebida em um contexto de crítica aos efeitos da política isolacionista dos EUA (Hosti, 1992), apresentou grande influência no campo da

\footnotetext{
${ }^{7}$ Em contraste, Deutsch (1978), sinaliza uma relação hierárquica entre as elites, com uma gradação de influência: no topo da cadeia, estão as elites econômicas/sociais; seguidas pelas políticas, comunicacionais, pelos influenciadores da opinião pública e, finalmente, pela opinião pública de forma geral.
} 
ciência política na Guerra Fria e encontrou eco em internacionalistas como Morgenthau (1948), que também considerava a opinião pública um elemento marginal na política externa. Converse (1964) conduziu uma pesquisa seminal em opinião pública e política externa, encontrando baixa correlação e coerência entre o pensamento de política doméstica e política externa em surveys nos EUA.

A atribuição de irracionalidade à opinião pública por Almond e autores realistas guarda relação com o próprio período na qual foi concebida: em tempos de Guerra Fria, a reação popular a temas de política externa era vista como um fator de desestabilização para Estados que deveriam tomar decisões sensíveis em um período de tensões internacionais. O ponto de inflexão sobre a mood theory de Almond foi o envolvimento dos Estados Unidos na Guerra do Vietnã (1964-1973), momento no qual se multiplicaram as pesquisas de opinião pública independentes a respeito do conflito em meio a grandes mobilizações populares sobre um importante tema da política internacional (Hosti, 1992). O próprio conceito de opinião pública passa a ser questionado nesse período, por autores como Pierre Bourdieu (1973) ${ }^{8}$.

O que se seguiu nos anos 1970 e 1980 foram uma série de trabalhos que contestavam os postulados do Consenso Almond-Lippmann: Rosenau (1967), Caspary (1970), Hurwitz e Peffley (1987), Page-Shapiro (1988), Inglehart (1988). Hosti destaca que, apesar das contestações, ninguém ainda confrontou a tese principal de Almond: a de que o público tem baixo conhecimento em política externa. Bennett (1994) afirma que nem mesmo a Guerra do Golfo, a primeira a ser transmitida em tempo real via televisão, modificou de forma significativa esse

\footnotetext{
${ }^{8}$ Bourdieu (1973) prefere definir a opinião pública como um "système d'intérêts" (sistema de interesses). Ele afirma que a opinião pública não existe, mas sim grupos de pressão organizados: "Bref, j'ai bien voulu dire que l'opinion publique n'existe pas, sous la forme en tout cas que lui prêtent ceux qui ont intérêt à affirmer son existence. J'ai dit qu'il y avait d'une part des opinions constituées, mobilisées, des groupes de pression mobilisés autour d'un système d'intérêts explicitement formulés; et d'autre part, des dispositions qui, par définition, ne sont pas opinion si l'on entend par là, comme je l'ai fait tout au long de cette analyse, quelque chose qui peut se formuler en discours avec une certaine prétention à la cohérence."
} 
cenário. Os pontos de convergência entre esses pesquisadores estão na existência de uma estrutura mínima de coerência nas opiniões sobre política externa; e na falsa dicotomia entre internacionalismo e isolacionismo, que não descreveria de forma precisa as linhas de opinião internacional.

Page e Shapiro (1988) também criticam o consenso Almond-Lippmann, discordando da teoria sobre volatilidade da opinião pública. Os autores sustentam que a mood theory é um mito e que a opinião coletiva para temas externos tem estabilidade. Analisando uma base de 6 mil questões de pesquisas de opinião pública realizadas nos EUA de 1935-1982, Page e Shapiro afirmam que os picos de mudanças da opinião pública não se devem à sua volatilidade, mas sim à natureza própria das relações internacionais, que apresenta frequentemente mudanças repentinas de cenário em locais cujas informações chegam mediadas pelo governo e pela imprensa.

Inglehart (1988) também argumenta que a opinião pública é mais estável do que preconiza a mood theory. De acordo com ele, diferentes sociedades apresentam orientações culturais duráveis, que compõem a chamada "cultura cívica", uma estrutura coerente de valores alinhados com a satisfação à vida pessoal, satisfação política, confiança interpessoal e suporte à ordem atual de sua própria sociedade. Inglehart argumenta ainda que uma cultura cívica local é durável, mas não imutável, e que também apresenta consequências importantes para a viabilização de instituições democráticas. Essa argumentação é a espinha dorsal da chamada Hipótese Culturalista.

Hurwitz e Peffley (1987), por sua vez, afirmam que o cidadão médio pensa sobre suas crenças e valores de forma hierárquica e organizada. Segundo eles, alinhamentos conservadores ou liberais de cada indivíduo constituem indicadores fracos para determinar a atitude da opinião pública ou de indivíduos em política externa. O custo de participação é considerado um fator importante na distância do público em relação aos temas internacionais, já que dependem de seus governos e 
de comentadores na mídia para saber o que está acontecendo no exterior. $\mathrm{Na}$ mesma linha, Stimson (2004) constata que a atitude opinião pública em temas domésticos é fundamentalmente diferente das atitudes voltadas para a política externa, e que em ambos os casos o público em geral é ignorante para assuntos políticos.

\subsection{AS NOVAS VARIÁVEIS NO DEBATE: A INTERNET E AS REDES SOCIAIS}

A revisão de literatura em opinião pública e política externa apresentou a evolução do debate ao longo da segunda metade do Século XX, no qual os binômios irracionalidade/instabilidade e racionalidade/estabilidade em temas externos ocuparam o centro da pauta nas democracias liberais.

Essa conjuntura está em acelerada transformação desde o início do Século XXI, essencialmente por três fatores: 1) $O$ advento da internet para a sociedade civil, iniciada via computadores pessoais e aprofundada pelos smartphones; 2) 0 advento das redes sociais; 3) A crise dos partidos políticos centristas ocidentais e os consequentes debates sobre polarização política. Essas três mudanças, iniciadas nos países desenvolvidos, rapidamente se tornaram um fenômeno global.

O segundo passo deste trabalho será apresentar brevemente os dados da evolução do interesse em notícias internacionais em três rodadas de As Américas e O Mundo (2010, 2014, 2018), após dimensionar a adesão à internet e às redes sociais no Brasil, além de verificar a dinâmica do posicionamento político dos respondentes das surveys ao longo da última década.

De acordo com dados do Banco Mundial, o acesso à internet no Brasil cresceu de maneira constante entre 2010 e 2017. Em 2010, 40,65\% da população brasileira tinha acesso à internet. O valor chegou a 51,04\% em 2013 e alcançou 60,87\% em 
2016. A maior evolução anual, no entanto, foi entre 2016 e 2017, quando a rede mundial de computadores atingiu $67,47 \%$ dos brasileiros.

Os dados do Banco Mundial sobre os planos de telefonia móvel por 100 habitantes apresentaram uma dinâmica diferente. Em 2010, existiam 100,62 assinaturas para cada centena de brasileiros. Os números subiram constantemente, até atingir o pico em 2015, quando havia 147,85 assinaturas por 100 habitantes. A partir de 2016, se dá uma acentuada queda e os números retrocedem para 105,01 em 2017.

O volume de usuários de redes sociais apresentou forte alta no período, acompanhando os dados de crescimento de acesso à internet, ainda que a adesão nas assinaturas de telefonia móvel tenha involuído. Dados da survey As Américas e O Mundo (2014 e 2018) apontam que o número de usuários subiu de 52,8\% em 2014 para 78\% em 2018, ultrapassando o próprio acesso à internet médio no marco cronológico. Entre os usuários de 2018, 61,9\% declararam ter perfil no Facebook.

A partir dos dados do Banco Mundial e de As Américas e O Mundo, verificamos que o público respondente da survey em 2018 apresenta maior probabilidade de acesso à internet e de ter perfil em rede social na comparação com 2010. Nesse novo cenário, a polarização política tem sido muito discutida nos âmbitos da ciência política e das relações internacionais. Uma das questões ${ }^{9}$ colocadas ao público nas rodadas dizia respeito à escala de seu posicionamento político pessoal de 0 (esquerda) a 10 (direita). O gráfico a seguir sinaliza as dinâmicas de distribuição dos posicionamentos políticos ao longo das três rodadas.

${ }^{9}$ Em uma escala de 0 a 10, em que 0 significa politicamente associado à esquerda e 10 à direita, onde você se encontra? (2010); Em uma escala de 0 até 10, em que 0 significa politicamente associado à esquerda e 10 à direita, onde você se encontra? (2014); Em uma escala de 0 até 100, em que 0 significa politicamente associado a esquerda e 100 a direita, onde o senhor/senhora se colocaria (2018). No caso da questão da rodada 2018, os resultados foram padronizados para a escala 0-10 para se tornarem comparáveis com os das demais rodadas. 
De início, verificamos que existe tendência de concentração no centro político nas três rodadas, mas que a extrema-direita se torna tão relevante na distribuição quanto o centro a partir de 2014. Outro fator importante é que o volume de respondentes de centro-esquerda (2-4) diminui no mesmo período em que se amplia a concentração na direita. Por outro lado, se revela a tendência de mais respondentes se posicionarem na extrema-esquerda (0) ao longo do tempo.

\section{FIGURA 1 | ESPECTRO POLÍTICO DOS RESPONDENTES}

\section{ESQUERDA E DIREITA}

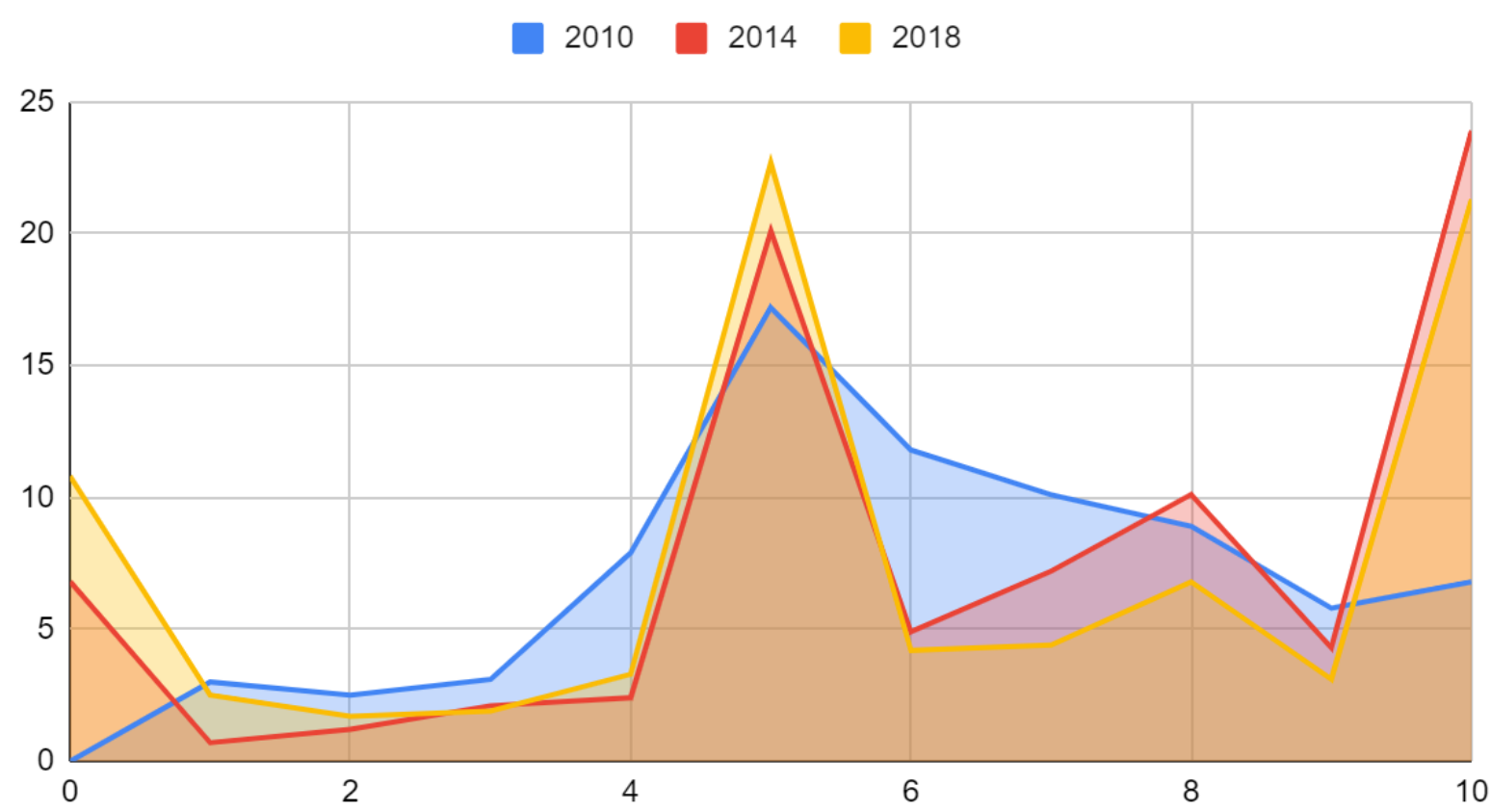

Fonte: As Américas e O Mundo

Em 2010, considerando a faixa de 0 a 4, a maior concentração estava em 4 (7,9\% dos entrevistados). A partir de 2014, a maior concentração passa a ao 0 , com 6,8\%, com a margem sendo ampliada para 10,8\% em 2018. Em conjunto, os respondentes declarando estar na faixa de 2-4 diminuem.

O mesmo fenômeno de diminuição de espectros intermediários ocorre na centrodireita (6-9), onde todos os percentuais são menores em relação a 2010. Em contraste, os entrevistados que se definiam como 10 passaram de 6,8\% em 2010 
para 21,3\% em 2018. Também houve crescimento entre os respondentes de centro (5), que eram $17,2 \%$ e passaram a $22,7 \%$.

Talvez um dos possíveis efeitos do protagonismo da política doméstica pós-2013 tenha sido a diminuição dos respondentes que não souberam definir o seu posicionamento político ou que não responderam. Esse grupo, que correspondia a 23,1\% em 2010, caiu para 16,3\% em 2014, mas voltou a subir para 17,8\% em 2018. Portanto, o público de 2018 é mais conectado, com tendência a ter perfil em redes sociais e a ser mais conservador na comparação com a rodada de 2010.

Apesar do crescimento da conectividade no Brasil e da ampliação nas definições de posicionamentos políticos, a atenção ${ }^{10}$ a notícias internacionais apresentou variação menos acentuada nas surveys na comparação com as alterações na distribuição do posicionamento político. A proporção do público que se declarou muito atento aos temas internacionais por meio das notícias subiu de 21,9\% para $27,2 \%$ entre 2010 e 2018.

Entre os que apresentam média atenção, houve pequena oscilação de 33,7\% para $31,3 \%$. Os que se consideram pouco atentos variaram de $24,8 \%$ para $26,4 \%$, enquanto os que declararam ser nada atentos oscilaram de 16,3\% para 13,1\%. Em 2010, 2,9\% afirmaram que não seguiam as notícias, contra 0,7\% em 2018. Em suma, os respondentes muito atentos cresceram entre 2010 e 2014, mas voltaram a cair em 2018, e o contrário ocorreu entre os nada atentos.

Dada a relativa estabilidade no interesse em notícias internacionais, apesar da teórica diminuição do custo de informar-se, é importante conhecermos o quadro de posicionamentos em temas externos, para verificação de possíveis alterações ou permanências em temas importantes das relações exteriores do País.

${ }^{10}$ Quando assiste às notícias, quão interessado você está quanto às relações do Brasil com outros países: muito interessado, razoavelmente interessado, pouco interessado ou nada interessado? 


\subsection{AS AMÉRICAS E O MUNDO | UM PANORAMA (2010, 2014, 2018)}

Investigações conduzidas no Brasil, México, Colômbia, Peru e Equador indicam que, como nos levantamentos dos EUA e da Europa, há um sistema de crenças políticas regular e sólido em política externa. Ao analisar os dados do projeto para Brasil, Colômbia, México, Peru e Equador, Castillo, Maldonado e Schiavon (2015) afirmam que existe um sistema de crenças políticas estável e consistente que equipa a opinião pública desses países com ferramentas para compreender a realidade internacional, ainda que com limitações de conhecimentos em assuntos internacionais. A variável dependente dos autores foi a atitude dos países mencionados com relação aos Estados Unidos, usando cinco variáveis de controle: educação, idade, renda, interesse em notícias internacionais e contato com o exterior.

No caso da rodada brasileira de As Américas e O Mundo de 2010, Almeida, Carneiro e Onuki (2012) afirmam que há alta correlação entre grau de interesse em questões externas e grau de instrução no País. O interesse entre os mais escolarizados é mais que o dobro em comparação com os menos escolarizados. Entre o público geral, foi registrado pouco contato com o exterior: apenas $3,8 \%$ do público desinteressado e desinformado e $11,2 \%$ do público informado e interessado havia viajado para fora do País. As rodadas de 2014 do público e dos líderes de 2016 (Almeida et al, 2017) apontam um crescimento no contato pessoal com o exterior para $9,8 \%$ entre o público desinformado e desinteressado e de $20,6 \%$ para o público informado e interessado.

Levando em conta as investigações já realizadas sobre o tema e considerando as alterações de cenário referentes ao acesso à internet e ao uso de redes sociais, analisaremos se o cenário de forte ampliação da polarização política no País influencia de algum modo as opiniões do público brasileiro em relação a temas externos nas três rodadas. Desta forma, a análise em painel será conduzida em 
dois blocos, contemplando os posicionamentos com maior estabilidade e os que apresentaram alterações relevantes ao longo do marco cronológico.

\subsubsection{POSICIONAMENTOS ESTÁVEIS NA POLARIZAÇÃO}

Os posicionamentos dos brasileiros que apresentam maior estabilidade entre 2010 e 2018 estão centrados na importância do País no presente, nos objetivos prioritários de política externa, na entrada de costumes estrangeiros e na relação com as potências mundiais. Com relação à relevância ${ }^{11}$ do Brasil no plano internacional no presente, o volume dos que consideram o País importante ou muito importante oscila entre $82,5 \%$ em 2010 e $85,1 \%$ em 2018. No entanto, "importante" $(45,9 \%)$ tem o maior percentual em 2018 , em contraste com "muito importante" (48,7\%) em 2010.

Foram selecionados ${ }^{12} 11$ objetivos $^{13}$ de política externa, classificados pelos respondentes como Muito Importante, Importante, Pouco Importante ou Nada Importante. As variações negativas ou positivas em cada uma das 11 pautas reforçaram tendências já existentes nas três rodadas. Dez dos onze objetivos de política externa são classificados por mais de $70 \%$ do público como Muito Importante ou Importante nas três rodadas.

\footnotetext{
${ }^{11}$ No plano internacional, qual é a importância do Brasil: muito importante, razoavelmente importante, pouco importante ou nada importante?

${ }^{12}$ Foram considerados apenas os objetivos cujas questões estão presentes nas três rodadas

${ }^{13}$ Gostaria que o Sr(a) me dissesse qual a importância que acredita que cada um dos seguintes objetivos deve ter para a política exterior do Brasil, ou seja, se o Sr(a) os considera muito importante, importante, pouco importante ou nada importante?
} 


\section{TABELA 1 | OBJETIVOS DE POLÍTICA EXTERNA}

OBJETIVO DE POLÍTICA EXTERNA
Fortalecer a ONU
Fortalecer a OEA
Combater o terrorismo internacional
Ajudar a levar a democracia a outros países
Ajudar a melhorar o nível de vida nos países menos
desenvolvidos
Prevenir a proliferação de armas nucleares
Combater o narcotráfico e o crime organizado
Proteger os interesses dos brasileiros em outros países
Atrair investimentos estrangeiros para o Brasil
Proteger o meio ambiente
Promover a integração regional

\begin{tabular}{|c|c|c|c|}
\hline \multicolumn{4}{|c|}{ Muito Importante/Importante } \\
\hline 2010 & 2014 & 2018 & Variação \\
\hline $78.90 \%$ & $80.70 \%$ & $84.90 \%$ & $+7,6 \%$ \\
\hline $63.70 \%$ & $51.60 \%$ & $72.50 \%$ & $+13,8 \%$ \\
\hline $87.10 \%$ & $83.50 \%$ & $86.70 \%$ & $-0,5 \%$ \\
\hline $83.20 \%$ & $82.10 \%$ & $81.90 \%$ & $-1,6 \%$ \\
\hline $87.70 \%$ & $88.70 \%$ & $93.80 \%$ & $+7,0 \%$ \\
\hline $87.50 \%$ & $70.80 \%$ & $77.80 \%$ & $-11,1 \%$ \\
\hline $93.50 \%$ & $93.60 \%$ & $94.80 \%$ & $+1,4 \%$ \\
\hline $92.10 \%$ & $92 \%$ & $92.10 \%$ & $0 \%$ \\
\hline $88 \%$ & $79.70 \%$ & $92.10 \%$ & $+4,7 \%$ \\
\hline $94.30 \%$ & $98 \%$ & $99.10 \%$ & $+5,1 \%$ \\
\hline $82.20 \%$ & $84.70 \%$ & $81.90 \%$ & $-0,4 \%$ \\
\hline
\end{tabular}

Fonte: As Américas e O Mundo

O apoio ao fortalecimento da ONU e da OEA apresentam, respectivamente, variações de $+7,6 \%$ e $+13,8 \%$, bem como a ajuda na melhora do nível de vida de países menos desenvolvidos do que o Brasil, que teve variação de $+7,0 \%$. Por outro lado, o apoio à prevenção da proliferação de armas nucleares apresentou variação negativa de $-11,1 \%$. A falta de suporte à prevenção da proliferação de armas nucleares foi replicada na classificação Pouco Importante/Nada Importante: o percentual subiu $106,5 \%$, passando de $9,3 \%$ para $19,2 \%$. Para todos os objetivos de política externa, houve queda no percentual dos que não souberam ou não responderam.

Outro ponto de estabilidade nos posicionamentos do público diz respeito à entrada de ideias e costumes ${ }^{14}$ estrangeiros. Entre os que consideravam o fato positivo, o

14 Você considera a entrada de ideias e costumes de outros países no Brasil um fato positivo ou negativo? 
patamar subiu de 54,9\% em 2010 para $61,3 \%$ em 2018. A alta foi menos expressiva entre os que consideravam o fato negativo, de 29,9\% em 2010 para 31,7\% em 2018. $O$ volume de respondentes indiferentes à entrada de costumes estrangeiros no país caiu de $11,5 \%$ para $3,3 \%$ ao longo dos oito anos de surveys.

As respostas do público em relação a diferentes potências internacionais também mantém as mesmas tendências ao longo das três rodadas. A ascensão econômica chinesa foi perguntada ${ }^{15}$ de forma específica na comparação com os Estados Unidos. Tanto as reações positivas quanto as negativas seguiram na mesma direção: o público que vê o fato como positivo subiu de $52,1 \%$ para $59,7 \%$; já os que veem o fator como negativo passaram de $25,8 \%$ para $30,1 \%$.

Outra questão ${ }^{16}$ abordada foi a confiança nas potências mundiais para a manutenção da paz internacional. Nesse tema, os Estados Unidos são o país que mais inspiram confiança nos brasileiros: de 41,3\% em 2010, 33,1\% declararam confiar no país norte-americano em 2018. A Inglaterra teve alta na confiança, passando de $3,2 \%$ (2010) para $12,5 \%$ na última survey. A China apresentou oscilação de $13,3 \%$ para $12,9 \%$ na última rodada, enquanto a Rússia variou de $2 \%$ para $4,4 \%$. A França se manteve estável em $14,8 \%$ nos três levantamentos. O percentual dos que não souberam ou não responderam foi de $14,9 \%$ para $10,6 \%$.

Quando o assunto muda para os países com maior potencial de desestabilização mundial, Rússia e Estados Unidos compartilham a desconfiança no público. Em 2010, ambos estavam empatados na primeira colocação, com 21,5\%. Em 2018, os Estados Unidos subiram para $28,6 \%$, enquanto a Rússia assumiu a primeira colocação com $30,5 \%$. A China fez uma trajetória oposta: de $20,8 \%$ na primeira survey, caiu para 17,8\% em 2018. França e Inglaterra também apresentaram dados menores em 2018 na comparação com a primeira rodada. A França foi de 3,7\%

\footnotetext{
${ }^{15} \mathrm{Na}$ sua opinião, se a economia da China crescesse até ser tão grande quanto a dos Estados Unidos, você acha que esse fato seria positivo ou negativo para o mundo?

${ }^{16}$ Qual dos seguintes países Ihe inspira maior confiança para manter a paz no mundo? E qual é o país que Ihe inspira menor confiança para manter a paz no mundo?
} 
para $2,5 \%$ enquanto a Inglaterra passou de $6,6 \%$ para $4,1 \%$. Os entrevistados que não sabiam ou não responderam caíram de 19,8\% em 2010 para 8,9\% em 2018.

\subsubsection{POSICIONAMENTOS ALTERADOS NA POLARIZAÇÃO}

$\mathrm{Na}$ seção anterior, apresentamos questões que mantiveram um comportamento mais estável a respeito da importância do Brasil, dos objetivos de política externa e da entrada de costumes estrangeiros. A relação com as potências mundiais manteve suas tendências iniciais ao longo de 2010, 2014 e 2018, apesar das grandes mudanças na política doméstica e na internacional nesse período.

De fato, a mudança mais significativa nos conflitos ${ }^{17}$ (passados e futuros) foi notada pelo público no cenário regional: a percepção da Venezuela como causadora de conflitos regionais nos últimos dez anos subiu de 15,2\% (2010) para 43,9\% (2018). Com relação aos próximos dez anos, a alta da Venezuela também foi importante: de $15,4 \%$ para $37,1 \%$.

Essa tendência foi inversa a da Colômbia nos dois cenários: em relação ao passado, a queda foi de 17,3\% (2010) para 5\% (2018); em relação a próxima década, a tendência se mantém com baixa de 16,3\% (2010) para 3,8\% (2018). Mais dois movimentos podem ser observados: a queda no volume de respondentes que não souberam responder a essas perguntas. Em relação à última década, o patamar caiu de $29,8 \%$ para $17,9 \%$ e, em relação ao futuro, de $34,4 \%$ para $20,3 \%$ entre 2018 e 2018.

As mudanças nas dinâmicas domésticas de Colômbia e Venezuela indicam uma alteração de comportamento do público brasileiro: antes, a percepção de riscos de conflitos regionais originava-se em um vizinho com problemas centrados no narcotráfico e na segurança pública. Ao final da década, a percepção de risco é

\footnotetext{
${ }^{17}$ Nos últimos 10 anos, qual país da América Latina você acredita que gerou mais conflitos na região? ; E nos próximos 10 anos, qual país você acredita que poderá gerar mais conflitos na região?
} 
deslocada para outro país vizinho, mas com issues de natureza política e governado pela esquerda.

A polarização na política doméstica brasileira, acompanhada do deslocamento de parte do eleitorado para a direita do espectro político, pode ter sido importante nessa dinâmica. Os atores políticos domésticos brasileiros exploraram a Venezuela como um mau exemplo, buscando associá-la a um governo brasileiro com queda de popularidade após 2013.

A qualidade ${ }^{18}$ das relações do Brasil com a América Latina no passado e no futuro foi outro posicionamento que apresentou alterações mais importantes ao longo do período de polarização na política doméstica. Em ambos os casos, os respondentes identificaram piora no cenário ao longo do tempo. Considerando os últimos dez anos, os que identificaram que as relações estavam melhores eram 74,8\% em 2010 , versus 55,5\% em 2018. A percepção de piora em relação ao passado saltou de $6,7 \%$ (2010) para 28,4\% (2018). A visão de piora nas relações com a América Latina para a próxima década apresentou queda menos acentuada. A perspectiva de melhora nas relações passou de 73,4\% (2010) para 64,5\% (2018). Já a opinião de piora nas relações para o futuro subiu de $5,1 \%$ para $18,5 \%$ no mesmo período.

Nesse cenário, o público deixa de preferir posições de liderança ${ }^{19}$ e influência ${ }^{20}$ do Brasil e opta por uma postura de colaboração com os vizinhos. Ser líder regional era o papel preferencial de $49,5 \%$ do público em 2010 , número que caiu para $30,7 \%$ em 2018. O papel de colaborar com os outros países da região partiu de $31,9 \%$ em 2010, para o primeiro posto na preferência em 2018, com 40,3\%. A preferência pelo

${ }^{18}$ Comparando com os últimos 10 anos, você acha que as relações do Brasil com o resto da América Latina estão melhores ou piores? E em 10 anos, você acha que as relações de seu país com o resto da América Latina estarão melhores ou piores?

${ }^{19}$ Qual das seguintes informações se aproxima mais do que você pensa sobre o papel do Brasil na América Latina? <1>0 Brasil deveria procurar ser o líder da região <2> 0 Brasil deveria colaborar com outros países latino-americanos sem pretender ser líder $<3>0$ Brasil deveria manter-se afastado dos esforços latino-americanos

${ }^{20}$ Nos últimos 10 anos, qual país da América Latina foi o mais influente da região? ; E nos próximos 10 anos, qual país da América Latina terá mais influência na região? 
afastamento oscilou de 10,4\% (2010) para 20,1\% (2018). A mesma dinâmica ocorre quando o público opina sobre a influência passada e futura do Brasil. Em ambos os casos, a visão de influência passada e futura do Brasil baixa de 62\% em 2010 para $39 \%$ em 2018.

A mudança mais aguda no cenário de polarização doméstica se dá, no entanto, quando os brasileiros olham para o passado: em 2010, 79,2\% dos entrevistados consideravam o País mais importante do que há dez anos atrás, volume que cai para $57,1 \%$ em 2018. Na contramão, 35,7\% dos brasileiros opinaram que o País era menos importante em 2018 do que era em 2008, contrastando com os 9,3\% na survey de 2010. Os que consideram o Brasil igual há dez anos no plano internacional caíram de 7,6\% (2010) para 1,6\% (2018). Para o futuro, o valor para "igual" é muito próximo, de 1,3\%. Também são mais estáveis os percentuais em relação a perspectivas futuras: $71,2 \%$ consideram que o Brasil estará melhor em dez anos, versus 75,1\% em 2010.

FIGURA 2

RELAÇÕES DO BRASIL COM AMÉRICA LATINA NA ÚLTIMA DÉCADA

2010

2014

2018

80

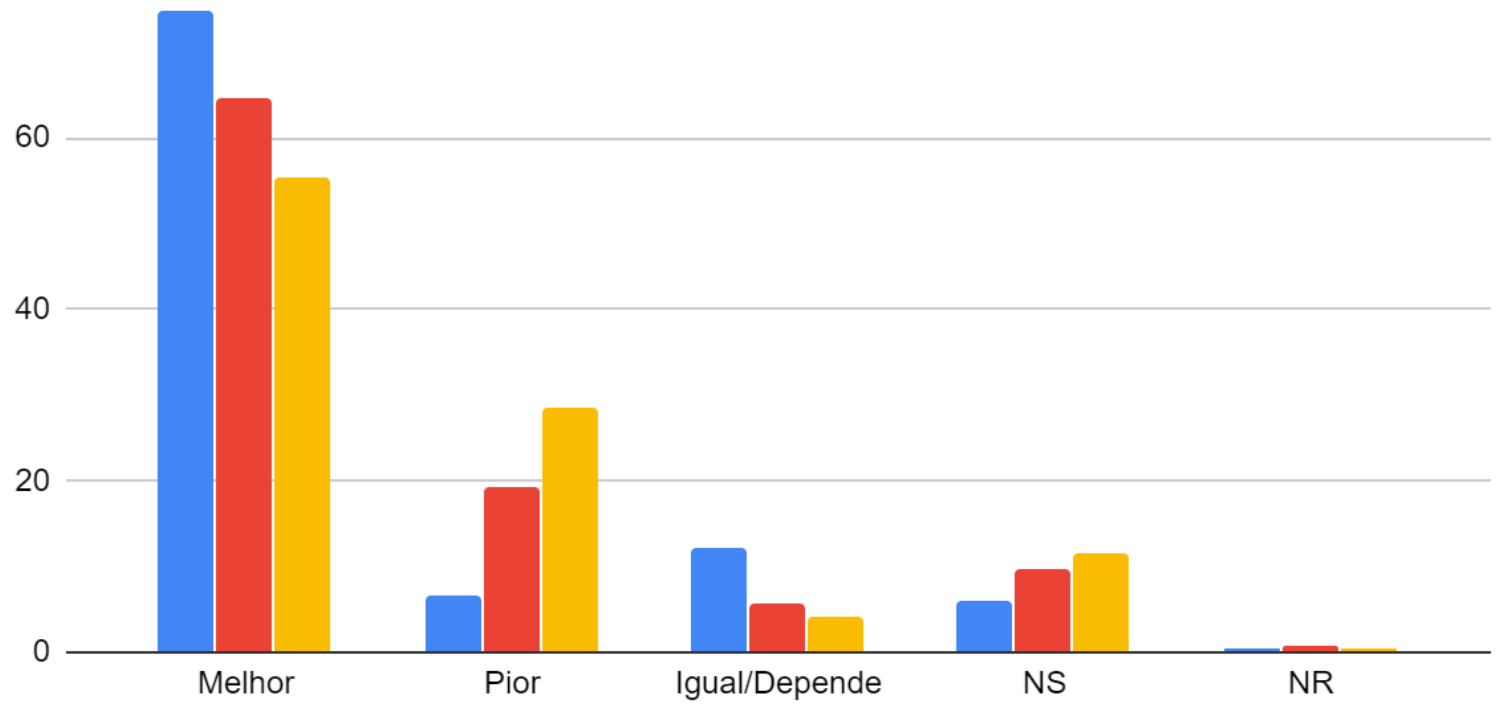

Fonte: As Américas e O Mundo 
FIGURA 3

BRASIL E LIDERANÇA NA AMÉRICA LATINA

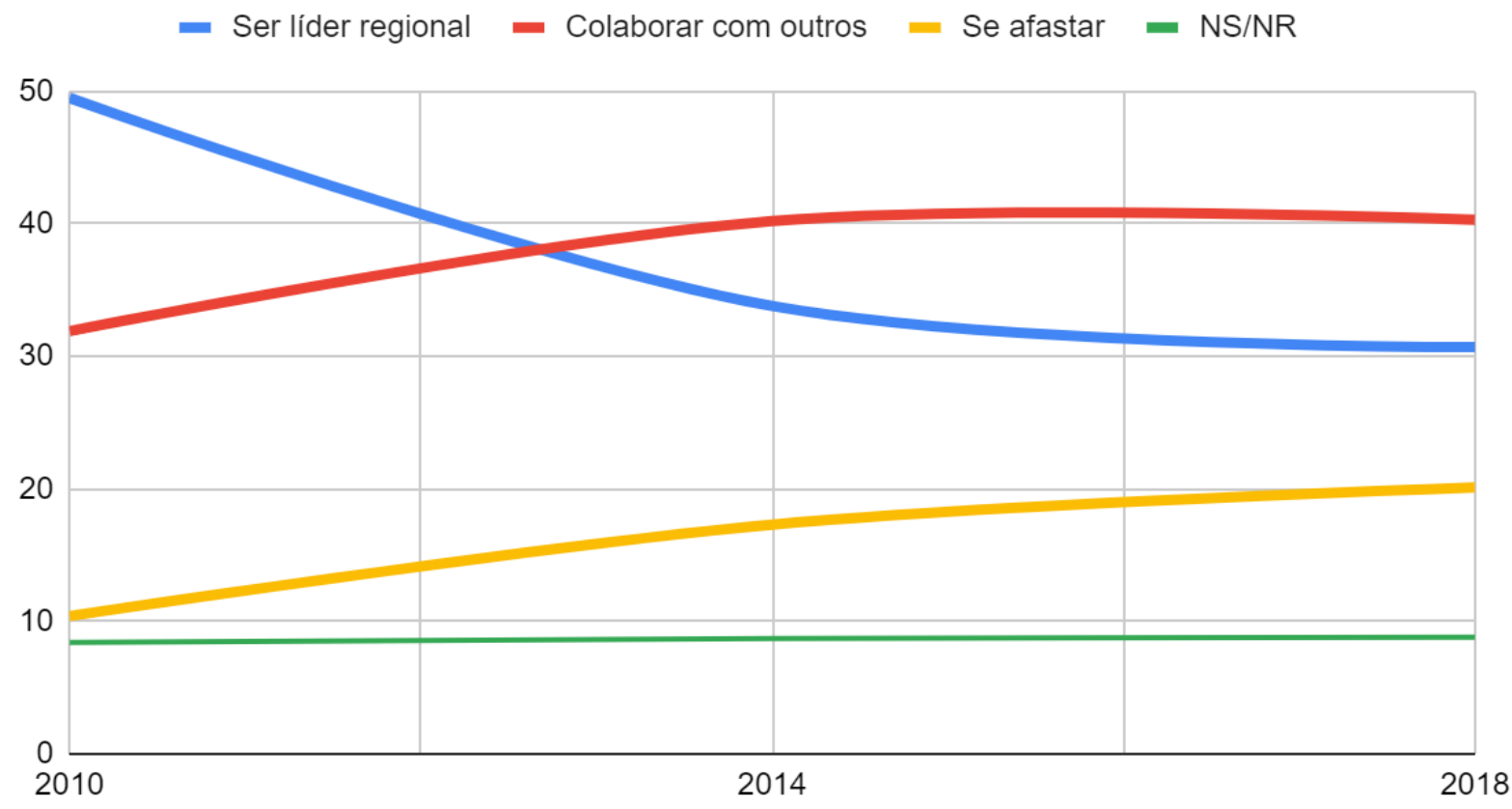

Fonte: As Américas e O Mundo

FIGURA 4

A IMPORTÂNCIA DO BRASIL NOS ÚLTIMOS DEZ ANOS

- Mais - Menos - Igual - NS/NR

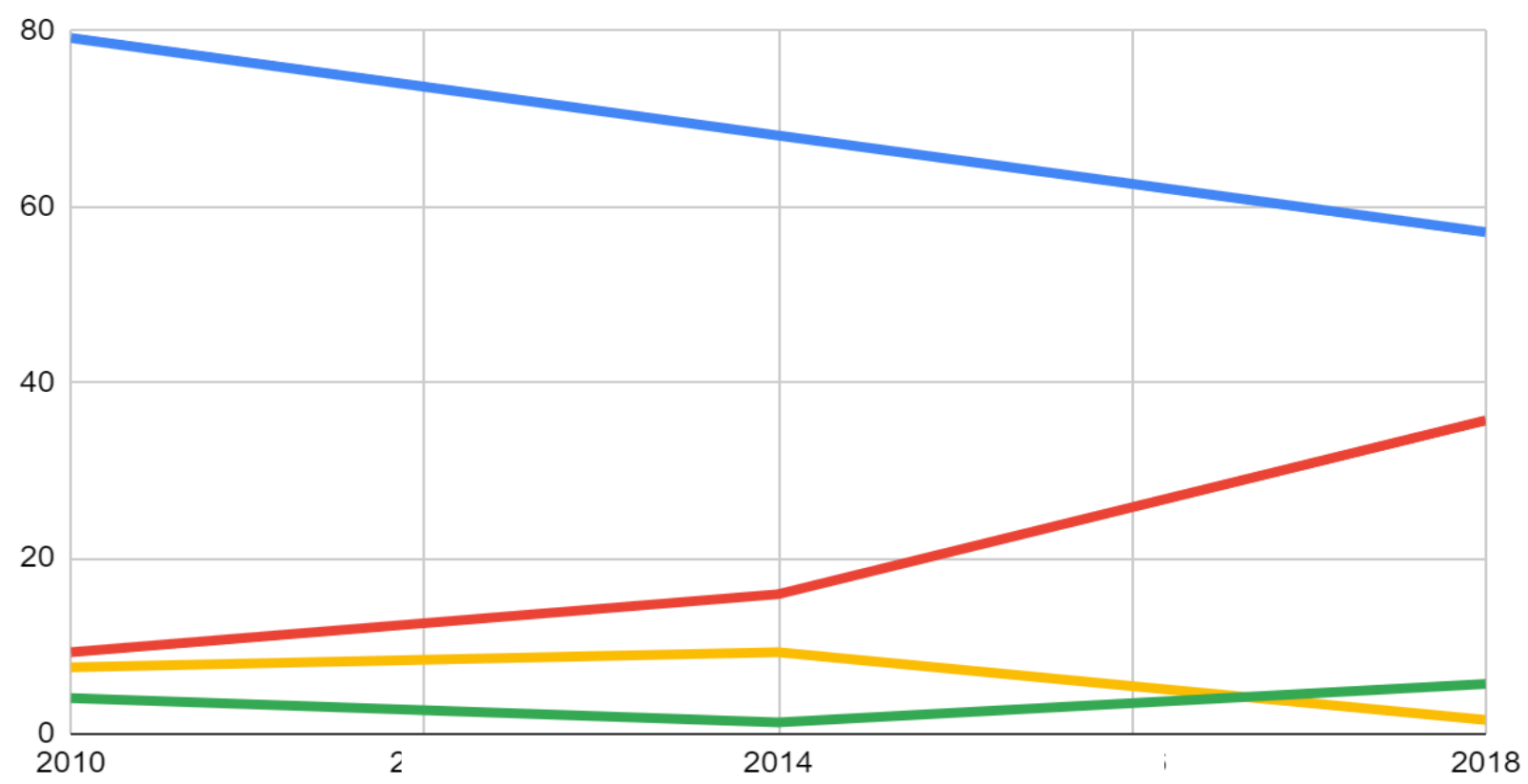

Fonte: As Américas e O Mundo 
Por fim, o público demanda mais envolvimento do Brasil nos assuntos mundiais ao longo das rodadas. O volume de respondentes que considera que o Brasil deve se envolver ${ }^{21}$ ativamente em assuntos mundiais subiu de 68,9\% em 2010 para 87\% em 2018. Já os que consideram que o País deve se manter afastado caíram de $17,8 \%$ para 10,3\%. Também caíram os que responderam "nem um, nem outro" (de $5,5 \%$ para $0,3 \%$ ) e os que não souberam ou preferiram não responder (de $7,8 \%$ para 2,3\%).

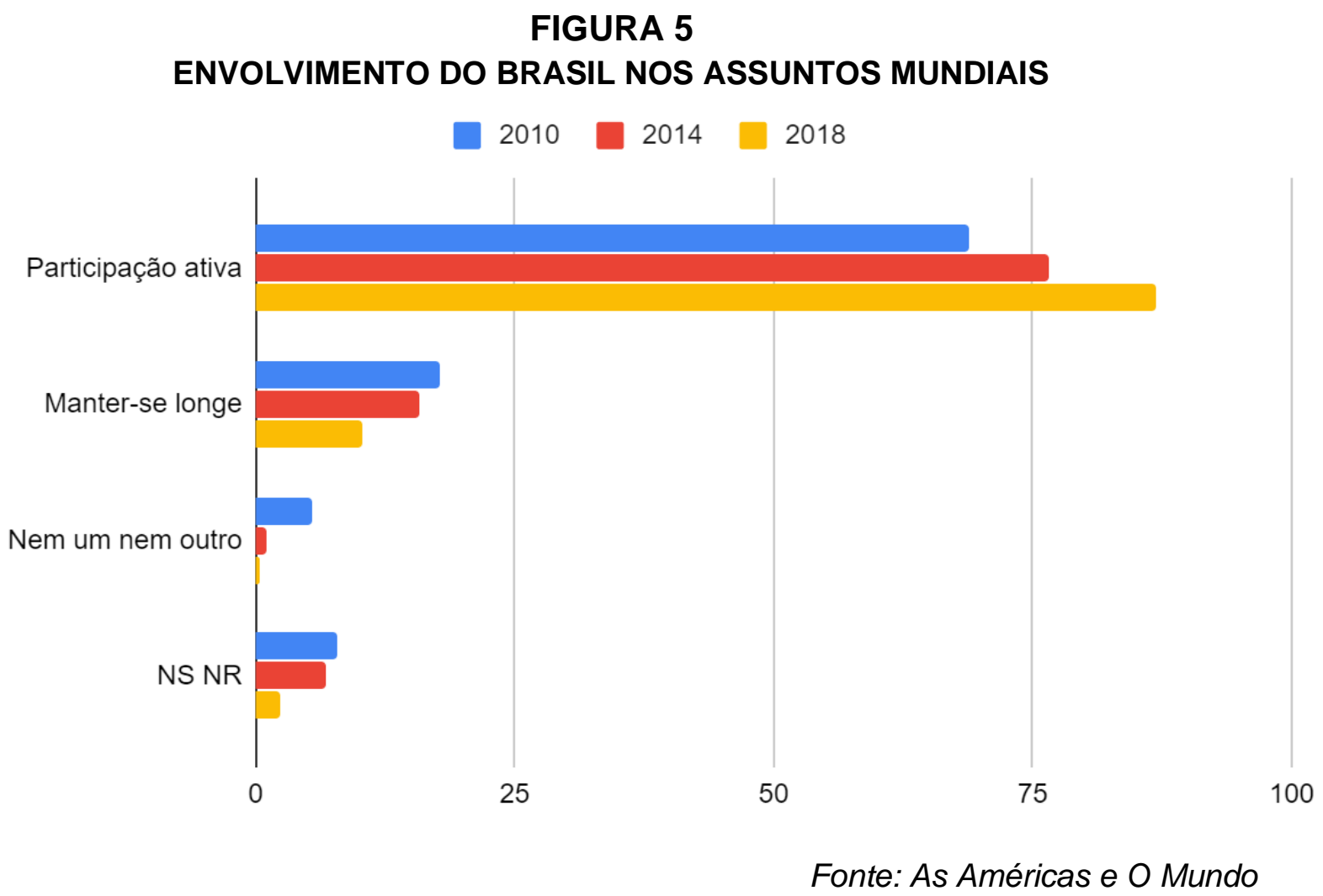

${ }^{21}$ Em sua opinião, o que é melhor para o futuro do Brasil, ter participação ativa em assuntos mundiais, ou manter-se longe dos assuntos mundiais? 


\subsection{OS ATALHOS COGNITIVOS: OS CAMINHOS PARA ACESSAR OS TEMAS INTERNACIONAIS MUDARAM?}

Em todas as nuances de estabilidade ou mudanças nas opiniões do público sobre política externa na survey As Américas e O Mundo, há uma constante: o volume de pessoas que declararam não saber ou preferiram não responder as questões caiu de forma regular. Como discutimos no início do capítulo, a queda nessas categorias de respostas ocorre de modo inversamente proporcional ao crescimento do acesso à internet e à adesão às redes sociais. Na literatura de ciência política e relações internacionais, os temas externos são tidos como desconhecidos por parte significativa do público, convencionado como "opinião pública" ao longo do Século $\mathrm{XX}$.

A opinião pública é um conceito ${ }^{22}$ difundido por Walter Lippman (1965), que afirma que as imagens de si e dos outros, em combinação com suas demandas, propósitos e relacionamentos, constituem as suas opiniões públicas. Key (1961) sustenta que a opinião pública é constituída pelas opiniões ${ }^{23}$ individuais de pessoas físicas, as quais os governos creem ser prudente levar em consideração.

Ambos conceitos foram forjados a partir de ideias de hegemonia dos meios de comunicação de massa sobre o público, expresso em teorias da comunicação como a Hipodérmica (anos 1930) e o Agenda-Setting (anos 1960). Muitas teorias de comunicação do Século XX tendem a apresentar a opinião pública como uma unidade, mas esse quadro vai mudando ao longo do tempo.

O imaginário de unidade da opinião pública tem raízes históricas na própria atitude dos governos ao longo da Guerra Fria. Cohen sinaliza que a burocracia da política

\footnotetext{
22 No seu clássico Public Opinion, publicado originalmente em 1922, Lippman define a opinião pública como: "The pictures inside the heads of these human beings, the pictures of themselves, of others, of their needs, purposes, and relationship, are their public opinions" (Lippman, 1965)

23 "(...) those opinions held by private persons which governments find prudent to heed" (Key, 1961)
} 
externa nos Estados Unidos considerava a imprensa como a fonte primária da opinião pública e a utilizava como ferramenta de mensuração dos humores da população para balizar a tomada de decisões de política externa (Cohen, 1963; Cohen, 1995). O trânsito das ideias de política internacional e política externa era, portanto, fortemente associado ao trânsito de ideias nos veículos de imprensa.

Não por casualidade, Zaller et al (2000) encontraram forte alinhamento entre posicionamentos do governo dos EUA e cobertura da imprensa local ao longo de 35 crises internacionais de 1945 a 1991. O alinhamento ocorre tanto em relação aos Republicanos quanto aos Democratas. A cobertura dos issues internacionais por parte da imprensa é ativada a partir dos debates internos das elites, mas quando as elites assumem posições de conflitos com os policymakers, o relacionamento dos governos com a opinião pública se torna crescentemente problemático (Powlick et al, 1998). É precisamente o que ocorre no caso da Guerra do Vietnã, que sinaliza um ponto de ruptura nos estudos sobre a interação entre opinião pública e política externa.

A centralidade dos fluxos de informação política das elites para o público é sistematizada por Zaller (1992), que define um modelo composto pelo trinômio: (1) fluxos de informação presentes nos discursos das elites; (2) diferentes níveis de exposição às mídias por parte dos eleitores; (3) as predisposições políticas, que são os filtros aplicados a cada mensagem recebida. A questão é como os fluxos de informação provenientes da imprensa e das elites são decodificados pelo público geral, em especial a respeito de temas distantes e sofisticados, como são os de política internacional. Zaller (2003) afirma que as limitações presentes na decodificação de assuntos complexos para o cidadão comum são um consenso na economia, psicologia e na ciência política.

Baum et al (2008) indicam que a capacidade informacional da opinião pública é um problema central para a compreensão do ambiente no qual a política externa é desenvolvida. Eles identificam dois consensos entre as principais investigações em 
Oopinião pública e política externa: (a) a desvantagem informacional na comparação com as elites da comunidade de política externa; (b) que são parcialmente compensadas pelos atalhos cognitivos (heuristic clues ou shortcuts), auxiliares na compreensão de informações complexas do campo internacional. Essa desvantagem informacional pode ter sido afetada pela maior oferta e menor custo de informação a partir das redes sociais.

De acordo com Popkin (1994), a racionalidade presente na informação escassa sobre temas políticos segue uma lógica de combinação de aprendizado e informações de experiências passadas, cotidiano, mídias e campanhas políticas. No processo de comportamento eleitoral abordado pelo cientista político, ele afirma que o uso dos atalhos cognitivos tem o objetivo de obter, simplificar e avaliar as informações políticas disponibilizadas na mídia, que são trianguladas nas conversas em relacionamentos de confiança e de figuras políticas já conhecidas pelo eleitor. Os atalhos cognitivos são, portanto, os caminhos utilizados pelo público para decodificar os assuntos políticos complexos, com o fim de tomar decisões eleitorais e elaborar posicionamentos sobre temas sofisticados, de política doméstica ou internacional.

Powlick et al (1998) sustentam que a aquisição de informação factual é custosa, de forma que o público geral considera "irracional" construir um posicionamento político sofisticado sobre notícias externas remotas de seu cotidiano. Os autores salientam ainda que a construção de um posicionamento é dificultada pela ausência de contato pessoal com estrangeiros, inclusive em países desenvolvidos e multiculturais como os Estados Unidos. Para Schmitt-Beck (2003), o alto custo de participação para a informação política também envolve variáveis como renda, tempo, motivação e autoconfiança no uso de atalhos cognitivos mais sofisticados para a decodificação de assuntos políticos complexos.

Neuman et al (1992) afirmam que essa conexão de cidadãos comuns com temas políticos domésticos e externos - via atalhos cognitivos - ocorre de forma a 
interromper os acontecimentos de seu mundo privado, sendo, portanto, acidental, improvisada e desorganizada. Com a crescente dependência das mídias nas sociedades urbano-industriais desde os anos 1980, esse processo de interrupção se aprofunda ainda mais.

As redes sociais, acessadas com mais frequência do que os meios de comunicação offline - tornaram esse cenário ainda mais complexo. A complexidade desse cenário tem impacto sobre o trânsito de ideias na opinião pública, uma vez que o ambiente comunicacional que origina e difunde informações políticas é profundamente transformado. Uma das mais importantes transformações é a quebra do monopólio dos meios offline no trânsito dessas ideias.

A definição de quais são os atalhos preferenciais é objeto de debate na literatura. Utilizando um modelo de comunicação considerando as vias entre elites, grupos de interesse, políticos eleitos e a opinião pública, Powlick (1995) afirma que políticos eleitos e notícias na imprensa são vias mais utilizadas na compreensão de temas internacionais quando comparados às elites e grupos de interesse.

Na mesma linha de argumentação, Berinsky (2007) afirma que na ausência de conhecimento sobre temas externos, os eleitores emulam os posicionamentos de seus políticos preferenciais como atalhos para temas internacionais, delegando aos representantes a tarefa de encontrar um posicionamento sobre temas que thes são estranhos. Esse exercício é válido tanto para quando se é situação quando se é oposição ao governo. Essa estratégia permite aos eleitores tomar decisões racionais e coerentes sobre temas distantes e complexos. Berinsky afirma ainda que, na medida em que o nível de informação política é ampliado, os eleitores conseguem distinguir posicionamentos conflitantes intraelites.

Powlick et al (1998) afirmam que o público utiliza seus valores mais importantes como atalhos cognitivos para a formação de posicionamentos em issues. Em consonância, Druckman (2001) sustenta que a alta "capacidade" ou "qualificação" 
dos cidadãos para formar posicionamentos políticos tem diversas variáveis apontadas pela literatura. Entre elas estão a abundância de informações; o uso eficiente de atalhos cognitivos/informacionais; ou ainda os limites dos issues e a estabilidade de valores.

Na mesma linha de argumentação, Aldrich et al (2006) sustentam que, no caso específico de atalhos cognitivos para política externa, as preferências partidárias, as notícias e o discurso das elites são alguns dos caminhos mais utilizados. Eles salientam ainda que, na média, os cidadãos desinformados têm a capacidade de tomar decisões políticas similares aos muito informados.

Aldrich et al (1989) também afirmam que, apesar de informações políticas escassas, os eleitores também têm a capacidade de diferenciar programas de política externa entre os candidatos por meio de seus atalhos cognitivos, e que essa diferenciação influencia na sua escolha de votos. Em adição, Krosnick et al (1990) defendem que o público geral associa o desempenho pessoal do chefe do Executivo ao desempenho em temas internacionais. Os autores analisaram dados do National Election Study 1986 (EUA) e da cobertura da imprensa estadunidense sobre a Nicarágua no mandato Ronald Reagan.

Quais são as novas variáveis na questão dos atalhos cognitivos a partir da chegada da internet para a sociedade civil nos anos 1990 ? O primeiro ponto levantado é que a disponibilidade de mais informação alterou a forma como os temas internacionais são cobertos pela imprensa. Baum (2003) sustenta que as hard news internacionais foram paulatinamente adaptadas para soft news, para que pudessem se encaixar melhor em talk-shows e telejornais, em uma mescla de temas complexos com entretenimento. De acordo com o autor, esse movimento nos Estados Unidos permaneceu mesmo após os atentados de 11 de setembro de 2001.

O segundo ponto é levantado por Risse-Kappen (1991). Em estudo sobre os comportamentos das opiniões públicas dos Estados Unidos, Japão, Alemanha 
Ocidental e França em relação a União Soviética, Risse-Kappen (1991) divide a opinião pública entre: (1) opinião pública de massa; (2) attentive public, interessado em política de forma geral; (3) issue public, interessado em temas específicos. Em uma fase pré-difusão da internet mas já na Revolução Informacional, o autor já indica que uma elevada segmentação de interesses não se dá somente nas elites, conforme definido por Almond ${ }^{24}$ na Guerra Fria, mas também entre o público geral.

Defendo que essa divisão se aprofunda ainda mais adiante com a construção de comunidades digitais e clusters via redes sociais, que se constituem na prática como redes de portes desiguais a partir de opiniões distintas acerca de diferentes regiões e países, que constituem diferentes campos para o trânsito de informações entre diferentes redes de opinião pública.

O terceiro ponto é o de que, segundo Livingston et al (2003), as mudanças tecnológicas proporcionadas pela internet provocaram um aumento do volume de cobertura de notícias internacionais nas mídias, mas que por outro lado, a autoridade das fontes de informação governamentais foi reforçada em paralelo. $O$ meu argumento é o de que esse reforço das fontes governamentais se dá apenas na primeira fase da difusão da internet para o público, até meados dos anos 2000, quando está datada a difusão das grandes redes sociais conhecidas, e que hoje os governos e a própria imprensa constituem dois entre muitos clusters nos quais as informações políticas circulam.

Ou seja, a lógica de reforço da autoridade governamental nas coberturas em temas internacionais, sinalizada na Guerra Fria e continuada na primeira fase da internet, se dilui na medida em que os governos e a imprensa não são mais os atalhos cognitivos principais para a compreensão de temas externos, mas as comunidades políticas e não-políticas em redes sociais nas quais os cidadãos conectados estão inseridos. Portanto, as discordâncias a respeito de temas políticos antes restritos às

\footnotetext{
${ }^{24}$ Conforme sinalizado na revisão bibliográfica do início do capítulo, Almond tipifica os públicos entre atentos e desatentos. A classificação de Risse-Kappen eleva a complexidade dessa tipificação a partir dos issues.
} 
elites transbordam para uma opinião pública antes tida como segmentada em um sentido partidário, mas que passa a ser dividida a partir de um grande número de issues, materializados em diferentes clusters nas redes sociais. Nesse sentido, Estados e imprensa se enxergam em uma dinâmica informacional nova nos anos 2010, na qual não têm o controle dos fluxos informacionais, tomando ações ainda em curso para a retomada desses fluxos.

A formação das redes de issues e de interesses nas relações internacionais ganha força antes mesmo das redes sociais. Risse-Kappen (1991) sinaliza que redes de políticas públicas internacionais apresentam dinâmicas distintas que afetam o seu funcionamento, funcionamento que está sujeito à influência do público. Ele identifica três tipos de redes: a) em países com instituições políticas centralizadoras e organizações sociais fracas, a rede tende a ser dominada pelo Estado. b) países com sociedades mais heterogêneas e com alto grau de mobilização social apresentam mais força da sociedade civil e, portanto, um papel mais importante da opinião pública; c) países com instituições políticas e organizações sociais de forças comparáveis tendem a ser caracterizados por uma democracia corporativa.

Ou seja, antes as redes de políticas públicas estavam sujeitas à influência do público em especial a depender da força ou da fraqueza das organizações sociais offline. A partir das redes sociais, qualquer cidadão externo a essas organizações, mas interessado e conectado aos clusters presentes nas redes de política externa pode ter alguma influência nessa dinâmica. Essa possibilidade de influência também ocorria nas redes offline, mas de forma mais indireta, a partir da mediação dos atalhos cognitivos sinalizados anteriormente.

O uso da internet pela sociedade civil em sua fase pré-redes sociais apresentava um otimismo influenciado pelo final da Guerra Fria e pelo auge da Globalização Liberal. Esse clima de otimismo continuaria à época do nascimento das redes sociais. A ideia central era a de que a internet seria um instrumento de aprofundamento da democracia liberal e de ampliação das liberdades civis por meio 
de novas ferramentas de deliberação. Essa visão muda a partir dos vazamentos do Wikileaks (2010); e do início de revoltas urbanas turbinadas pelas redes sociais, como Occupy Wall Street (2011) e a Primavera Árabe (2011), movimentos que apresentaram continuidade no Egito (2013), Turquia (2013) e Brasil (2013).

Essas transformações geram uma forte reação dos governos com relação à internet e às redes sociais no plano internacional. Essas reações, no caso de regimes não democráticos, se dão pela tentativa de estabelecer limites no uso e nos conteúdos compartilhados. No caso das democracias, as próprias eleições presidenciais e parlamentares em diferentes países ocidentais e latinos sinalizam novos rumos para diferentes cenários de política doméstica, com implicações na distribuição de preferências do eleitorado e da composição das principais forças partidárias nos parlamentos.

Com esses marcos iniciais, podemos identificar cinco tendências de crises que se apresentam na década de 2010: são as crises econômica, comunicacional, de convergência política, dos partidos políticos e da democracia liberal. Quando se fala em crise econômica, não se refere apenas à Crise do Subprime nos EUA (2008), mas também sobre a desaceleração econômica mais ampla ocorrida nos países capitalistas centrais após o final da Guerra Fria (1989), cuja consequência mais marcante foi a estagnação das classes médias nos países industrializados.

A crise comunicacional se dá a partir do advento da internet para a sociedade civil e das redes sociais. Mudam tanto a comunicação entre governo e cidadãos, quanto a comunicação dos próprios cidadãos entre si. A internet e as redes sociais são os ingredientes básicos das crises de outras duas crises intimamente relacionadas: convergência política e dos partidos centristas tradicionais. Com relação à crise de convergência política, Da Empoli (2019) sinaliza que a política offline nas democracias liberais apresentava uma tendência centrípeta. Para a criação de um consenso majoritário, as mensagens políticas deveriam ser moderadas e segmentadas a categorias identitárias mais amplas - como sindicatos, estudantes e 
empresários, por exemplo. Essa dinâmica favoreceu em geral os candidatos e partidos centristas.

A chegada do Big Data muda radicalmente esse cenário. Em primeiro lugar, o Big Data torna possível a microssegmentação e a customização da mensagem política de forma precisa e individualizada. E, na era da política digital, o engajamento se dá primariamente pelo compartilhamento de conteúdos extremos e de forte apelo emocional. Portanto, o comportamento de candidatos competitivos eleitoralmente muda: de centristas "moderados e preparados" nos termos das democracias liberais, os candidatos competitivos devem-se comportar como hubs dos trending topics na política, se possível provocando-os e manipulando-os em benefício de seu espectro político. Então, a crise de convergência política carrega a política do centro para os extremos do espectro como uma "força centrífuga" (Da Empoli, 2019).

Os principais perdedores nessa dinâmica centrífuga são os partidos centristas tradicionais das democracias liberais. Eles perdem poder conforme a política caminha para os extremos do espectro, reforçando o discurso de deslegitimidade das "elites", conceito que ganha especial elasticidade nesse novo cenário. Por fim, as quatro crises indicadas somam-se a outra já em curso entre as democracias liberais: a da queda de seus índices de confiança sistêmicos. A queda dos índices de confiança nas democracias liberais atinge tanto as democracias mais antigas (como, EUA, Reino Unido e França), como as democracias da chamada "terceira onda" após os anos 1980 (América Latina, Ásia e Leste Europeu), de acordo com dados da World Value Survey (Moisés, 2005; Cattenberg e Moreno, 2005; Moisés e Carneiro, 2008)

$\mathrm{Na}$ conjuntura das cinco crises, Susskind (2018) sustenta que os "filtros informativos" se apoiam na confiança que o público deposita em terceiros para: (a) encontrar e reunir informações; (b) escolher as relevantes de serem documentadas; (c) decidir a profundidade de contextualização e detalhamento necessária; (d) compartilhar com os possíveis interessados. Para o autor, os pressupostos deste 
trabalho dirigido aos públicos interessados em notícias são os de que as informações recebidas são verdadeiras e hierarquizadas pela sua importância. Conforme discutido anteriormente, essas funções eram dominadas pela imprensa offline ao longo do Século XX, que dividia com o Estado a função de ser a principal via para que o público acessasse aos distantes temas internacionais.

Susskind afirma que, com as redes sociais, o Estado tenta avançar novamente em um território de construção da percepção pública de terceiros. Esse trabalho era atribuído a uma imprensa independente nas democracias liberais e hoje é disputado abertamente pelos agentes públicos - e também por outros atores, como Estados estrangeiros - nas redes sociais. Como vimos, a entrada do Estado como ator nas redes sociais não se dá de forma espontânea e planejada: os agentes públicos são sugados para essa dinâmica em virtude de crises sistêmicas, instrumentalizadas por atores externos para a sua desestabilização por motivos diversos. O papel de construção social da agenda-setting é rompido com a quebra do monopólio da imprensa offline, com quem os Estados desenvolveram relações de relativa estabilidade ao longo das décadas pré-internet (Zaller et al, 2000).

Em outras palavras, a dinâmica dos atalhos cognitivos utilizados pelo público para acessar a temas internacionais passam por uma profunda transformação ao longo das duas primeiras décadas deste século. Muitos alicerces dos atalhos cognitivos passam por rompimentos, segundo Da Empoli (2019). Elencaremos brevemente sete dessas quebras:

1. Quebra da intermediação informacional offline: As redes sociais demarcam o fim da intermediação informacional da imprensa offline em caráter de exclusividade. Para seguirem relevantes, os veículos de comunicação formados em um mundo pré-internet devem se submeter aos novos parâmetros de interação/engajamento, internos às redes sociais e externos a eles mesmos. As tensões entre Facebook e de veículos de comunicação tradicionais no Ocidente são sintomas disso. 
2. Quebra da autoridade da fonte: No mundo offline, com discursos legitimados pelos filtros da imprensa e dos livros, havia uma hierarquização de fontes e de seus discursos. Com as redes sociais, o engajamento em posts legitima mais uma opinião do que o seu próprio conteúdo. Em última análise, isso tem impacto direto não só na autoridade de fontes estatais, mas na de fontes científicas que utilizam evidências de investigações para os debates públicos. Se o engajamento é menor, o discurso tem menor valor.

3. Quebra dos conteúdos comunitários: Além do critério de autoridade da fonte na comunicação online ter sido alterado, a customização das notícias (incluindo a customização de fake news) tem contribuído para a quebra de conteúdos comunitários. Diferentes campos políticos estão cada vez mais isolados em suas bolhas, com acesso a conteúdos desconectados dos da oposição.

4. Quebra do politicamente correto: Para Da Empoli (2019), a estratégia de comunicação da direita populista é "quebrar os códigos do politicamente correto" construídos pela esquerda e pelos liberais ao longo das últimas cinco décadas. Esse processo é acentuado pelas três quebras mencionadas anteriormente.

5. Quebra do espectro político: os novos partidos operam com uma lógica distinta das esquerdas e direitas nas democracias liberais do século XX. Nessa lógica, os findings a respeito de cada eleitor no Big Data têm mais relevância do que o espectro ideológico auto-atribuído ou socialmente atribuído a cada eleitor. Considerando o cenário no qual as definições usuais de esquerda e direita são marginalizadas pela nova direita, a nova estratégia política apontada por Da Empoli (2019) passa pela nova divisão entre "povo" e "elites", incluindo o contingente de revoltados de todos os espectros no campo "popular". Isso também afeta a coerência dos conteúdos programáticos, antes submetidos ao espectro clássico de direita e esquerda, mas que agora são engolidos pelos tópicos que geram engajamento.

6. Quebra da convergência pelo Centro: Nas democracias liberais pré-digitais, a convergência dos candidatos "viáveis" de esquerda e direita ocorria pelo 
Centro do espectro político. A estratégia era o diálogo com um máximo de grupos sociais representativos. Na era do Big Data, os conteúdos mais extremistas geram mais engajamento e indicam com maior precisão os grupos-alvo, pela via dos algoritmos. Parte dessa convergência dos candidatos passava pela necessidade de comprovar experiência na administração pública e de compor uma equipe de governo que mesclasse competência técnica e boas conexões políticas para viabilizar o programa de governo. Essas vantagens comparativas anteriores passam a ser evidências de pertencimento às "elites" e são substituídas por outras características desejadas entre o eleitorado, dentre as quais estão a capacidade de gerar engajamento, a inexperiência administrativa e especialmente a falta de conexões com as "elites".

7. Quebra da Globalização Liberal: As "elites globalistas" são o principal alvo da nova direita, cujo objetivo em seu conjunto é interromper o processo de globalização nos moldes liberais e retornar a um sistema nacionalista de equilíbrio de poder entre potências.

O resultado de todas as quebras ocorridas ao longo da última década são as divisões. São divididas as informações, as realidades construídas socialmente, os objetivos em meio a essa realidade e os valores que motivam tais objetivos. A divisão das informações receptadas se dá tanto pela via das informações verídicas, mas ultrassegmentadas por algoritmos, quanto pela via das fake news - já operantes ainda na Guerra Fria sob a alcunha de desinformação. Cada peça de informação (ou desinformação) constrói um quebra-cabeça da realidade ${ }^{25}$ cujo quadro difere

\footnotetext{
${ }^{25}$ Sobre a divisão social do conceito de "realidade”, Da Empoli (2019) contextualiza: “ “De maneira análoga, a política newtoniana estava adaptada a um mundo mais ou menos racional, controlável, no qual a uma ação correspondia uma reação e onde os eleitores podiam ser considerados como os átomos dotados de pertencimentos ideológicos, de classe ou de território, dos quais derivavam escolhas políticas definidas e constantes. De certa maneira, a democracia liberal é uma construção newtoniana, baseada na separação dos poderes e na ideia de que é possível, para os governantes e os governados, tomar decisões racionais, em cima de uma realidade mais ou menos objetiva. Empurrada a seu extremo, é a abordagem que pode conduzir, no dia seguinte à queda do Muro de Berlim, Francis Fukuyama a proclamar o fim da História. Com a política quântica, a realidade objetiva não existe. Cada coisa se define, provisoriamente, em relação a uma outra, e,
} 
cada vez mais do outro espectro político. Ou seja, a realidade deixa de ser compartilhada e passa a ser customizada. Susskind (2018) adiciona um problema extra a esse quadro de "política da pós-verdade": esse cenário tende a acentuar o problema e tornar os diferentes polos cada vez mais distantes.

Se antes a convergência política pelo Centro indicava os mesmos objetivos a serem atingidos pela esquerda ou pela direita no pós Guerra Fria (por exemplo, o aprofundamento da Globalização Liberal), agora a distância entre os polos torna cada vez mais problemática a ideia de dialogar nos termos de uma democracia liberal. Nesse contexto, os próprios valores sobre o que é um político ideal para ocupar cargos de liderança sofre uma divisão. Inexperiência administrativa e confronto ao sistema político são qualidades para um polo, e defeitos para o outro.

Nessa conjuntura de crises, quebras e divisões, Susskind (2018) defende que os dados são poder. De acordo com ele, as entidades que controlarem os dados controlarão três fontes de poder no futuro: força (coerção), escrutínio e percepção de controle. Essas são fontes de poder porque cada vez mais uma gama maior de comportamentos humanos é transformada em dados, fato que deve ser acentuado futuramente com $\circ 5 \mathrm{G}$ e a internet das coisas; e porque a forma como nós organizamos esses dados revela muito dos nossos valores políticos.

Dessa maneira, a posse de mais dados sobre nós aumenta a probabilidade do uso desses dados para moldar as nossas preferências políticas de forma significativamente mais precisa do que os meios de comunicação de massa offline o conseguiram. A tese de Susskind é que, ao longo do tempo, tais poderes sobre os dados se concentrarão crescentemente nas mãos do Estado e de grandes corporações tecnológicas.

sobretudo, cada observador determina sua própria realidade. No novo mundo, como dizia o ex-presidente do Google, Eric Schmidt, é cada vez mais raro ter acesso a conteúdos que não sejam feitos sob medida. Os algoritmos da Apple, do Facebook ou do próprio Google fazem com que cada um de nós receba informações que nos interessam" 
A relevância do marco cronológico desta década de crises, quebras de paradigmas e divisionismos é precisamente essa: Estados e grandes corporações tecnológicas estão em movimento para assumir o controle da maior gama de dados possível. Evidentemente, os Estados saíram atrás nessa corrida, sendo pegos de surpresa no início da década por movimentos sociais massivos e vazamentos de informações muito sensíveis. Portanto, tratamos nesta tese da transição dos atalhos cognitivos dos públicos das mídias offline para as redes sociais online.

Estudaremos como os atalhos cognitivos se organizam em redes online de política internacional, a partir de 59 estudos de caso em redes bilaterais do Brasil com países dos cinco continentes. Qual é a extensão da influência online dos governos e da imprensa em um momento de ampliação da segmentação de interesses em política internacional e de crises em variados âmbitos? Como se dividem os atalhos cognitivos das redes nesse contexto? A hipótese é a de que páginas de governo, política e das mídias não são os principais atalhos cognitivos para o público nas relações internacionais. 


\section{INTERESSES INTERNACIONAIS EM REDE: QUAIS OS ATALHOS PARA TEMAS DISTANTES?}

\subsection{AS REDES SOCIAIS E A DIVERSIFICAÇÃO DE ATORES NO CENÁRIO INTERNACIONAL}

A diversificação de atores nas relações internacionais, amplamente discutida a partir dos anos 1990 no bojo da globalização liberal, foi acompanhada pela difusão de websites e em redes sociais como ferramentas de comunicação desses mesmos atores. Os usuais condutores dos debates públicos em temas externos, como Estados, organismos multilaterais e a imprensa offline, se viram envolvidos em uma dinâmica distinta, alterada pela multiplicidade de influenciadores encontrada em meio aos novos participantes.

A mudança na natureza de dados e metodologias decorrentes da difusão da internet nos anos 1990 e 2000 promovem o que é qualificado por Lazer et. al (2009) como o campo das "ciências sociais da computação", com novas abordagens para problemas de pesquisas já conhecidos e explorados pela via das surveys, tais como confiança política, influência, difusão de informações, dinâmica da opinião pública e de mobilizações políticas. Os dados oriundos das redes sociais permitem observar de forma direta, por exemplo, as conexões entre eleitores, legisladores e governos (Sinclair, 2016; Barberá et al, 2014).

A análise de redes explora dados para além dos atributos individuais (sexo, renda, educação, entre outros ${ }^{26}$ ) e suas respectivas correlações. Ela possibilita mensurar e posicionar graficamente indivíduos e instituições em uma rede de influenciadores (García et al, 2016). Esses influenciadores assumem papel mais ativo e diverso em

\footnotetext{
${ }^{26}$ Golder et al (2014) sustentam que o público online tem tendência de ser mais jovem e mais educado em relação à distribuição geral da população. Por essa diferença na distribuição, os autores afirmam ser um equívoco supor que os mundos offline e online se sobrepõem. Apesar das diferenças de distribuição em relação ao universo de população, Bisbee e Larson (2017) encontram similaridade robusta em relacionamentos offline e online registrados em redes sociais.
} 
relação aos gatekeepers ${ }^{27}$ das mídias offline do Século XX. Para Rogers (2012), a web reconfigura o que foi nomeado como esfera pública por Habermas (2014) e possibilita que vejamos a rede como uma "grande conversação".

$\mathrm{Na}$ era das redes sociais, no entanto, essa grande conversação é centrada cada vez mais nos issues (Marres et al, 2005) e influenciada pelo clima de polarização ${ }^{28}$ política, em evidência no estudo das ciências sociais no Ocidente e na América Latina. De acordo com Marin e Wellman (2010), as relações sociais expressas em forma de rede abrangem um leque de socially relevant nodes que integram locais geográficos (bairros, cidades, países), instituições e indivíduos. O estudo dessas relações ${ }^{29}$ envolve a seleção dos integrantes de uma determinada rede, suas similaridades e o fluxo de suas interações.

Parte das investigações em redes sociais são criticadas por focar em excesso as métricas sem atentar para suas implicações qualitativas. De acordo com Tufekci (2014), uma das maneiras de balancear esse processo é por meio da condução de pesquisas multimétodos e multidisciplinares sobre o mesmo problema de pesquisa, combinando a análise de redes com surveys, entrevistas, etnografias que possam contrabalancear possíveis vieses de outros métodos. Marsden (1990), por sua vez, sustenta que a análise de redes foca níveis intermediários entre o individual e 0 nível populacional. Em complemento, Borgatti e colegas (2009) asseveram que a

${ }^{27} \mathrm{O}$ gatekeeper é o profissional de comunicação que exerce a função de filtrar as grandes quantidades de informação que fluem para os meios de comunicação de massa (White, 1964). O conceito de gatekeeper foi importante nos anos 1970 para a criação da teoria derivada do agenda-setting dos veículos de imprensa, segundo a qual os veículos de comunicação exercem uma função de estabelecer os temas que serão debatidos na ordem do dia, em especial na política e na economia.

28 Goel e colegas (2010) comparam opiniões políticas entre amigos no Facebook, apontando que amigos têm desacordo sobre temas políticos entre si com maior frequência do que a prevista, devido a projeções de estereótipos e projeções não correspondentes à realidade. A investigação destaca que isso ocorre apesar das semelhanças de crenças mais frequentes entre amigos do que em relação a indivíduos de fora de seu círculo social. ${ }^{29}$ Georg Simmel (1955) argumenta que a sociedade é a rede de relações e o que resulta das mesmas. As interações online e offline nessa rede de relações são partes de uma mesma continuidade. Elas refletem as redes de relacionamentos de indivíduos que compartilham crenças, ideias, percepções e mitos sobre a sociedade na qual vivem. As redes sociais são o reflexo online de conexões sociais desenvolvidas offline. 
principal característica da teoria das redes é o foco no relacionamento entre os atores, em contraste com o foco nos atributos dos atores nas pesquisas de opinião convencionais.

A análise de redes sociais ${ }^{30}$ é focada no estudo de parâmetros de relações em uma rede específica, que no caso específico desta investigação é a rede brasileira conectada à política externa e à política internacional. Esse construto social pode ser revelado a partir dos nós (páginas ou perfis) e clusters (grupos de nós), que aproximam dos nós com afinidades em uma mesma região do grafo (rede) nos quais estão localizados.

A formação das redes de páginas pode contribuir para conhecermos os caminhos utilizados pela opinião pública para se conectar a outros países e a assuntos globais. De acordo com Popkin (1993) e Baum et al (2008), o público se apoia em atalhos informacionais para a compreensão dos temas externos, sustentados por opiniões de elites políticas confiáveis de seus respectivos campos políticos e de seus meios de comunicação de preferência. Como já mencionado, os meios de comunicação de preferência passam por uma profunda mudança de perfil, quando comparamos com as primeiras rodadas de survey sobre política externa. Há uma migração, ainda em curso, do offline para o online. No contexto desta investigação, os atalhos cognitivos podem ser concebidos como ferramentas de compreensão de informações internacionais pela via das redes sociais.

Nesse sentido, a investigação do objeto opinião pública e política externa no Brasil não está centrada somente nos atributos de indivíduos e instituições pela via das surveys, conforme explorado no capítulo anterior, mas na resultante dos mesmos atributos para as redes sociais, tanto as presentes na web quanto as já constituídas previamente offline. As relações de causalidade não estão apenas nos atributos, mas no construto social formado a partir delas (Marin e Wellman, 2010). Desta

\footnotetext{
${ }^{30} \mathrm{~A}$ análise de redes sociais é posterior à análise de redes, que têm seus primeiros usos metodológicos em um mundo offline. O primeiro exemplo difuso dessa metodologia se dá no trabalho de Moreno (1934).
} 
forma, a proposta desta investigação é a de cruzar duas bases de dados distintas para aprofundar o que se conhece a respeito do comportamento da opinião pública brasileira com relação a temas externos, avançando do campo das surveys para as redes sociais.

Relações estruturais podem ser analisadas por meio da construção de redes ${ }^{31}$ de filiação e as redes emergentes a partir de dados das redes sociais. Quando consideramos redes de filiação, nos referimos aos públicos interessados em relações internacionais nas redes sociais - os seguidores de páginas e perfis partes das redes formadas pelo Brasil, países estrangeiros e organismos/instituições internacionais. As redes emergentes, por sua vez, se constituem a partir dos buzzes gerados por temas pontuais, da ordem do dia das notícias, que podem estar contidos ou não nos limites das redes de filiação, que por definição englobam um público instável. A opção deste trabalho é pelas redes de filiação, levando em conta a tese de estabilidade dos valores da opinião pública no que tange à política externa, explorada na Hipótese Culturalista ${ }^{32}$.

\subsection{QUESTÃO DE PESQUISA E HIPÓTESE}

Q1 | Quais são os principais clusters que exercem a função de atalhos cognitivos nas 59 redes bilaterais construídas?

H1 | Governos e Mídias não são os atalhos cognitivos hegemônicos nas redes de páginas de relações internacionais, em virtude da diversificação de clusters nas redes

\footnotetext{
${ }^{31}$ Além disso, há um dilema presente na dinâmica das redes: o do trade-off entre redes eficientes e redes robustas (Hafner-Burton et al, 2009). Redes eficientes tendem a ser menores, pois os caminhos para percorrê-las de ponta a ponta são mais diretos. Por outro lado, nas redes robustas, os caminhos entre os nós são mais diversos, devido a comunidades mais densas. Tanto redes mais robustas quanto as redes mais eficientes, no entanto, estão sujeitas ao fenômeno qualificado pela literatura como "small-world phenomenon": a ideia de que há poucos degraus de separação entre dois indivíduos de ambientes distantes (Milgram et al, 1967). Neste levantamento, ambos os tipos de redes levantados pelos autores estão presentes, em decorrência da diferença de interesse mútuo na comparação de cada uma das redes bilaterais

32 Inglehart (1988)
} 


\subsection{MÉTODOS E CONSTRUÇÃO DA BASE DE DADOS}

No total, foram construídas 59 redes bilaterais entre o Brasil e países das Américas, Europa, África, Ásia, Oriente Médio e Oceania. Os dados das redes foram obtidos no Facebook via aplicativo Netvizz, em 2018. Foram selecionados nós-sementes relevantes em política internacional e relações culturais entre o Brasil e cada um dos 59 países em separado.

A partir daí, foram extraídas as redes de likes e follows entre as páginas em deep2, com estratégia snowball ${ }^{33}$. Apesar dos tamanhos e métricas distintas obtidas em cada rede, todas elas foram padronizadas pelos mesmos modelos de distribuição do grafo no software Gephi: OpenOrd e ForceAtlas2, seguidos do cálculo de modularidade para a identificação de clusters. O cálculo de modularidade tem o objetivo de conhecer como se distribuem as diferentes comunidades (clusters) dentro de um mesmo grafo, que é a representação gráfica da rede bilateral. O cálculo dos clusters para as 59 redes conduziu a uma proposta de tipologia para simplificar as 600 classificações diferentes presentes nas redes por meio de assuntos comuns aos nós.

Para a análise de cada um dos agrupamentos de páginas, são consideradas as seguintes métricas:

- Nós: Páginas públicas de pessoas físicas ou instituições

\footnotetext{
${ }^{33} \mathrm{~A}$ amostragem de tipo snowball possibilita que se obtenha mais dados dentre as unidades de determinadas comunidades, ao mesmo tempo em que permite limitá-la de forma mais precisa (Marsden, 1990; Weber \& Monge, 2011; Golder et al, 2014). Por outro lado, as observações têm uma tendência de viés maior em relação às surveys tradicionais, que contam com amostras aleatórias da distribuição populacional real. Por essa razão, os autores reiteram que o estudo da dinâmica de opinião nas redes sociais tem papel complementar em relação aos métodos das surveys. Isso ocorre porque, se as surveys têm um desenho voltado para refletir a distribuição de opiniões entre os diferentes segmentos populacionais, por outro lado não possibilitam - como na análise de redes - a visualização dos fluxos, da difusão e da clusterização desses dados. A proposta de mesclar uma base de dados da survey As Américas e O Mundo e a construída via Netvizz no Facebook, com amostragem snowball, caminha nesse sentido.
} 
- Arestas: Conexões (likes, follows) entre as páginas, não necessariamente mútuas

- Componentes (Nós) fortemente conectados: Métrica que mensura quantos dos nós presentes na rede estão fortemente integrados à rede como um todo

- Grau (Degree): quantidade de conexões de cada nó. Podem ser de dois tipos: Grau de Entrada (recebidas) ou Grau de Saída (feitas). A média de arestas de entrada e saída por nó é chamada de grau médio (Average Degree).

- Comprimento médio de caminho: Média da menor distância entre os nós da rede. Menores distâncias indicam mais proximidade entre os nós.

- Diâmetro de Rede: Número de passos necessários para se ir aos dois nós mais distantes na rede

A seguir, apresentamos os dados gerais das redes construídas por continente.

- AMÉRICAS: Foram construídas 15 redes no Facebook envolvendo páginas de interesse do Brasil e de países das Américas. Os países analisados reúnem no total 6.890 nós e 36.592 arestas.

- EUROPA: Foram construídas 23 redes bilaterais entre Brasil e Europa. No total, são 15.006 nós e 97.072 arestas.

- ÁSIA/ORIENTE MÉDIO/OCEANIA: As três regiões reúnem 15 redes, com uma soma de 8.769 nós e 58.058 arestas.

- ÁFRICA: Foram construídas seis redes no Facebook envolvendo páginas de interesse do Brasil e de países da África ${ }^{34}$. Em conjunto, os países somam 2.803 nós e 19.710 arestas.

\footnotetext{
${ }^{34}$ Além das seis redes consideradas para a pesquisa, foram construídas outras 32 redes de países africanos distintos de forma exploratória. Os resultados não apresentaram significância, portanto elas não foram incluídas na análise.
} 


\subsection{MÉTRICAS DOS CLUSTERS}

Esta pesquisa identificou $600^{35}$ classificações diferentes de páginas nas 59 redes. Para efeitos de padronização e para que uma comparação fosse efetuada de modo mais eficaz, as 600 classificações foram recategorizadas em 10 clusters baseados em assuntos comuns às páginas de cada um dos grupos. Em seu conceito estrito, os clusters formariam grupos de nós mais integrados entre si em cada uma das redes em teoria. Na prática, a depender da organização dos diferentes grafos, eles podem formar grupos autônomos ou integrados a páginas de outras categorias. Nesse caso, os clusters são tratados como uma categoria qualitativa.

Os clusters e seus respectivos escopos classificatórios são:

1. CULTURA | Museus, galerias de arte, cinemas, produtoras, centros culturais, teatros, música e setor livreiro.

2. COMUNIDADES DE INTERESSE | Comunidades de interesse em temas diversos estritamente online e não institucionalizadas offline.

3. EDUCAÇÃo | Escolas, universidades, centros de pesquisa, divulgação científica e intercâmbio.

4. ESPORTES | Páginas sobre esportes, incluindo a diáspora de escolas de capoeira brasileiras pelo mundo.

5. GASTRONOMIA | Restaurantes, bares, serviços em gastronomia e alimentação.

6. GOVERNO/POLÍTICA | Embaixadas e consulados, instituições públicas, políticos e partidos políticos.

7. MíDIA | Mídias, agências de comunicação, blogs, páginas de figuras públicas e websites.

8. ORGANIZAÇÕES/TERCEIRO SETOR | Organizações não-governamentais, organismos multilaterais, clubes, associações e instituições religiosas.

\footnotetext{
${ }^{35}$ A relação completa das classificações de páginas considerada para cada um dos clusters se encontra no Appendix
} 
Diferenciam-se das Comunidades de Interesse pela sua institucionalização formal offline.

9. SETOR PRIVADO | Empresas privadas, com exceção das contempladas pelos demais clusters aqui listados.

10. TURISMO | Páginas da divulgação turística; serviços em turismo, como hotéis, transportes e agências.

O cluster com mais páginas entre as 59 redes construídas, em termos absolutos, é o de Cultura, com 5.265 nós, seguido por Mídia (4.865) e Governo/Política (4.333). Organizações/Terceiro Setor apresenta 4.053 páginas, à frente de Turismo (3.567), Educação (3.380), Setor Privado (3.336) e Comunidades de Interesse (3.163). Gastronomia (1.192) e Esportes (1.086) são os clusters que apresentam menos nós entre todos.

FIGURA 6 CLUSTERS EM RELAÇÃO AO TOTAL DE PÁGINAS DO LEVANTAMENTO

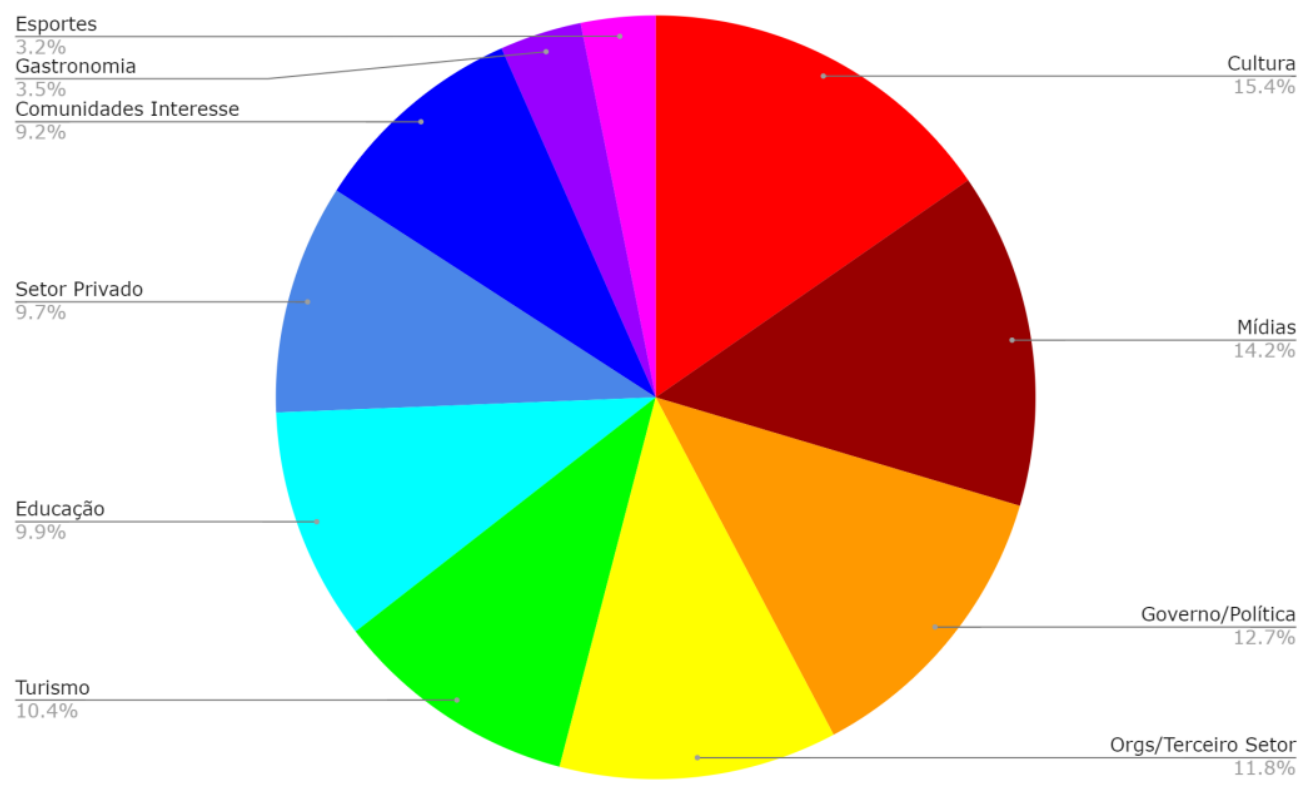

Fonte: Produção do autor 


\subsubsection{CULTURA}

O cluster de Cultura é o que apresenta mais nós nas redes bilaterais em termos absolutos, com média de 89,24 páginas por rede. Dezesseis redes bilaterais apresentam mais de 89 nós de Cultura em suas redes. No entanto, nem todas as redes com volumes acima da média em Cultura tem esse cluster como o principal.

Dez redes bilaterais tem a Cultura como cluster hegemônico. Dentre elas, estão três das maiores redes do levantamento: Espanha, França e Hungria. A média de nós de cultura em relação ao total de páginas para o grupo é de $25 \%$. Essa marca é superada por sete países do grupo, com exceção do Japão (22,2\%), da Espanha $(18,7 \%)$ e da Polônia (14,4\%). A média de 855 nós por rede é influenciada pelo tamanho das redes bilaterais espanhola, francesa e húngara e, na mesma proporção, do volume de nós fortemente conectados e de arestas.

Dentre o grupo dos que superam a média de nós de Cultura, somente França e Hungria têm grau médio superior ao valor de 5,023. Por outro lado, o comprimento médio de caminho de Áustria, Coreia do Sul, Dinamarca, México e Vietnã é mais curto em relação a média do grupo. Vale destacar, no entanto, que a França $(4,031)$ se aproxima da média, mesmo apresentando uma rede bilateral significativamente maior em relação às demais do grupo. Com relação ao Diâmetro, apresentam redes mais compactas a Áustria (7), Coreia do Sul (8), Dinamarca (9) e México (9). 
TABELA 2 | A CULTURA COMO CLUSTER PRINCIPAL

\begin{tabular}{cccccccc}
\hline & NÓS CULT. & NÓS REDE & NÓS FORTES & ARESTAS & GR. MÉDIO & C. MÉD. CAM. & DIÂMETRO \\
MÉDIA & $\mathbf{2 1 4}(\mathbf{2 5 \% )}$ & $\mathbf{8 5 5}$ & $\mathbf{4 2 2}$ & $\mathbf{6 0 1 0}$ & $\mathbf{5 , 0 2 3}$ & $\mathbf{3 , 8 9 9}$ & $\mathbf{1 0 , 7}$ \\
ÁUSTRIA & $53(33,5 \%)$ & 158 & 73 & 588 & 3,722 & 3,300 & 7 \\
COREIA DO & $43(32 \%)$ & 134 & 103 & 351 & 2,619 & 3,239 & 8 \\
SUL & $112(39,7 \%)$ & 282 & 139 & 1277 & 4,528 & 3,711 & 9 \\
DINAMARCA & 1120 & 747 & 15828 & 8,978 & 4,146 & 13 \\
ESPANHA & $330(18,7 \%)$ & 1763 & 1143 & 26454 & 10,039 & 4,031 & 11 \\
FRANÇA & $682(25,8 \%)$ & 2635 & 629 & 6500 & 5,272 & 4,794 & 12 \\
HUNGRIA & $332(26,9 \%)$ & 1233 & 531 & 3735 & 3,907 & 4,556 & 13 \\
JAPÃO & $213(22,2 \%)$ & 956 & 109 & 616 & 3,330 & 3,046 & 9 \\
MÉXICO & $75(40,5 \%)$ & 185 & 486 & 3300 & 3,981 & 4,719 & 13 \\
POLÔNIA & $120(14,4 \%)$ & 829 & & & & $F O n$ & \\
\hline
\end{tabular}

Fonte: Produção do autor

\subsubsection{MÍDIA}

As sete redes bilaterais com maioria de páginas de Mídia são médias ou pequenas: todas têm menos de 1000 nós em suas respectivas redes. Canadá, China e Turquia apresentam volume de arestas acima da média. As redes que apresentam páginas de Mídia acima da média geral de $23,5 \%$ estão entre as menores entre as 59 construídas: Bolívia (27,2\%), Romênia (43,9\%) e Venezuela (34,9\%). Os três países estão abaixo da média em nós, nós fortes, arestas e grau médio. Porém, por possuírem redes menores, têm menor comprimento médio de caminho e diâmetro. Cuba $(23,5 \%)$ tem valor igual ao da média.

Canadá e Turquia, que apresentam os maiores volumes de arestas do grupo, são os que têm a menor proporção de nós de Mídia: 16,9\% e 20,2\%, respectivamente, o que indica redes mais diversificadas, apesar da liderança do cluster Mídia. China $(22,1 \%)$ e Suíça (22\%) se aproximam mais da média de nós de mídia por rede. Um ponto de relevância acerca desse grupo é sobre a heterogeneidade com relação à liberdade do uso da internet. Em ranking construído pela Freedom House (2019), o Canadá é considerado o terceiro país mais livre do mundo no uso da internet, com 
87 pontos. Turquia (37), Venezuela (30 pontos), Vietnã (24), Cuba (22) e China (10) estão entre os países menos livres no uso da rede mundial de computadores.

\section{TABELA 3 | A MÍDIA COMO CLUSTER PRINCIPAL}

\begin{tabular}{cccccccc}
\hline & NÓS MID. & NÓS REDE & NÓS FORTES & ARESTAS & GR. MÉDIO & C.. MÉD. CAM. & DIÂMETRO \\
MÉDIA & $\mathbf{8 6}(\mathbf{2 3 , 5 \% )}$ & $\mathbf{3 6 6}$ & $\mathbf{2 3 5 , 3}$ & $\mathbf{1 3 4 8 , 6}$ & $\mathbf{3 , 3 8 2}$ & $\mathbf{3 , 9 2 1}$ & $\mathbf{1 1 , \mathbf { 1 }}$ \\
BOLÍVIA & $30(27,2 \%)$ & 110 & 98 & 191 & 1,736 & 2,638 & 7 \\
CANADÁ & $93(16,9 \%)$ & 548 & 254 & 2745 & 5,009 & 4,453 & 14 \\
CHINA & $115(22,1 \%)$ & 519 & 382 & 1521 & 2,931 & 6,067 & 15 \\
CUBA & $84(23,5 \%)$ & 357 & 180 & 1945 & 5,448 & 3,653 & 9 \\
ROMÊNIA & $124(43,9 \%)$ & 282 & 225 & 731 & 2,592 & 2,264 & 6 \\
SUÍÇA & $50(22 \%)$ & 227 & 137 & 727 & 3,203 & 3,996 & 14 \\
TURQUIA & $159(20,2 \%)$ & 786 & 529 & 2643 & 3,363 & 5,605 & 14 \\
\hline
\end{tabular}

Fonte: Produção do autor

\subsubsection{GOVERNO/POLÍTICA}

O cluster de Governo/Política é o maior em 14 redes bilaterais das 59 construídas. Isso o torna o cluster mais difuso na comparação com os outros nove. Esse grupo contempla redes médias e pequenas das Américas, Europa, África, Ásia e Oriente Médio. A média de páginas de Governo/Política em relação ao total de nós é de $27,3 \%$ para este grupo, valor ligeiramente superior na comparação com os clusters de Cultura e Mídia. Oito das quatorze redes bilaterais superam a média de 27,3\%: Argentina, Cabo Verde, Equador, Filipinas, Finlândia, Peru, República Dominicana e Uruguai. Dessa forma, metade dos países acima da média são sul-americanos e um faz parte da Comunidade de Países de Língua Portuguesa.

Seis países apresentam volume de nós fortemente conectados acima do valor médio de 197 - Argentina, Bélgica, Índia, Israel, Líbano e Portugal. O mesmo grupo também está acima da média no número de arestas, acompanhado da rede bilateral Brasil-Finlândia. Com relação ao grau médio, a composição das redes bilaterais 
líderes é distinta: Equador, Filipinas, Finlândia, Israel, Líbano e Portugal apresentam métrica superior a 5,968. O comprimento médio de caminho é mais curto que a métrica média nas redes bilaterais da Argentina, Filipinas, Finlândia, Israel e República Dominicana.

\section{TABELA 4 | GOVERNO/POLÍTICA COMO CLUSTER PRINCIPAL}

\begin{tabular}{cccccccc}
\hline & NÓS GOV/POL & NÓS & NÓS FORTES & ARESTAS & GR. MÉDIO & C.. MÉD. CAM. & DIÂMETRO \\
MÉDIA & $\mathbf{1 0 9}(\mathbf{2 7 , 3 \% )}$ & $\mathbf{3 9 9}$ & $\mathbf{1 9 7}$ & $\mathbf{2 6 0 1}$ & $\mathbf{5 , 9 6 8}$ & $\mathbf{3}, 767$ & $\mathbf{1 0 , 1}$ \\
ARGENTINA & $222(30,2 \%)$ & 735 & 377 & 4124 & 5,611 & 2,638 & 13 \\
BÉLGICA & $145(23,1 \%)$ & 627 & 307 & 3493 & 5,571 & 3,999 & 10 \\
CABO VERDE & $30(36,5 \%)$ & 82 & 40 & 292 & 3,561 & 4,129 & 11 \\
EQUADOR & $92(28,4 \%)$ & 323 & 140 & 2018 & 6,248 & 4,502 & 13 \\
FILIPINAS & $75(61,9 \%)$ & 121 & 56 & 766 & 6,331 & 2,503 & 6 \\
FINLÂNDIA & $103(28,6 \%)$ & 359 & 183 & 3222 & 8,975 & 3,308 & 8 \\
GRÉCIA & $54(26,7 \%)$ & 202 & 96 & 939 & 4,649 & 3,841 & 9 \\
ÍNDIA & $157(20,2 \%)$ & 777 & 420 & 4019 & 5,172 & 6,164 & 14 \\
ISRAEL & $160(23,6 \%)$ & 677 & 299 & 7741 & 11,434 & 3,559 & 10 \\
LíBANO & $140(25,2 \%)$ & 554 & 269 & 3719 & 6,713 & 4,110 & 12 \\
PERU & $81(37,3 \%)$ & 217 & 88 & 1303 & 6,005 & 3,798 & 11 \\
PORTUGAL & $99(16,8 \%)$ & 587 & 294 & 3719 & 6,336 & 4,212 & 12 \\
R.DOMINICANA & $21(48,8 \%)$ & 43 & 20 & 162 & 3,767 & 2,125 & 4 \\
\hline
\end{tabular}

Fonte: Produção do autor

\subsubsection{ORGANIZAÇÕES/TERCEIRO SETOR}

Quatro redes têm as Organizações/Terceiro Setor como principal cluster: Armênia, Haiti, Moçambique e Ucrânia. A rede bilateral Brasil-Moçambique tem porte significativamente maior em relação às demais do grupo. A média da proporção de nós de Organizações/Terceiro Setor em relação ao total é de 30,9\%, marca superada por Moçambique e igualada pelo Haiti. Moçambique e Haiti apresentam os maiores graus médios entre as quatro redes bilaterais. Armênia e Haiti têm as redes mais compactas na comparação com Moçambique. 


\section{TABELA 5 | ORGANIZAÇÕES/TERCEIRO SETOR COMO CLUSTER PRINCIPAL}

\begin{tabular}{cccccccc}
\hline & NÓS ORG. & NÓS REDE & NÓS FORTES & ARESTAS & GR. MÉDIO & C. MÉD. & DIÂMETRO \\
MÉDIA & $154(30,9 \%)$ & 498 & 226 & 4618 & 5,555 & 3,876 & 10.5 \\
ARMÊNIA & $25(20,6 \%)$ & 121 & 72 & 349 & 2,884 & 3,425 & 9 \\
HAITI & $78(30,9 \%)$ & 252 & 138 & 1327 & 5,660 & 3,510 & 8 \\
MOÇAMBIQUE & $454(33,1 \%)$ & 1368 & 546 & 15492 & 8,536 & 4,676 & 13 \\
UCRÂNIA & $141(55,73 \%)$ & 254 & 151 & 1305 & 5,138 & 3,893 & 12 \\
\hline
\end{tabular}

Fonte: Produção do autor

Moçambique e Haiti têm a ONU como importante catalisadora. No caso do Haiti, a presença se amplia em decorrência da MINUSTAH e da recente imigração de haitianos para o Brasil. Moçambique compartilha o mesmo idioma e também investimentos públicos e privados de origem brasileira. As redes da Armênia e da Ucrânia estão nesse grupo por motivos diferentes: ambos os países têm comunidades de imigrantes históricas no Brasil, cuja consequência objetiva é a maior presença de clubes, associações e instituições religiosas diretamente ligadas a essas heranças culturais. Nesses estudos de caso, verificamos maior presença nas redes dos armênio-brasileiros em São Paulo e das comunidades ucranianobrasileiras no Paraná.

\subsubsection{TURISMO}

Há considerável diversidade geográfica entre as redes com liderança do cluster de Turismo. África do Sul, Austrália, Croácia, Emirados Árabes Unidos, Noruega, Nova Zelândia, República Tcheca e Tailândia integram esse grupo. Dentre os oito países do grupo, a Austrália se destaca. Mesmo com uma grande diferença de métricas em relação aos outros integrantes do grupo, que poderia resultar em uma rede mais diversa, o país da Oceania é o que tem a maior proporção de nós de Turismo: 
$35,7 \%, 5,8 \%$ pontos percentuais acima da média geral de $29,9 \%$.

As demais redes bilaterais acima dessa média são Croácia (31,6\%), Noruega $(31,3 \%)$ e Tailândia (33,5\%). Devido à influência da Austrália sobre as médias gerais do grupo, as três redes bilaterais estão abaixo da média em nós, nós fortes, arestas e grau médio. O comprimento médio de caminho, que se espera ser mais curto para redes menores, é mais curto na própria rede australiana em comparação com Croácia, Noruega e Tailândia. Com relação ao diâmetro, o menor é o da rede croata. Austrália e Noruega estão na média, e a Tailândia, com 15, apresenta uma rede mais dispersa.

\section{TABELA 6 | TURISMO COMO CLUSTER PRINCIPAL}

\begin{tabular}{cccccccc}
\hline & NÓS TUR. & NÓS & NÓS FORTES & ARESTAS & GR.MÉDIO & C. MÉD. CAM. & DIÂMETRO \\
MÉDIA & $156(29,9 \%)$ & 521 & 212 & 4134 & 5,404 & 4,309 & 12 \\
ÁFRICA DO SUL & $77(24,3 \%)$ & 316 & 156 & 1626 & 5,146 & 4,326 & 14 \\
AUSTRÁLIA & $652(35,7 \%)$ & 1825 & 511 & 20528 & 11,248 & 4,069 & 12 \\
CROÁCIA & $73(31,6 \%)$ & 231 & 107 & 1130 & 4,892 & 4,254 & 11 \\
EMIRADOS & $73(23,6 \%)$ & 309 & 199 & 1053 & 3,408 & 4,541 & 12 \\
ÁRABES & $138(31,3 \%)$ & 440 & 218 & 2025 & 4,602 & 4,735 & 12 \\
NORUEGA & $108(17 \%)$ & 632 & 235 & 5638 & 8,921 & 3,763 & 8 \\
NOVA ZELÂNDIA & $108(26,1 \%)$ & 153 & 107 & 349 & 2,281 & 3,814 & 12 \\
REP. TCHECA & $40(26,1 \%$ & 724 & 2,732 & 4,973 & 15 \\
TAILÂNDIA & $89(33,5 \%)$ & 265 & 169 & 724 & \\
\hline
\end{tabular}

Fonte: Produção do autor

\subsubsection{EDUCAÇÃO}

Apenas cinco redes bilaterais têm a Educação como principal cluster, sendo quatro de países europeus e três de países de língua inglesa. A rede bilateral Estados Unidos-Brasil é a maior rede desse grupo. A média de páginas de Educação para o 
grupo é de 20,1\%, mais baixa em relação aos clusters anteriores, indicando redes diversas e com presenças importantes dos demais dez clusters.

Holanda (18\%), Reino Unido (17\%) e Suécia (19,5\%), com redes consideravelmente menores que a norte-americana, exibem valores proporcionais próximos. A Irlanda destoa do grupo, com 39,9\% de suas páginas pertencendo ao cluster educacional, fomentadas pela ampliação do país como destino de intercâmbio estudantil e de estágios para os brasileiros.

O país vizinho do Reino Unido está abaixo da média de nós, nós fortemente conectados e arestas. No entanto, apresenta um grau médio alto em relação ao grupo, menor comprimento médio de caminho e menor diâmetro.

\section{TABELA 7 | EDUCAÇÃO COMO CLUSTER PRINCIPAL}

\begin{tabular}{cccccccc}
\hline & NÓS EDU. & NÓS & NÓS FORTES & ARESTAS & GR.MÉDIO & C. MÉD. CAM. & DIÂMETRO \\
MÉDIA & $180(20,1 \%)$ & 894 & 378 & 5428 & 5,658 & 4,212 & 11,6 \\
EUA & $390(17,4 \%)$ & 2229 & 886 & 14693 & 6,592 & 5,406 & 19 \\
HOLANDA & $109(18 \%)$ & 604 & 246 & 3627 & 6,005 & 3,863 & 9 \\
IRLANDA & $201(39,9 \%)$ & 503 & 214 & 3234 & 6,429 & 3,881 & 9 \\
REINO UNIDO & $129(17 \%)$ & 758 & 306 & 4158 & 5,485 & 4,328 & 11 \\
SUÉCIA & $74(19,5 \%)$ & 378 & 241 & 1429 & 3,780 & 3,584 & 10 \\
\hline
\end{tabular}

Fonte: Produção do autor

\subsubsection{SETOR PRIVADO}

O Setor Privado é o cluster mais importante em seis redes bilaterais, com média de $21,6 \%$ para cada uma, valor ligeiramente superior ao cluster educacional. As redes têm tamanho variado, sendo mais extensas nos casos de Alemanha e Itália, médias 
nos casos de Angola e Chile e menores com relação ao Marrocos e ao Paraguai.

A média de nós do Setor Privado no total da rede é superada em quatro dos seis países: Alemanha (22,2\%), Itália (22,1\%), Marrocos $(32,9 \%)$ e Paraguai $(24,3 \%)$. Angola (17,3\%) e Chile $(17,6 \%)$ apresentam valores proporcionais próximos e ambos abaixo da média.

Alemanha e Itália superam as médias das métricas gerais para nós, nós fortes e arestas. No grau médio, os valores estão mais altos do que a média para Alemanha, Itália e Paraguai. Somente a Itália apresenta comprimento médio de caminho mais longo em relação aos três demais países com maior presença do Setor Privado. O Diâmetro é mais curto para Marrocos e Paraguai.

Todas as redes bilaterais apresentam mais de 1.000 arestas, com exceção do Marrocos, que conta com apenas 250. Isso resulta em um grau médio de apenas 1,374 na rede como um todo, indicando baixa integração entre os diferentes clusters e nós.

\section{TABELA 8 | SETOR PRIVADO COMO CLUSTER PRINCIPAL}

\begin{tabular}{cccccccc}
\hline & NÓS S.PRI. & NÓS & NÓS FORTES & ARESTAS & GR. MÉDIO & C. MÉD. CAM. & DIÂMETRO \\
MÉDIA & $\mathbf{1 3 9}(\mathbf{2 1 , 6 \% )}$ & $\mathbf{6 4 6}$ & $\mathbf{3 8 8}$ & $\mathbf{2 9 9 6}$ & $\mathbf{4 , 0 0 6}$ & $\mathbf{4 , 1 7 7}$ & $\mathbf{1 2}$ \\
ALEMANHA & $260(22,2 \%)$ & 1166 & 547 & 7688 & 6,593 & 4,174 & 13 \\
ANGOLA & $94(17,3 \%)$ & 541 & 424 & 1422 & 2,628 & 4,448 & 14 \\
CHILE & $94(17,6 \%)$ & 534 & 344 & 1860 & 3,483 & 4,759 & 13 \\
ITÁLIA & $241(22,1 \%)$ & 1088 & 669 & 4695 & 4,315 & 5,045 & 17 \\
MARROCOS & $60(32,9 \%)$ & 182 & 160 & 250 & 1,374 & 2,957 & 6 \\
PARAGUAI & $89(24,3 \%)$ & 366 & 188 & 2065 & 5,642 & 3,679 & 9 \\
\hline
\end{tabular}

Fonte: Produção do autor 


\subsubsection{COMUNIDADES DE INTERESSE}

O cluster das Comunidades de Interesse contempla os nós cujos interesses expressos nos respectivos países não são institucionalizados, como nos casos de Governo/Política e Organizações/Terceiro Setor. Três redes têm como principal cluster as Comunidades de Interesse: Egito, Palestina e Rússia. Apesar de não ser uma nação soberana nos mesmos marcos legais que Egito e Rússia, a Palestina foi incluída como rede bilateral em função da sua relevância em termos de métricas e na política internacional. A proporção média de nós relativos a esse cluster é de $25,6 \%$. Palestina (25,8\%) e Rússia (26,7\%) superam essa marca, e o Egito não. A Palestina supera as médias para nós, nós fortemente conectados, arestas e grau médio. Já a Rússia apresenta comprimento médio de caminho e diâmetro mais curtos.

É importante sinalizar que as três localidades desse grupo, por razões diversas, apresentam internet sujeita a intervenções mais agudas dos governos, incluindo as redes sociais. Por esse motivo, diferentemente de outras redes bilaterais, a proporção de fanpages brasileiras ou de terceiros países é maior do que o usual, que é uma divisão mais igualitária de páginas brasileiras e do país-alvo da rede bilateral. De acordo com o Freedom House Index, o Egito tem 26 pontos em liberdade na internet, e a Rússia, 31, em uma escala de 0 a 100.

\section{TABELA 9 | COMUNIDADES DE INTERESSE COMO CLUSTER PRINCIPAL}

\begin{tabular}{cccccccc}
\hline & NÓS COM. & NÓS & NÓS FORTES & ARESTAS & GR. MÉDIO & C. MÉD. CAM. & DIÂMETRO \\
MÉDIA & $109(25,6 \%)$ & 425 & 294 & 1700 & 3,329 & 4,008 & 9,666 \\
EGITO & $77(24,5 \%)$ & 314 & 268 & 628 & 2,000 & 3,958 & 8 \\
PALESTINA & $185(25,8 \%)$ & 715 & 428 & 3818 & 5,340 & 4,553 & 11 \\
RÚSSIA & $66(26,7 \%)$ & 247 & 186 & 654 & 2,648 & 3,514 & 10 \\
\hline
\end{tabular}

Fonte: Produção do autor 


\subsubsection{ESPORTES E GASTRONOMIA}

Os clusters de Esportes e de Gastronomia são os menores em termos de números absolutos e também em termos proporcionais. A média de nós de Gastronomia por rede é de 21 páginas por rede bilateral. Mesmo com um volume médio baixo, apenas 15 das 59 redes superam essa marca. Seis redes bilaterais têm mais de 50 nós em Gastronomia: três europeias (França, Itália, Hungria) e três americanas (Argentina, Estados Unidos e Chile). Abaixo da marca de 50 nós estão mais três redes europeias (Espanha, Portugal e Alemanha), três americanas (Paraguai, Peru e Canadá) e três representantes da Ásia/Oceania (Austrália, Japão e Nova Zelândia).

A média mais baixa entre todos os clusters é a de Esportes, com 19 por rede bilateral. A Colômbia supera essa média em mais de dez vezes, com 212 páginas nesse cluster. $O$ valor é mais que 0 dobro em relação à segunda e terceira colocadas, França (81) e Austrália (80). Estados Unidos e Chile são os outros dois representantes acima da média no continente americano ao lado da Colômbia. Entre os europeus acima da média estão Polônia, Espanha, Hungria e Holanda. Índia, Japão, Líbano, Nova Zelândia, Tailândia e Vietnã representam a ÁsiaOceania neste grupo. A única representante da África é a África do Sul, cuja rede bilateral contempla fanpages de jiu-jitsu brasileiro e capoeira.

A rede bilateral Brasil-Colômbia registra a única com hegemonia do cluster de Esportes, com 212 nós. Isso ocorre em virtude do expressivo número de páginas ligadas à capoeira, que conta com diversos centros no país vizinho. Esses centros também estão conectados com outras escolas do esporte no exterior, o que ajuda a explicar o seu volume. Já o cluster de Gastronomia não é o principal em nenhuma das redes construídas. 


\subsection{CARACTERÍSTICAS COMUNS ENTRE AS REDES A PARTIR DAS MÉTRICAS: UMA PROPOSTA DE TIPOLOGIA}

Observamos nas análises anteriores quais são as métricas gerais para cada rede a partir dos clusters hegemônicos, a partir da referência dos nós. A seguir, é proposta a formação dos clusters a partir do peso de todas as métricas, não por meio das classificações qualitativas das páginas.

A técnica usada foi o agrupamento qualitativo via análise de cluster a partir de nós, nós fortemente conectados, arestas, grau médio, comprimento médio de caminho e diâmetro. $O$ conjunto dessas métricas gera diferentes pesos para os indicadores das redes em perspectiva comparada.

A análise desenvolvida no software SPSS deu origem a três diferentes grupos, que foram nomeados de acordo com as suas afinidades: as redes gigantes, as redes ultraconectadas e as redes menores. Fazem parte desses grupos:

- GIGANTES | França, Estados Unidos, Austrália e Espanha

- ULTRACONECTADAS | Alemanha, Hungria e Israel

- REDES MENORES | As 52 redes bilaterais restantes

A técnica de agrupamento foi bem-sucedida na distinção dos três grupos, conforme podemos observar abaixo no boxplot das distribuições das métricas de nós e arestas Vs agrupamento qualitativo: 
FIGURA 7 | AGRUPAMENTO DE MÉTRICAS VERSUS NÓS

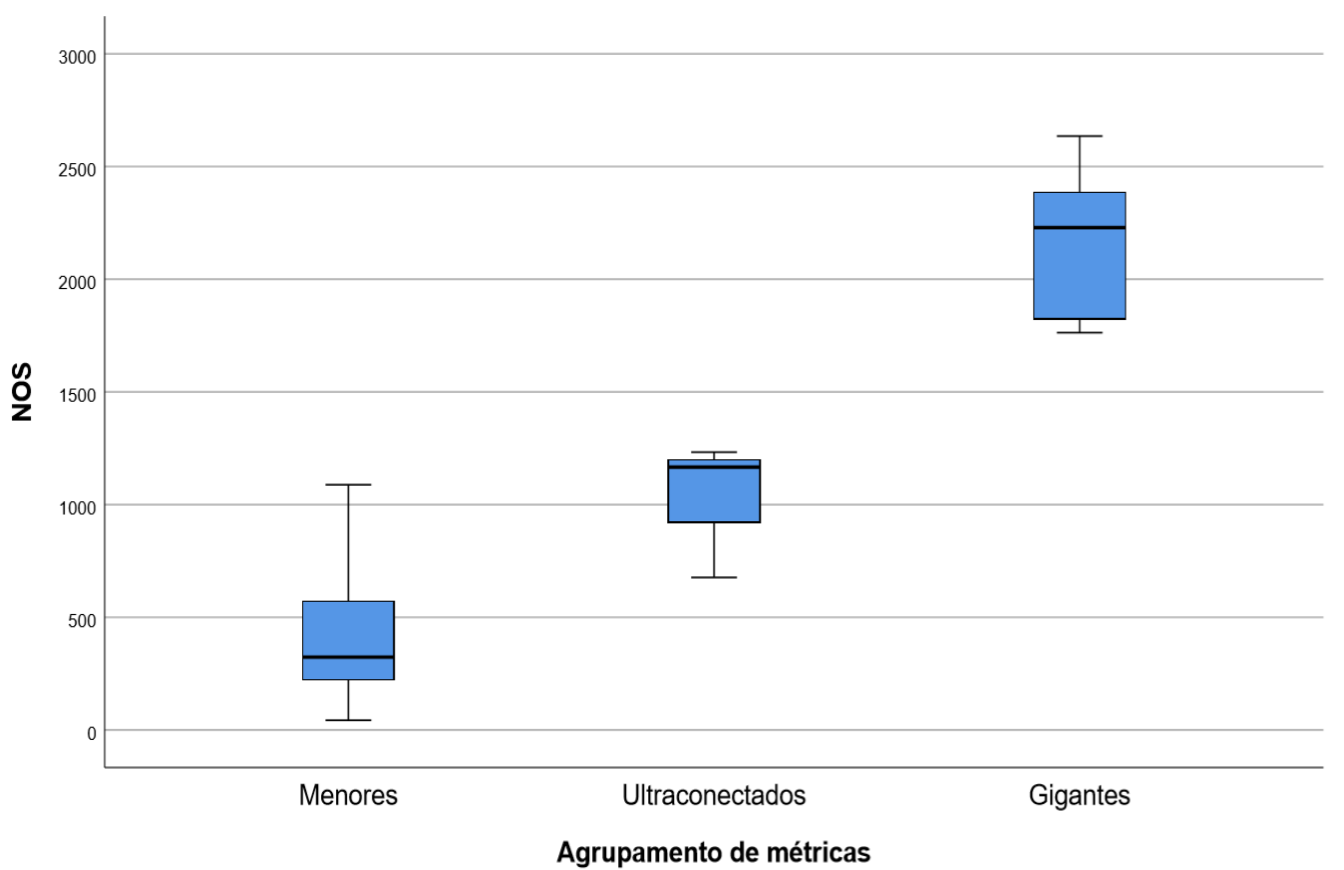

Fonte: Produção do autor

FIGURA 8 | AGRUPAMENTO DE MÉTRICAS VERSUS ARESTAS

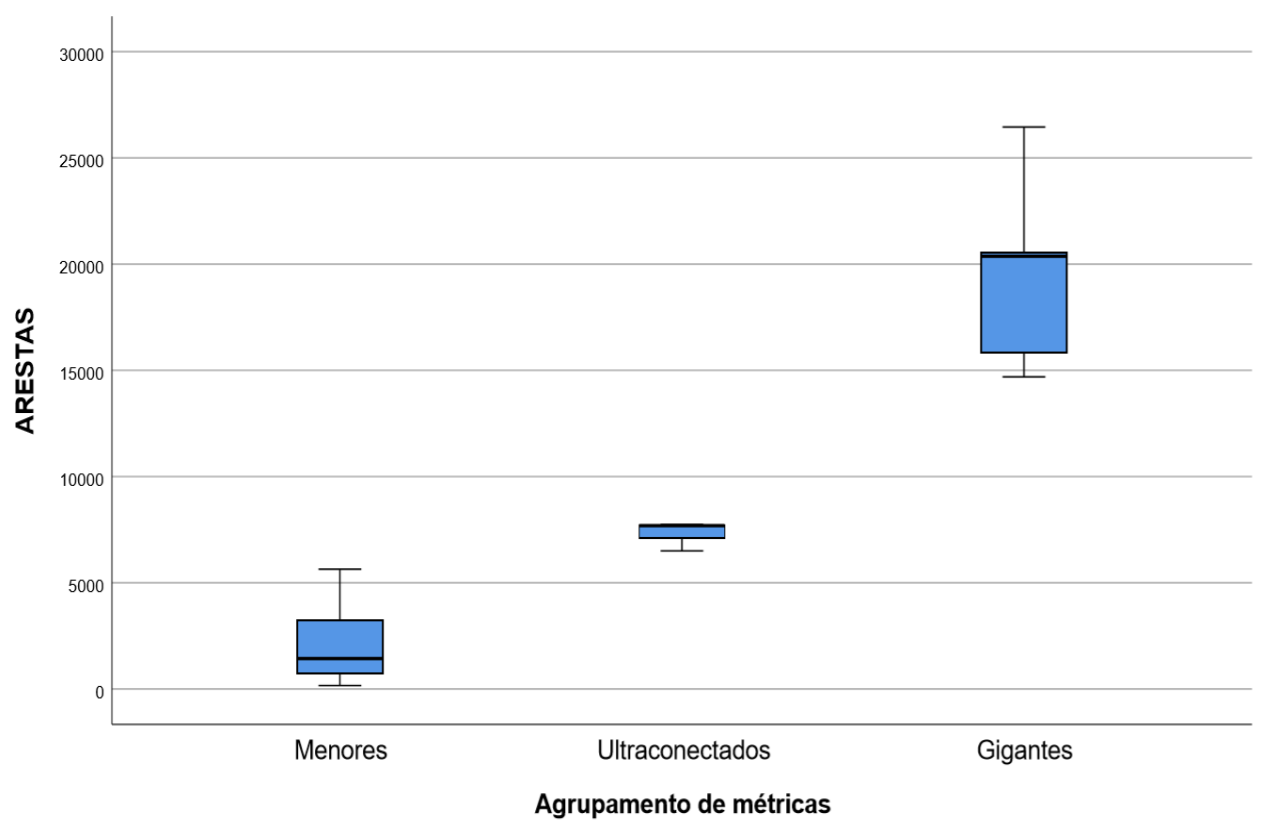


FIGURA 9 | REDE BILATERAL BRASIL-FRANÇA

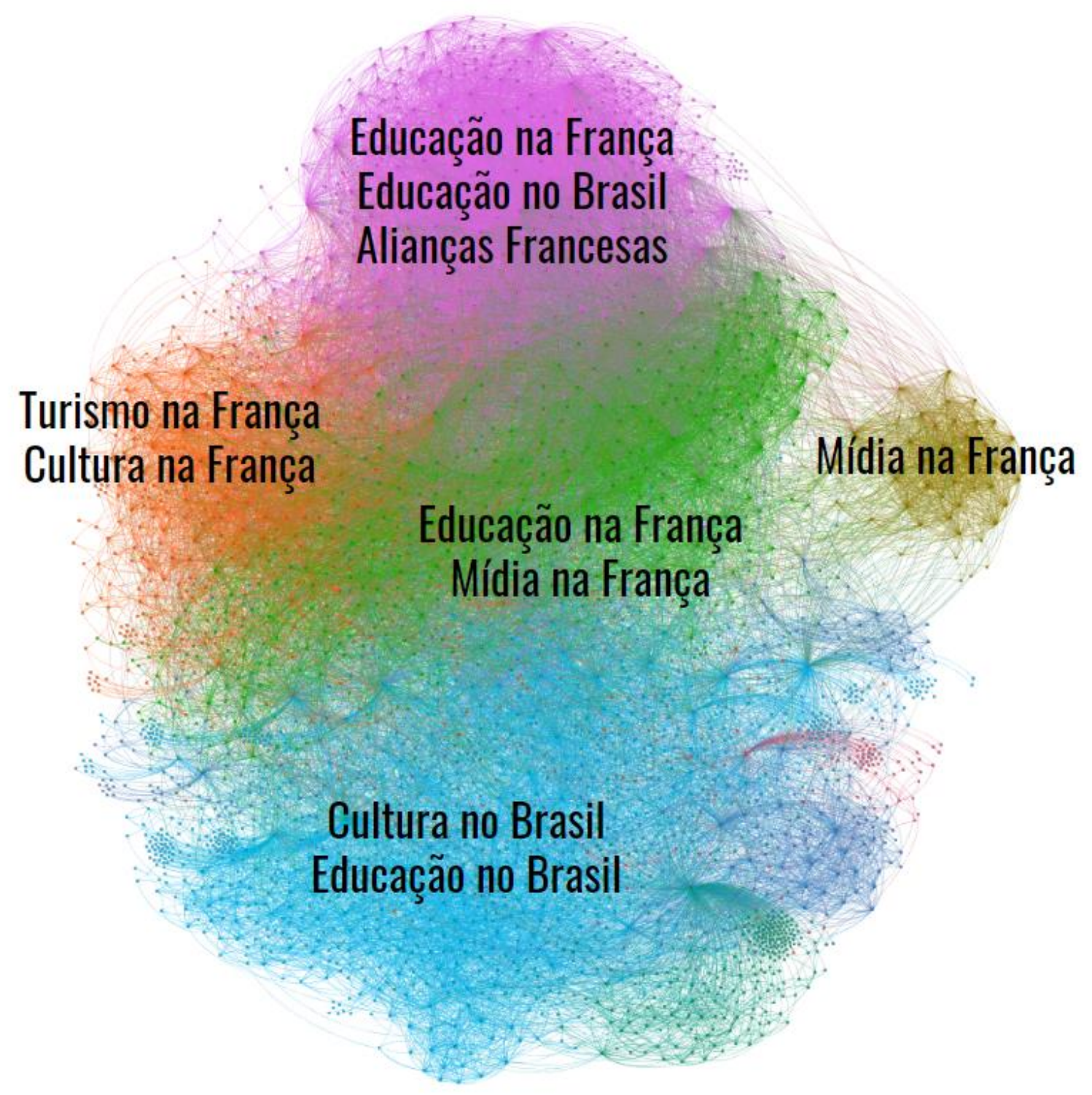


FIGURA 10 | REDE BILATERAL BRASIL-ESTADOS UNIDOS

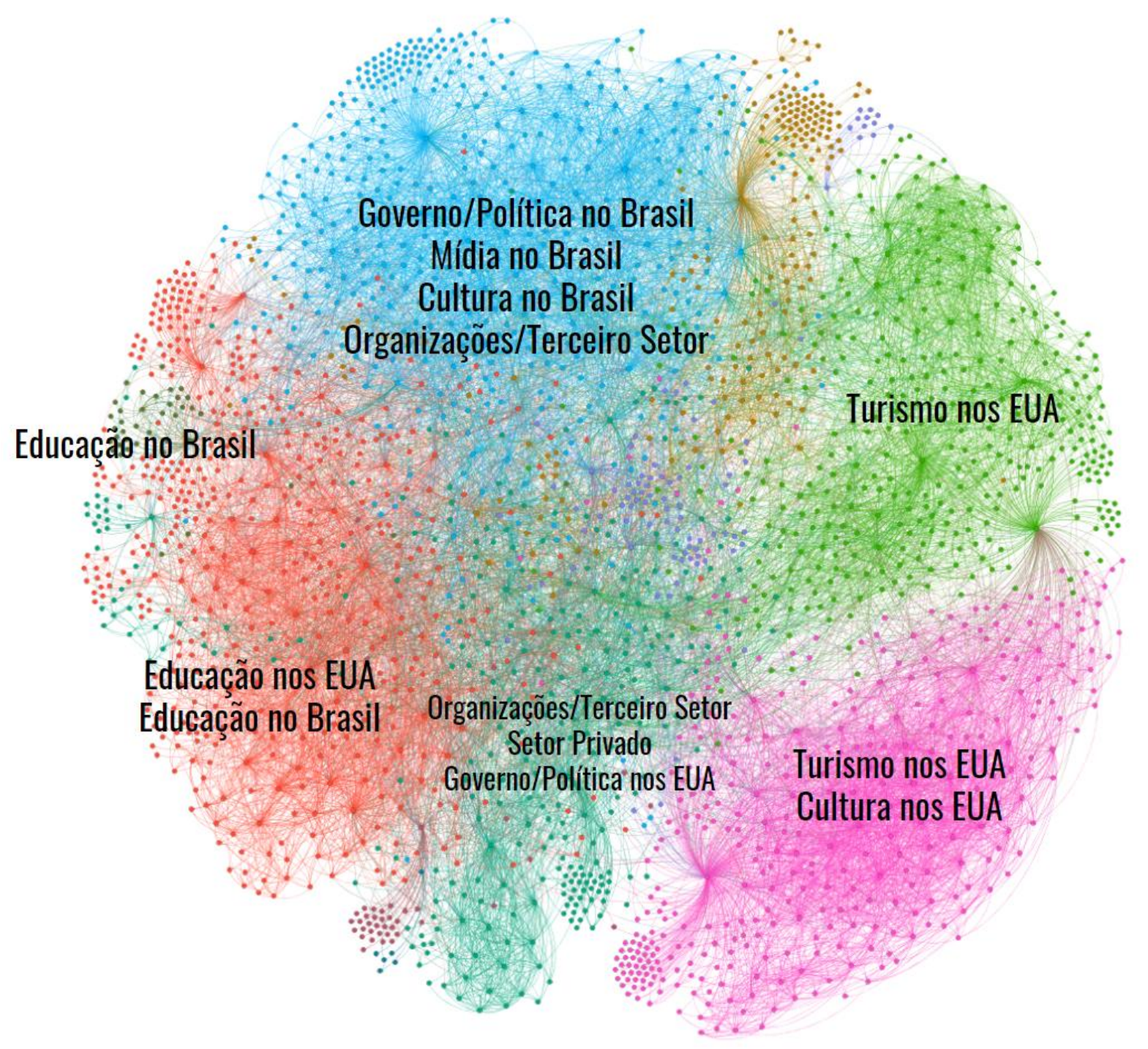


FIGURA 11 | REDE BILATERAL BRASIL-AUSTRÁLIA

Governo/Política no Brasil Organizações/Terceiro Setor no Brasil

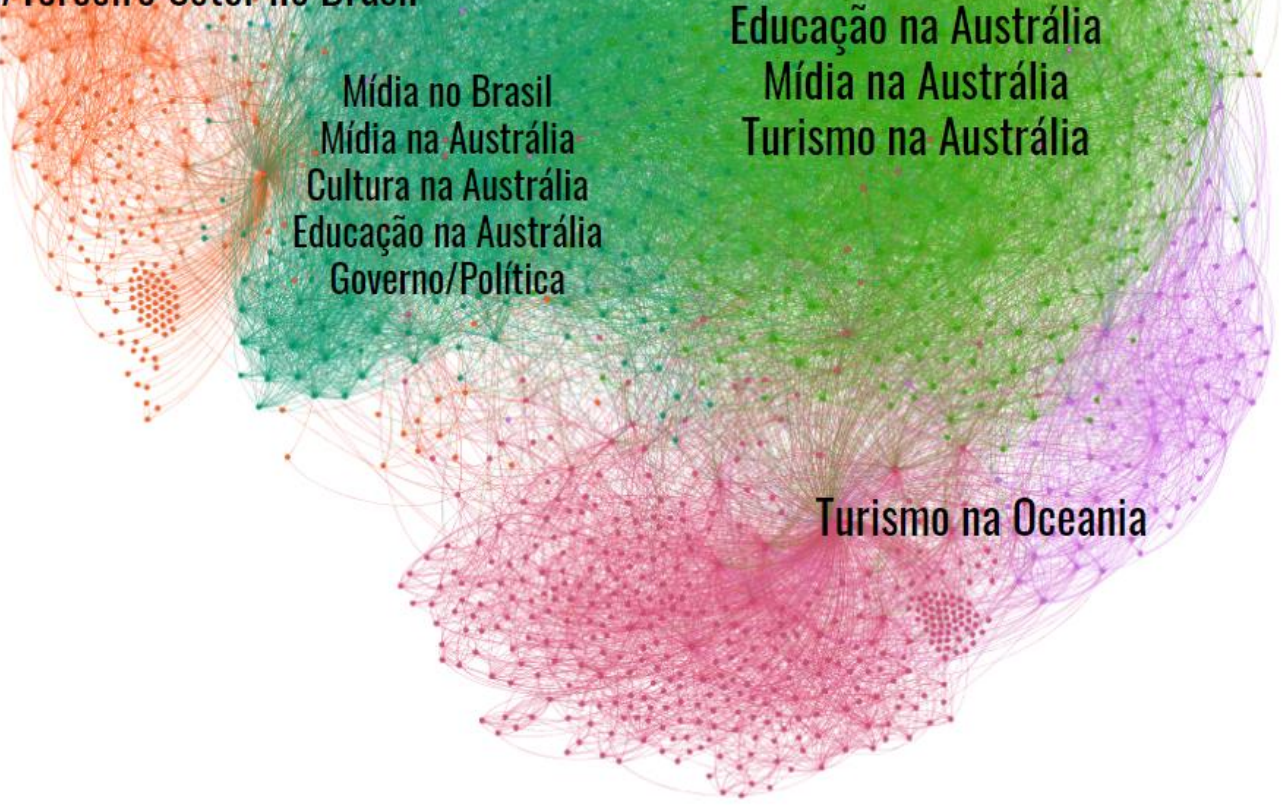


FIGURA 12 | REDE BILATERAL BRASIL-ESPANHA

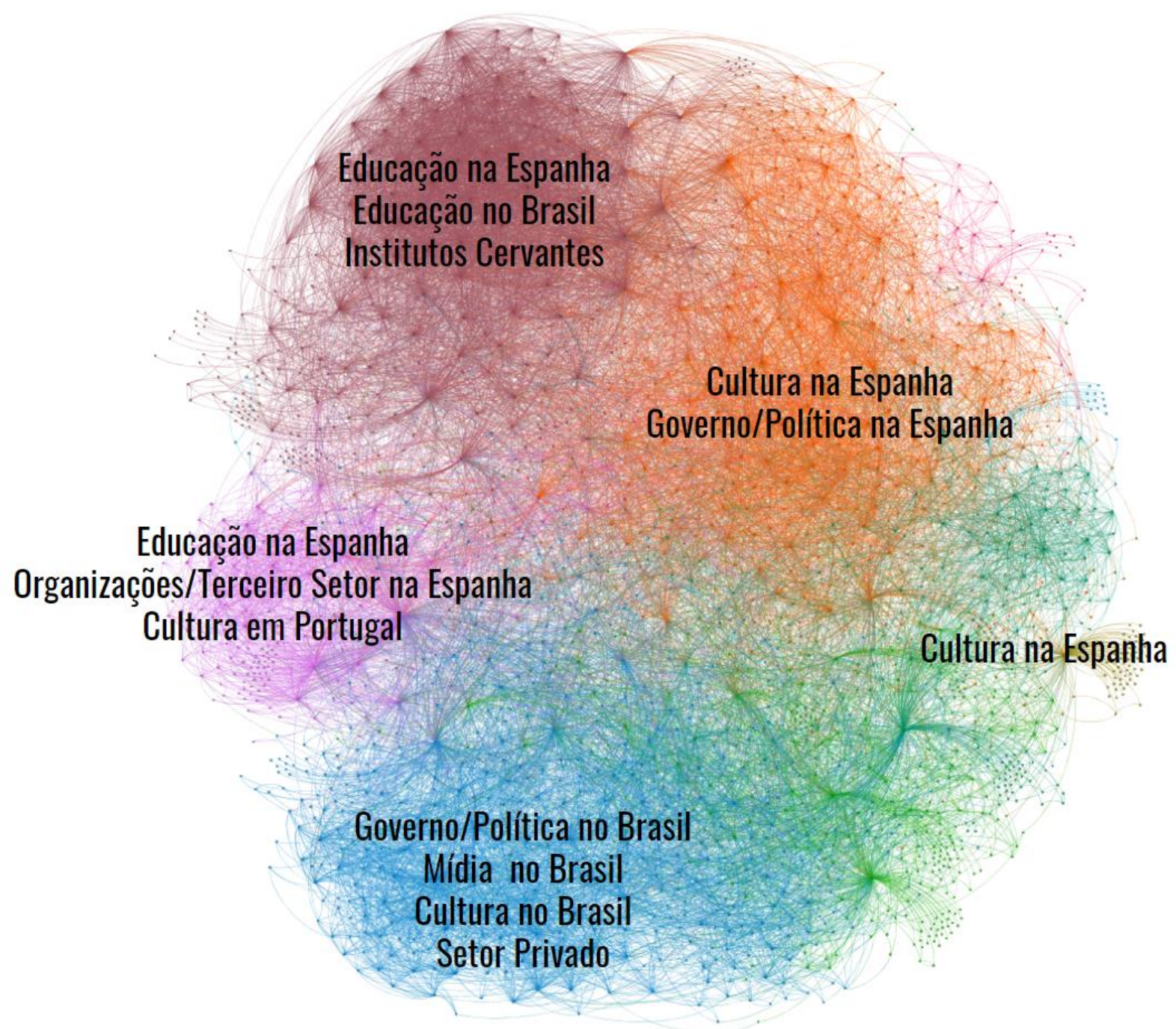


FIGURA 13 | REDE BILATERAL BRASIL-ALEMANHA

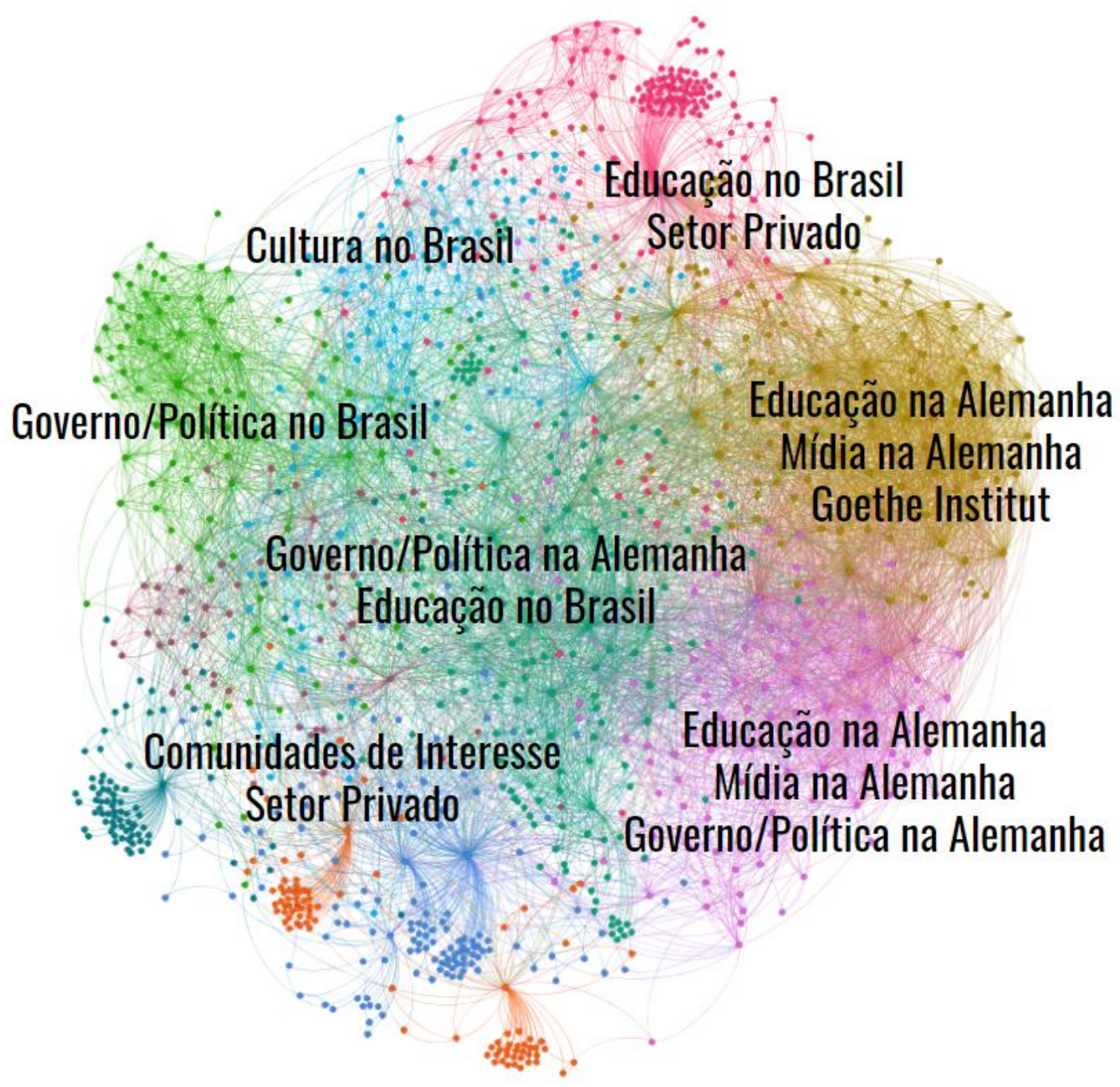


FIGURA 14 | REDE BILATERAL BRASIL-HUNGRIA

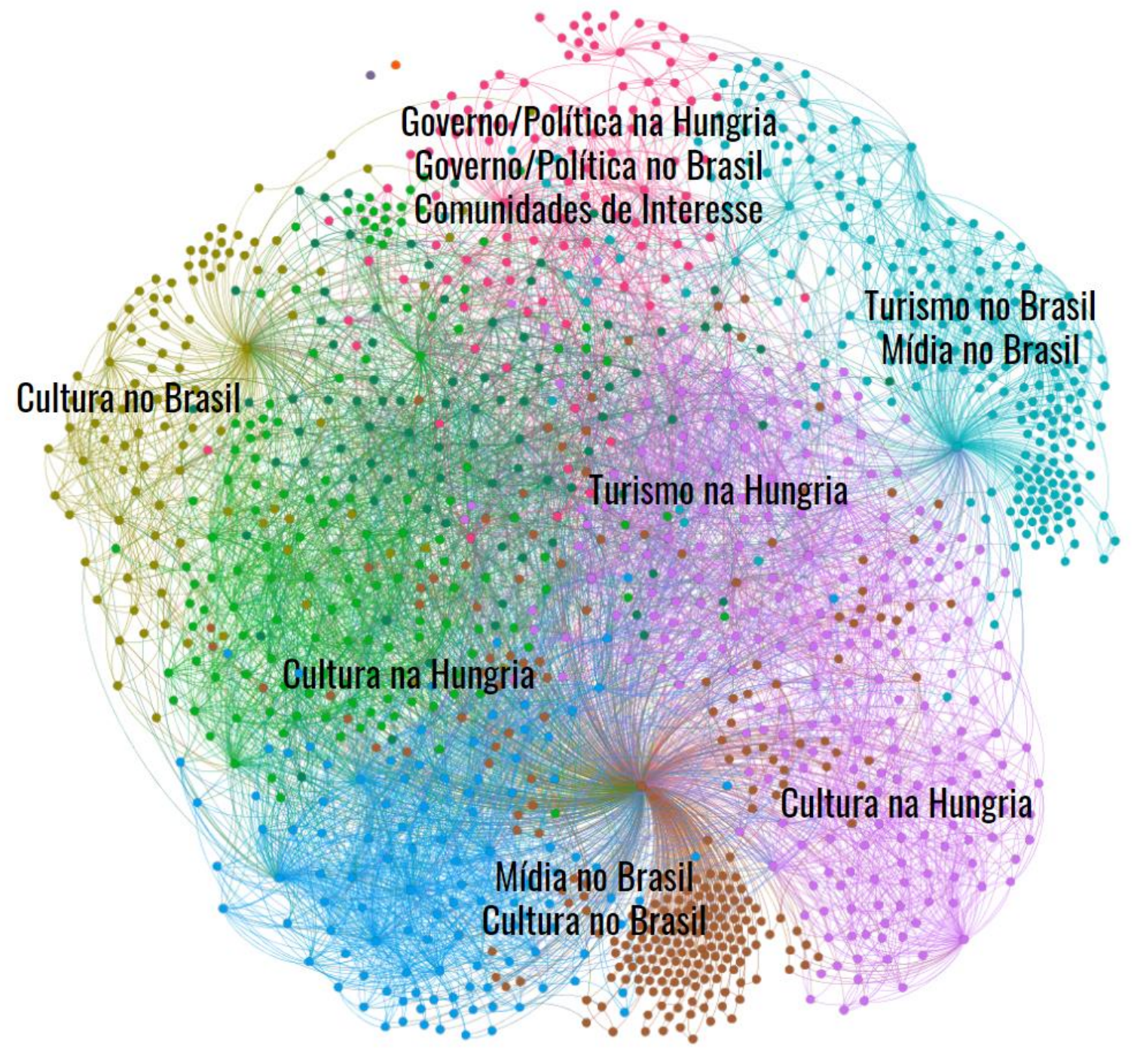


FIGURA 15 | REDE BILATERAL BRASIL-ISRAEL

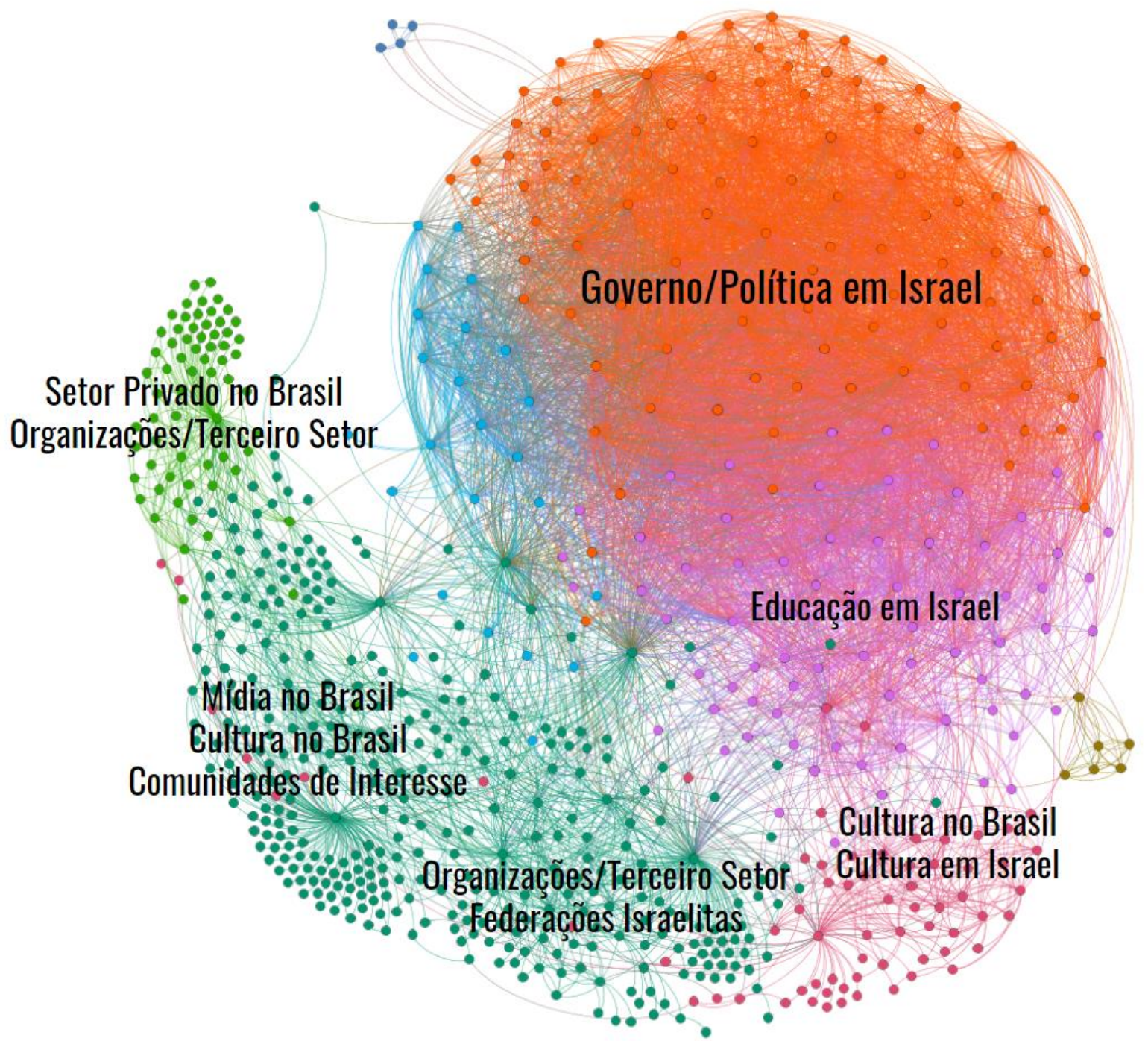




\subsection{AS REDES E A DIVERSIFICAÇÃO DE ATORES NAS RELAÇÕES INTERNACIONAIS}

A análise de 59 redes bilaterais por meio de diferentes métricas e dados qualitativos teve o objetivo de indicar parâmetros de discussão objetivos tanto para os atalhos de conexão da opinião pública, elites e atores de política externa, quanto do peso de cada um desses caminhos em bases comparativas para temas e países. As redes sociais desvelam uma via dupla para pensarmos os atalhos cognitivos e informacionais em assuntos globais: os demandados institucionalmente, por atores como Estados e organizações, e os demandados pelo público, por meio de diferentes interesses individuais. Essas demandas se mesclam, ganhando ou perdendo em volumes traduzidos nas métricas.

Como já sabido, todos os dez clusters já se constituíam como atores das relações internacionais em períodos anteriores ao do advento das redes sociais. Historicamente, a diversificação desses atores ganha influência na dinâmica global a partir da: (1) estratégia da diplomacia pública francesa, incorporando elementos de difusão cultural como política de Estado em fins do Século XIX; (2) disseminação global dos meios de comunicação de massa ao longo da primeira metade do Século XX, influenciada por atores privados e públicos; (3) multiplicação de atores nãoestatais na concepção de políticas públicas de impacto transnacional, fenômeno que ganha tração com as pautas ambientais na Conferência de Estocolmo (1972). A variável comum às diferentes ondas de diversificação de atores é o objetivo de tornar a sociedade civil influenciada ou participante em relação a objetivos nacionais de política externa e internacional e, mais recentemente, a issues globais.

A partir dos dados analisados, sustentamos que os clusters mais tradicionais nas relações internacionais seguem com relevância na nova estrutura desvelada nas redes sociais: Cultura, Mídia, Governo/Política e Organizações/Terceiro Setor, atores protagonistas em um mundo offline, renovam a sua importância no universo das redes. Porém, como colocado na hipótese, Governo/Política e Mídia, canais 
tradicionais para os atalhos cognitivos do público, não são mais as únicas rotas para o acesso às redes de temas de política internacional. Mais algumas observações sobre a mudança na natureza dessa centralidade se fazem necessárias.

Em primeiro lugar, o papel dos governos e do sistema político da democracia liberal em particular é alterado: ministérios e secretarias externos aos Ministérios de Relações Exteriores passam a desenvolver com mais frequência e profundidade cooperações internacionais de agendas próprias, muitas vezes autônomas ou até mesmo conflitantes. Nota-se esse fenômeno particularmente em Ministérios como Educação, Saúde e Defesa. Outro fenômeno importante é o desenvolvimento de relações internacionais a partir dos níveis subnacionais, em Estados e Prefeituras, que acabam trazendo para as redes uma maior variedade dos tipos de instituições públicas e de agendas presentes. Essa maior variedade comporta ainda as instituições de Organizações/Terceiro Setor e do Setor Privado, que se tornam mais volumosas em termos de nós, para além das "BINGOS" (Big Non-Governmental Organizations) e das grandes corporações transnacionais.

No cluster de Mídia, jornais, revistas e rádios de grandes conglomerados de comunicação são diluídos em meio à grande difusão de websites e blogs ao longo da década dos 2000, que consolidam a sua posição de influenciadores. A Mídia executa um papel importante na ligação com os nove demais clusters, que apontam para uma tendência crescente nas últimas duas décadas: a da segmentação de temas preferenciais no conteúdo direcionado ao público interessado em temas internacionais.

Essa tendência demonstra que a diplomacia de nichos tem ganhado espaço nas estratégias das instituições participantes do cenário internacional. São os casos dos clusters de Educação, Esportes, Gastronomia e Turismo. Mais que isso, revela que o novo lugar da Mídia nas relações internacionais não é ser o principal atalho informacional ao lado dos governos, mas o de ser um dos atalhos. 
O que a dinâmica das redes desvela não é apenas a multiplicação de grandes atores para além do Estado e das organizações multilaterais, diagnóstico amplamente discutido a partir do final da Guerra Fria; mas da diluição de seu poder com atores médios e pequenos, parte das mesmas redes. 


\section{INTERESSES EM REDE: DEZ RELAÇÕES BILATERAIS DO BRASIL NA VISÃO DOS BRASILEIROS CONECTADOS}

\subsection{AS RELAÇÕES DO BRASIL COM DEZ PAÍSES, SEGUNDO O PÚBLICO}

Considerando a ampliação da oferta de informação a partir da internet e das redes sociais ao longo da década dos 2010 , assim como a maior variedade entre os atalhos cognitivos possíveis nas redes de páginas e perfis que integram as redes sociais, será conduzida uma análise comparada em três etapas. Em primeiro lugar, buscaremos conhecer em painel as relações do público com dez países a partir da survey As Américas e O Mundo. Em seguida, o comportamento específico entre usuários e não-usuários do Facebook será comparado para a análise de possíveis diferenças entre ambos os grupos. Por fim, verificaremos se as diferenças de opiniões do público entre diferentes países guardam relação com as métricas dos nós e arestas de dez redes bilaterais entre o Brasil e cada um dos dez países selecionados.

Antes de desenvolvermos a análise comparada entre os países selecionados, conheceremos os dados de seis países em painel para as rodadas de 2010, 2014 e 2018: Argentina, China, Cuba, Estados Unidos, Japão e Venezuela. Quatro países serão analisados em separado, por estarem presentes somente na rodada 2018: África do Sul, Índia, México e Rússia. A questão comum a todos é: Diga-me, como você descreveria a relação do Brasil com os seguintes países: Amizade, Sociedade, Rivalidade, Ameaça, Não Sei, Não Responderei.

Para a Argentina, observamos relativa estabilidade na percepção de Amizade e queda seguida de retorno ao mesmo patamar em Sociedade entre 2014 e 2018. A percepção de Rivalidade apresentou queda de $8,4 \%$ e a de Ameaça oscilou positivamente em 3\%. Reunidas, as percepções de Amizade/Sociedade sobem de $60,9 \%$ em 2010 para $64,3 \%$ em 2018. Apesar da oscilação positiva de 3\% na visão de Ameaça, as percepções de Rivalidade/Ameaça em conjunto baixam de 30\% para 24,6\% na comparação entre 2010 e 2018. 
Com relação à China, a percepção de Amizade varia de 31,4\% em 2010 para 30,4\% em 2018. A queda na visão de Sociedade é maior, de $42,4 \%$ para $38,3 \%$. A Rivalidade oscila de $7,7 \%$ para $6,6 \%$, enquanto a visão de Ameaça aumenta de $6 \%$ para 12,6\%. Reunidas, as visões de Amizade/Sociedade somam 73,8\% em 2010, contra 68,7\% em 2018. Já as percepções de Rivalidade/Ameaça em conjunto oscilam de $18,3 \%$ para $19,2 \%$.

Cuba apresentou quedas mais acentuadas nos indicadores de Amizade e Sociedade, concomitantes a altas nas percepções de Rivalidade e Ameaça. Para Amizade, a baixa foi de $32,7 \%$ para $23,8 \%$ entre 2010 e 2018. Para Sociedade, a queda foi menos acentuada, de $30,8 \%$ para $25,7 \%$. A percepção de Rivalidade oscilou positivamente de 10,4 para 14,5\%, enquanto a de Ameaça mais que dobrou, de 9 para 21,4\%. As percepções de Amizade/Sociedade caíram de 63,5\% para $49,5 \%$, enquanto as de Rivalidade/Ameaça tiveram alta de $19,4 \%$ para $35,9 \%$.

A Venezuela, por sua vez, apresentou mudanças importantes em relação a sua percepção entre o público. A relação de Amizade passou de 33,9\% (2010) para $24,5 \%$ (2018), enquanto a Sociedade foi de $32,3 \%$ a $23,1 \%$. A visão de Rivalidade, por sua vez, subiu de $8,3 \%$ para $14,7 \%$, enquanto a de Ameaça constituiu a principal alteração, subindo de $6,5 \%$ para $24,8 \%$. As visões de Amizade/Sociedade em conjunto caíram de $66,2 \%$ para $47,6 \%$, enquanto Rivalidade/Ameaça passaram de $14,8 \%$ para $39,5 \%$. 
TABELA 10 | RELAÇÕES COM ARGENTINA E CHINA

\begin{tabular}{cccccccc}
\hline & \multicolumn{3}{c}{ ARGENTINA } & & \multicolumn{3}{c}{ CHINA } \\
& $\mathbf{2 0 1 0}$ & $\mathbf{2 0 1 4}$ & $\mathbf{2 0 1 8}$ & & $\mathbf{2 0 1 0}$ & $\mathbf{2 0 1 4}$ & $\mathbf{2 0 1 8}$ \\
AMIZADE & $31.40 \%$ & $33.30 \%$ & $33.80 \%$ & AMIZADE & $31.40 \%$ & $29.90 \%$ & $30.40 \%$ \\
SOCIEDADE & $29.50 \%$ & $25.50 \%$ & $30.50 \%$ & SOCIEDADE & $42.40 \%$ & $35 \%$ & $38.30 \%$ \\
RIVALIDADE & $24.60 \%$ & $25.70 \%$ & $16.20 \%$ & RIVALIDADE & $7.70 \%$ & $8.20 \%$ & $6.60 \%$ \\
AMEAÇA & $5.40 \%$ & $7 \%$ & $8.40 \%$ & AMEAÇA & $6 \%$ & $12 \%$ & $12.60 \%$ \\
N.S. & $8.80 \%$ & $8.10 \%$ & $10.80 \%$ & N.S. & $12.30 \%$ & $13.90 \%$ & $11.80 \%$ \\
N. R. & $0.40 \%$ & $0.40 \%$ & $0.30 \%$ & N.R. & $0.40 \%$ & $1 \%$ & $0.20 \%$ \\
\hline
\end{tabular}

Fonte: As Américas e O Mundo

TABELA 11 | RELAÇÕES COM CUBA E VENEZUELA

\begin{tabular}{cccccccc} 
& \multicolumn{3}{c}{ CUBA } & & & \multicolumn{3}{c}{ VENEZUELA } \\
& $\mathbf{2 0 1 0}$ & $\mathbf{2 0 1 4}$ & $\mathbf{2 0 1 8}$ & & $\mathbf{2 0 1 0}$ & $\mathbf{2 0 1 4}$ & $\mathbf{2 0 1 8}$ \\
AMIZADE & $32.70 \%$ & $32 \%$ & $23.80 \%$ & AMIZADE & $33.90 \%$ & $33.30 \%$ & $24.50 \%$ \\
SOCIEDADE & $30.80 \%$ & $27.20 \%$ & $25.70 \%$ & SOCIEDADE & $32.30 \%$ & $27.90 \%$ & $23.10 \%$ \\
RIVALIDADE & $10.40 \%$ & $8.60 \%$ & $14.50 \%$ & RIVALIDADE & $8.30 \%$ & $8.90 \%$ & $14.70 \%$ \\
AMEAÇA & $9 \%$ & $12.70 \%$ & $21.40 \%$ & AMEAÇA & $6.50 \%$ & $8.10 \%$ & $24.80 \%$ \\
N.S. & $16.50 \%$ & $17.80 \%$ & $14.20 \%$ & N.S. & $18.40 \%$ & $20.50 \%$ & $12.50 \%$ \\
N.R. & $0.60 \%$ & $1.70 \%$ & $0.40 \%$ & N.R. & $0.60 \%$ & $1.30 \%$ & $0.50 \%$ \\
\hline
\end{tabular}

Fonte: As Américas e O Mundo

Com relação aos Estados Unidos, ocorreram oscilações negativas ao longo das três rodadas. A relação de Amizade passou de 38,3\% (2010) para 35,3\% (2018), enquanto a baixa para Sociedade foi maior, de 41,4\% para 35,9\% entre 2010 e 2018. A visão de Rivalidade oscilou positivamente meio ponto percentual (5,9\% para 6,4\%), enquanto a percepção de Ameaça apresentou alta mais acentuada, de 5,1\% para 13,4\%. A visão de Amizade/Sociedade, de 79,7\% em 2010, baixou para 73,9\% em 2018. Já a percepção de Rivalidade/Ameaça foi elevada de 11\% para 19,8\%

O Japão também apresentou oscilação negativa na percepção de Amizade, caminhando de $41 \%$ para $36,7 \%$, enquanto a relação de Sociedade permaneceu estável na casa dos $38 \%$. A relação de Rivalidade também apresentou estabilidade na casa dos $4 \%$. No entanto, a visão de Ameaça cresceu de 3,1\% para 9,1\%. As visões de Amizade/Sociedade em conjunto caíram de 79,8\% para 74,9\%. Já a 
percepção de Rivalidade/Ameaça cresceu de 7,1\% para 13,5\%. Ainda assim, o Japão tem a menor percepção negativa entre os seis países que compõem o painel.

TABELA 12 | RELAÇÕES COM ESTADOS UNIDOS E JAPÃO

\begin{tabular}{cccccccc}
\hline & \multicolumn{3}{c}{ ESTADOS UNIDOS } & & \multicolumn{3}{c}{ JAPÃO } \\
& $\mathbf{2 0 1 0}$ & $\mathbf{2 0 1 4}$ & $\mathbf{2 0 1 8}$ & & $\mathbf{2 0 1 0}$ & $\mathbf{2 0 1 4}$ & $\mathbf{2 0 1 8}$ \\
AMIZADE & $38.30 \%$ & $38.10 \%$ & $35.30 \%$ & AMIZADE & $41 \%$ & $36.70 \%$ & $36.70 \%$ \\
SOCIEDADE & $41.40 \%$ & $33.80 \%$ & $35.90 \%$ & SOCIEDADE & $38.80 \%$ & $35.90 \%$ & $38.20 \%$ \\
RIVALIDADE & $5.90 \%$ & $7.20 \%$ & $6.40 \%$ & RIVALIDADE & $4 \%$ & $5.30 \%$ & $4.40 \%$ \\
AMEAÇA & $5.10 \%$ & $11.20 \%$ & $13.40 \%$ & AMEAÇA & $3.10 \%$ & $6.10 \%$ & $9.10 \%$ \\
N.S. & $8.90 \%$ & $8.80 \%$ & $8.80 \%$ & N.S. & $12.50 \%$ & $14.70 \%$ & $11.10 \%$ \\
N.R. & $0.40 \%$ & $1 \%$ & $0.20 \%$ & N.R. & $0.60 \%$ & $1.30 \%$ & $0.40 \%$
\end{tabular}

Fonte: As Américas e O Mundo

África do Sul, Índia, México e Rússia apresentam dados apenas para a rodada de 2018. Dentre os quatro, a percepção mais acentuada de Amizade é em relação ao país africano, com $41,3 \%$. Índia e México estão próximos, na casa dos $35 \%$, e a Rússia apresenta a menor visão de Amizade, com 24,7\%. Todos os quatro países têm relações de Sociedade para os brasileiros entre 30 e 32\%. A África do Sul conta com as menores percepções de Rivalidade $(5,1 \%)$ e Ameaça $(7,6 \%)$, enquanto a Rússia conta com as maiores (9\% e 19,4\%, respectivamente).

TABELA 13 | RELAÇÕES COM ÁFRICA DO SUL, ÍNDIA, MÉXICO E RÚSSIA

\begin{tabular}{ccccc}
\hline & ÁFRICA DO SUL & ÍNDIA & MÉXICO & RÚSSIA \\
AMIZADE & $41,3 \%$ & $35,4 \%$ & $35,6 \%$ & $24,7 \%$ \\
SOCIEDADE & $30,9 \%$ & $32,4 \%$ & $32,7 \%$ & $30,8 \%$ \\
RIVALIDADE & $5,1 \%$ & $6,1 \%$ & $7,3 \%$ & $9 \%$ \\
AMEAÇA & $7,6 \%$ & $8,5 \%$ & $9,6 \%$ & $19,4 \%$ \\
NÃO SABE & $14,5 \%$ & $17 \%$ & $14,4 \%$ & $14,4 \%$ \\
NÃO RESPONDEU & $0,5 \%$ & $0,5 \%$ & $0,3 \%$ & $0,3 \%$ \\
\hline
\end{tabular}

Fonte: As Américas e O Mundo 


\subsection{USO DO FACEBOOK E RELAÇÕES COM PAÍSES}

Conforme discutido no Capítulo 1, três fatores importantes ocorreram no País ao longo das três rodadas da survey: crescimento do acesso à internet; crescimento do acesso às redes sociais; e ampliação da polarização política. A partir de agora, exploraremos os dados da questão em relação aos países com a seguinte questão de pesquisa:

- Q2 | O uso do Facebook pelos respondentes gera alterações significativas nas percepções a respeito dos dez países em questão?

- H2 | O uso do Facebook altera positivamente as percepções de Amizade, Sociedade, Rivalidade e Ameaça dos respondentes a respeito dos dez países pesquisados

A estratégia adotada para o teste da hipótese foi a execução de dez regressões logísticas multinomiais, cujas variáveis-respostas são as relações com os países: 1) Amizade; 2) Sociedade; 3) Rivalidade; 4) Ameaça (Referência). A variávelexplicativa é o uso do Facebook: 1) Uso; 2) Não uso. Os detalhes das regressões conduzidas estão no final do capítulo.

A hipótese das diferenças entre usuários e não usuários do Facebook foi confirmada para todos os países nas relações de Amizade em comparação com Ameaça. A chance de um respondente usuário do Facebook ter uma relação de Amizade na comparação com Ameaça é de 2,2 vezes para o México e de duas vezes para a África do Sul. Três países têm chances maiores de $80 \%$ para os usuários do Facebook: Argentina (94\%), Índia (84\%) e China (81\%). Em relação aos Estados Unidos, a chance de relação de Amizade é $69 \%$ maior, valor próximo ao do Japão (67\%). Abaixo dos 50\% de chances estão Rússia (46\%), Cuba (32\%) e Venezuela $(30 \%)$.

A diferença entre usuários e não usuários do Facebook também foi confirmada para todos os países considerando a relação de Sociedade e, nesse caso, as 
disparidades de oito dos dez países analisados estão acima de $100 \%$. Com relação à Índia, a chance de uma relação de Sociedade é três vezes maior na comparação com Ameaça entre usuários e não usuários. Argentina (2,9 vezes), México (2,8 vezes), China (2,7 vezes) e África do Sul (2,7 vezes) vêm a seguir. Um usuário de Facebook tem 2,5 mais chances de atribuir à Rússia uma relação de Sociedade na comparação com um não usuário, valor maior que o do Japão (2,2 vezes) e da Venezuela (2 vezes). Cuba (+93\%) e Estados Unidos (+88\%) são os dois únicos países com chances menores do que 100\%.

Quando é considerada a relação de Rivalidade na comparação com Ameaça, os resultados apresentam outra dinâmica. Cinco países não apresentam diferenças significativas entre usuários e não usuários do Facebook: África do Sul, Estados Unidos, Japão, Rússia e Venezuela. Os cinco países que apresentam diferenças significativas de opinião de Rivalidade e Ameaça entre usuários e não usuários do Facebook são Argentina (2,4 vezes), México (2,2 vezes), China (+67\%), Cuba (+55\%) e Índia (+38\%).

\subsection{OS INTERESSES EM REDE NO FACEBOOK: DEZ PAÍSES EM RELAÇÃO COM O BRASIL}

Na survey, verificamos que os dez países apresentam níveis de interesse distintos entre o público investigado, e que as probabilidades de diferentes opiniões variam em função do envolvimento do respondente com as redes sociais. As disparidades de interesse entre os diferentes países também foram verificadas na construção da base de dados online. Foram construídas dez redes bilaterais entre o Brasil e África do Sul, Argentina, China, Cuba, Estados Unidos, Índia, Japão, México, Rússia e Venezuela. Os dados das redes foram obtidos no Facebook via aplicativo Netvizz, em 2018. Foram selecionados nós-sementes relevantes em política externa e internacional, diplomacia pública e cultura entre o Brasil e cada um dos países em separado. A partir daí, foram extraídas as redes de likes e follows entre as páginas em deep2, com estratégia snowball. Apesar dos tamanhos e métricas distintas 
obtidas em cada rede, todas elas foram padronizadas pelos mesmos modelos de distribuição do grafo no software Gephi: OpenOrd e ForceAtlas.

TABELA 14 | MÉTRICAS DE REDES BILATERAIS NO FACEBOOK

\begin{tabular}{ccccccc}
\hline & NÓS & ARESTAS & NÓS FORTES & GR.MÉDIO & C. MÉD. CAM. & DIÂMETRO \\
ÁFRICA DO SUL & 316 & 1626 & 156 & 5.146 & 4.326 & 14 \\
ARGENTINA & 735 & 4124 & 377 & 5.611 & 2.638 & 13 \\
CHINA & 519 & 1521 & 382 & 2.931 & 6.067 & 15 \\
CUBA & 357 & 1945 & 180 & 5.448 & 3.653 & 9 \\
EUA & 2229 & 14693 & 886 & 6.592 & 5.406 & 19 \\
ÍNDIA & 777 & 4019 & 420 & 5.172 & 6.164 & 14 \\
JAPÃO & 956 & 3735 & 531 & 3.907 & 4.556 & 13 \\
MÉXICO & 185 & 616 & 109 & 3.33 & 3.046 & 9 \\
RÚSSIA & 247 & 654 & 186 & 2,648 & 3,514 & 10 \\
VENEZUELA & 103 & 286 & 78 & 2,777 & 2,690 & 10 \\
\hline
\end{tabular}

Fonte: Produção do autor

As questões e hipóteses de pesquisa são:

Q3) A opinião positiva acerca de um país está correlacionada ao tamanho de sua rede bilateral?

$\rightarrow \mathrm{H} 3)$ Quanto mais positiva é a opinião a respeito de um país, mais volumosa (nós) e conectada (arestas) tende a ser a sua rede bilateral

Q4) A opinião negativa acerca de um país está correlacionada ao tamanho de sua rede?

$\rightarrow$ H4) Quanto mais negativa a opinião a respeito de um país, menos volumosa (nós) e conectada (arestas) tende a ser a sua rede bilateral. 
As variáveis a serem explicadas são as relações positivas ou negativas em comparação com os tamanhos das redes bilaterais entre o Brasil e cada um dos dez países em questão, medidas em termos de nós e arestas.

As relações foram divididas entre positivas (Amizade e Sociedade) e negativas (Rivalidade, Ameaça e Não Sabe). Nesse caso, a análise foi aplicada apenas aos respondentes que declararam acessar o Facebook na rodada 2018, contemplando $61,9 \%$ do $\mathrm{N}$ total. As redes foram tipificadas em função do volume de seus nós e de suas arestas, conforme a tabela a seguir:

\section{TABELA 15 | PORTES DAS REDES NO FACEBOOK}

\begin{tabular}{ccc}
\hline PEQUENA & NÓS & ARESTAS \\
& Até 300 nós & Até 1.000 arestas \\
México, Rússia, Venezuela & México, Rússia, Venezuela \\
MÉDIA & $301-600$ & \\
& & $1.001-2.000$ \\
GRANDE & África do Sul, China, Cuba & África do Sul, China, Cuba \\
& $601-900$ & $2.001-3.000$ \\
& Argentina, Índia & Nenhum \\
MUITO GRANDE & Acima de 901 & Acima de 3.001 \\
& EUA, Japão & Argentina, EUA, Índia, Japão
\end{tabular}

Fonte: Produção do autor

Foi desenvolvido um teste de associação qui quadrado entre opiniões positivas e opiniões negativas versus nós e arestas. O objetivo foi verificar as hipóteses a partir da análise das diferenças de distribuições entre os diferentes tamanhos de redes. Foi observada significativa diferença das distribuições entre opiniões positivas (Amizade, Sociedade) e negativas (Rivalidade, Ameaça e Não Sabe) tanto para volume de nós quanto para o volume de arestas.

Primeiramente, considerando os nós: as opiniões positivas se encontram como predominantes para todos os portes de redes em comparação. No entanto, a sua 
proporção varia de forma importante. Nas redes pequenas (México, Rússia e Venezuela), as opiniões positivas apresentam média de $61,8 \%$. Nas médias (África do Sul, China e Cuba), os valores se elevam para $67,8 \%$. Os percentuais seguem em elevação para as redes grandes (Argentina e Índia), passando a 70\%. Estados Unidos e Japão, as duas redes bilaterais consideradas muito grandes no levantamento, apresentam média de opiniões positivas de 77,7\%. Em contrapartida, as opiniões negativas caem de $38,2 \%$ nas redes pequenas para $22,3 \%$ nas redes muito grandes.

\section{TABELA 16 | OPINIÃO VERSUS TAMANHO DA REDE POR NÓS}

\begin{tabular}{ccccc}
\hline OPINIÃO & $\begin{array}{c}\text { REDES } \\
\text { PEQUENAS }\end{array}$ & REDES MÉDIAS & REDES GRANDES & $\begin{array}{c}\text { REDES MUITO } \\
\text { GRANDES }\end{array}$ \\
NEGATIVAS & $38.20 \%$ & $32.20 \%$ & $30.00 \%$ & $22.30 \%$ \\
POSITIVAS & $61.80 \%$ & $67.80 \%$ & $70.00 \%$ & $77.70 \%$ \\
\hline
\end{tabular}

A mesma tendência observada entre os nós prossegue quando analisamos as arestas. Entre as pequenas e as médias, os percentuais seguem nas mesmas faixas. Os países com volume menor de arestas são os mesmos em relação aos nós: México, Rússia e Venezuela entre os pequenos; e África do Sul, China e Cuba nos médios. Argentina e Índia têm mais de 3.001 arestas, e se juntam a Estados Unidos e Japão nessa faixa de métrica.

\begin{tabular}{c|ccc}
\multicolumn{2}{c}{ TABELA 17 | OPINIÃO VERSUS TAMANHO DA REDE POR ARESTAS } \\
\hline OPINIÃO & REDES PEQUENAS & REDES MÉDIAS & REDES MUITO GRANDES \\
NEGATIVAS & $38.20 \%$ & $32.20 \%$ & $26.10 \%$ \\
POSITIVAS & $61.80 \%$ & $67.80 \%$ & $73.90 \%$
\end{tabular}

Os testes de associação qui quadrado demonstraram que existe associação entre opiniões/positivas, volume de nós e volumes de arestas. Portanto, ambas as 
hipóteses de tendência de redes bilaterais maiores para países cujas opiniões são mais positivas e de menores quando as visões são mais negativas foram confirmadas a partir da análise comparada e dos testes realizados.

\section{FIGURA 16 | OPINIÃO VERSUS TAMANHO DA REDE POR NÓS}

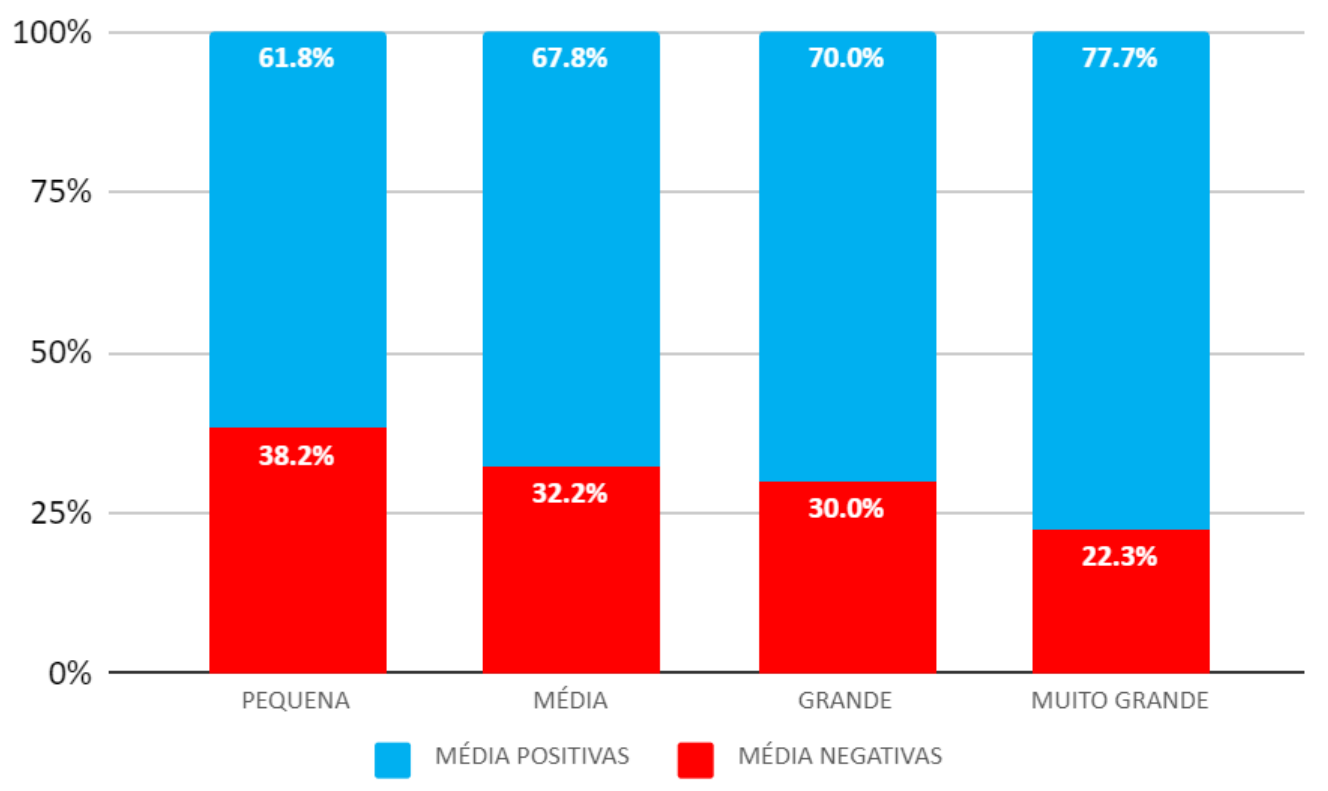

FIGURA 17 | OPINIÃO VERSUS TAMANHO DA REDE POR ARESTAS

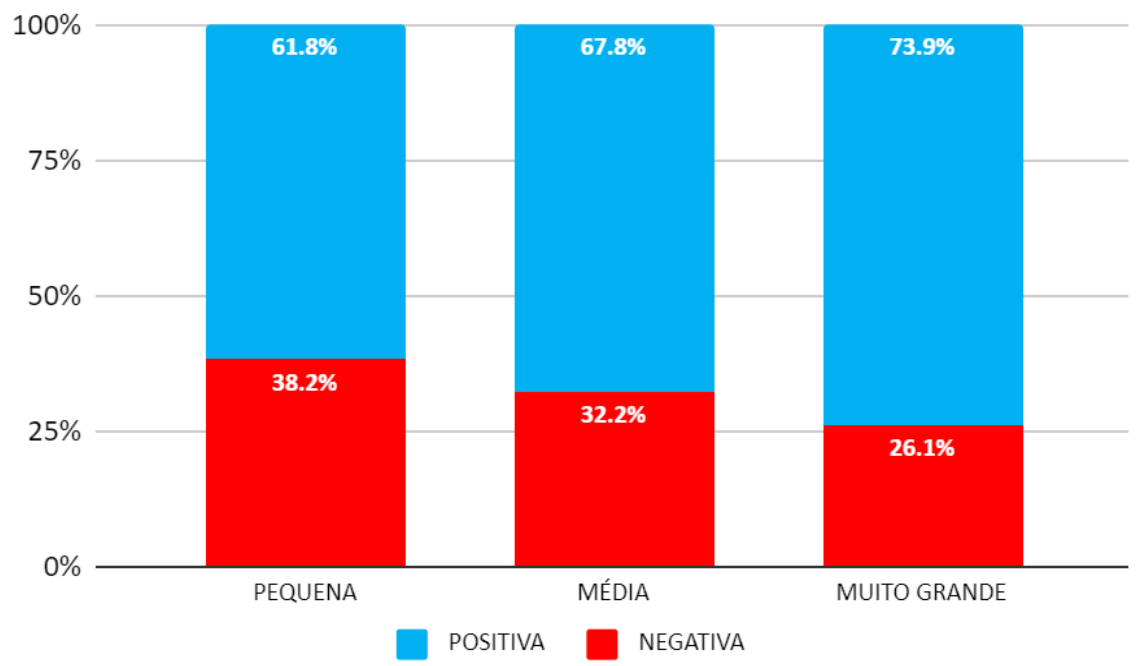




\subsection{QUE TIPOS DE NÓS TÊM PREDOMINÂNCIA EM CADA UMA DAS REDES BILATERAIS?}

Os 6.424 nós de todas as dez redes apresentam 600 classificações de páginas diferentes no Facebook. Retomamos aqui a mesma classificação de clusters de páginas realizada no Capítulo 2, a partir dos temas de Cultura, Comunidades de Interesse, Educação, Esportes, Gastronomia, Governo/Política, Mídia, Setor Privado, Organizações/Terceiro Setor e Turismo.

O cluster mais numeroso entre nas redes bilaterais selecionadas é o de Mídia, para as redes de Cuba, China e Venezuela. Cultura é o cluster principal para o Japão e o México, enquanto Governo/Política é o mais relevante para Argentina e Índia. Com um representante cada, estão Turismo (África do Sul), Educação (EUA) e Comunidades de Interesse (Rússia). Das cinco redes bilaterais pequenas ou médias em termos de nós, três têm a Mídia como cluster principal. As duas redes consideradas grandes têm predominância de Governo/Política. Por fim, as duas redes muito grandes têm como clusters principais Educação e Cultura.

TABELA 18 | CLUSTERS PRINCIPAIS POR PORTE DE REDE

\begin{tabular}{ccccc}
\hline PAÍS & NÓS & CLUSTER PRINCIPAL & PESO CLUSTER PRINCIPAL & PORTE DA REDE \\
& & & & \\
ÁFRICA DO SUL & 316 & TURISMO & $77(24,3 \%)$ & Média \\
ARGENTINA & 735 & GOVERNO/POLÍTICA & $222(30,2 \%)$ & Grande \\
CHINA & 519 & MÍDIA & $115(22,1 \%)$ & Média \\
CUBA & 357 & MÍDIA & $84(23,5 \%)$ & Média \\
EUA & 2229 & EDUCAÇÃO & $390(17,4 \%)$ & Muito grande \\
ÍNDIA & 777 & GOVERNO/POLÍTICA & $157(20,2 \%)$ & Grande \\
JAPÃO & 956 & CULTURA & $213(22,2 \%)$ & Muito grande \\
MÉXICO & 185 & CULTURA & $75(40,5 \%)$ & Pequena \\
RÚSSIA & 247 & COM. DE INTERESSE & $66(26,7 \%)$ & Pequena \\
VENEZUELA & 103 & MÍDIA & $36(34,9 \%)$ & Pequena \\
\hline
\end{tabular}


Entre redes bilaterais de diferentes portes, com países de diferentes regiões, verificamos que há grande diversidade entre as classificações dos nós predominantes, o que nos indica que possíveis fatores explicativos para a composição dessas redes são múltiplos. Porém, é importante salientar que Cuba e Venezuela - dois países de redes pequenas/médias e com distribuições polarizadas entre opiniões positivas e negativas - têm a Mídia como cluster principal.

Nesse caso da predominância da Mídia, a China é uma exceção, já que apresenta um padrão de distribuição diferente. Por outro lado, entre as redes grandes e muito grandes, há uma variação mais ampla da origem de predominância dos clusters, reflexo da maior complexidade das redes entre os países e das possíveis fontes de influência nas relações.

\section{TABELA 19 | REGRESSÃO LOGÍSTICA MULTINOMIAL (ÁFRICA DO SUL)}

\section{Case Processing Summary}

\begin{tabular}{llr|r} 
& & & \multicolumn{1}{c}{ Marginal } \\
\hline África do Sul & Amizade & 763 & Percentage \\
\cline { 2 - 4 } & Sociedade & 572 & $38,6 \%$ \\
\cline { 2 - 4 } & Rivalidade & 94 & $6,0 \%$ \\
\cline { 2 - 4 } & Ameaça & 141 & $9,0 \%$ \\
\hline Uso do Facebook & Sim & 984 & $62,7 \%$ \\
\cline { 2 - 4 } & Não & 586 & $37,3 \%$ \\
\hline Valid & & 1570 & $100,0 \%$ \\
\hline Missing & & 279 & \\
\hline Total & & 1849 & \\
\hline Subpopulation & & 2 & \\
\hline
\end{tabular}




\section{Model Fitting Information}

\begin{tabular}{l|r|r|r|r} 
& $\begin{array}{c}\text { Model Fitting } \\
\text { Criteria } \\
\text { Model }\end{array}$ & \multicolumn{2}{|c}{ Likelihood Ratio Tests } \\
Likelihood & Chi-Square & df & Sig. \\
\hline Intercept Only & 65,413 & & & \\
\hline Final & 36,944 & 28,468 & 3 &, 000 \\
\hline
\end{tabular}

\section{Pseudo R-Square}

\begin{tabular}{l|r} 
Cox and Snell &, 018 \\
\hline Nagelkerke &, 020 \\
\hline McFadden &, 008 \\
\hline
\end{tabular}

\section{Likelihood Ratio Tests}

\begin{tabular}{|c|c|c|c|c|}
\hline & $\begin{array}{l}\text { Model Fitting } \\
\text { Criteria }\end{array}$ & \multicolumn{3}{|c|}{ Likelihood Ratio Tests } \\
\hline Effect & $\begin{array}{c}-2 \text { Log } \\
\text { Likelihood of } \\
\text { Reduced Model }\end{array}$ & Chi-Square & df & Sig. \\
\hline Intercept & $36,944^{a}$ &, 000 & 0 & \\
\hline Uso do Facebook & 65,413 & 28,468 & 3 &, 000 \\
\hline
\end{tabular}

The chi-square statistic is the difference in -2 log-likelihoods between the final model and a reduced model. The reduced model is formed by omitting an effect from the final model. The null hypothesis is that all parameters of that effect are 0 .

a. This reduced model is equivalent to the final model because omitting the effect does not increase the degrees of freedom. 


\section{Parameter Estimates}

\begin{tabular}{|c|c|c|c|c|c|c|}
\hline \multicolumn{2}{|c|}{ África do Sul ${ }^{a}$} & $\mathrm{~B}$ & Std. Error & Wald & df & Sig. \\
\hline \multirow[t]{3}{*}{ Amizade } & Intercept & 1,306 &, 128 & 104,727 & 1 &, 000 \\
\hline & [Uso do Facebook=1] &, 714 &, 185 & 14,872 & 1 &, 000 \\
\hline & [Uso do Facebook=2] & $0^{b}$ & & . & 0 & \\
\hline \multirow[t]{3}{*}{ Sociedade } & Intercept & ,836 &, 136 & 38,056 & 1 &, 000 \\
\hline & [Uso do Facebook=1] & ,992 &, 192 & 26,734 & 1 &, 000 \\
\hline & [Uso do Facebook=2] & $0^{b}$ & & . & 0 & \\
\hline \multirow[t]{3}{*}{ Rivalidade } & Intercept &,- 668 &, 194 & 11,792 & 1 & ,001 \\
\hline & [Uso do Facebook=1] &, 514 & ,269 & 3,654 & 1 & ,056 \\
\hline & [Uso do Facebook=2] & $0^{b}$ & & . & 0 & \\
\hline
\end{tabular}

\section{Parameter Estimates}

\begin{tabular}{|c|c|c|c|c|}
\hline \multirow{2}{*}{\multicolumn{2}{|c|}{ África do Sul ${ }^{a}$}} & \multirow{3}{*}{$\operatorname{Exp}(B)$} & \multicolumn{2}{|c|}{$\begin{array}{l}\text { 95\% Confidence Interval for Exp } \\
\text { (B) }\end{array}$} \\
\hline & & & Lower Bound & Upper Bound \\
\hline \multirow[t]{3}{*}{ Amizade } & Intercept & & & \\
\hline & [Uso do Facebook=1] & 2,042 & 1,421 & 2,935 \\
\hline & [Uso do Facebook=2] & . & . & . \\
\hline \multirow[t]{3}{*}{ Sociedade } & Intercept & & & \\
\hline & [Uso do Facebook=1] & 2,696 & 1,851 & 3,927 \\
\hline & [Uso do Facebook=2] & . & . & . \\
\hline \multirow[t]{3}{*}{ Rivalidade } & Intercept & & & \\
\hline & [Uso do Facebook=1] & 1,671 & ,987 & 2,830 \\
\hline & [Uso do Facebook=2] & . & . & . \\
\hline
\end{tabular}


TABELA 20 | REGRESSÃo LOGÍSTICA MULTINOMIAL (ARGENTINA)

\section{Case Processing Summary}

\begin{tabular}{llr|r} 
& & & \multicolumn{1}{c}{ Marginal } \\
\hline Argentina & Amizade & 625 & Percentage \\
\cline { 2 - 4 } & Sociedade & 564 & $38,0 \%$ \\
\cline { 2 - 4 } & Rivalidade & 299 & $18,2 \%$ \\
\cline { 2 - 4 } & Ameaça & 156 & $9,5 \%$ \\
\hline \multirow{2}{*}{ Uso do Facebook } & Sim & 1038 & $63,1 \%$ \\
\cline { 2 - 4 } & Não & 606 & $36,9 \%$ \\
\hline Valid & & 1644 & $100,0 \%$ \\
\hline Missing & & 205 & \\
\hline Total & & 1849 & \\
\hline Subpopulation & & 2 & \\
\hline
\end{tabular}

\section{Model Fitting Information}

\begin{tabular}{l|r|r|r|r} 
& \multicolumn{1}{l}{$\begin{array}{l}\text { Model Fitting } \\
\text { Criteria } \\
\text { Model }\end{array}$} & \multicolumn{3}{|c}{ Likelihood Ratio Tests } \\
Likelihood & Chi-Square & df & Sig. \\
\hline Intercept Only & 75,096 & & & \\
\hline Final & 38,851 & 36,245 & 3 &, 000 \\
\hline
\end{tabular}

\section{Pseudo R-Square}

\begin{tabular}{l|r} 
Cox and Snell &, 022 \\
\hline Nagelkerke &, 024 \\
\hline McFadden &, 009 \\
\hline
\end{tabular}




\section{Likelihood Ratio Tests}

\begin{tabular}{l|r|r|r|r} 
& $\begin{array}{c}\text { Model Fitting } \\
\text { Criteria } \\
\text { Effect }\end{array}$ & \multicolumn{2}{l}{ Likelihood Ratio Tests } \\
$\begin{array}{l}-2 \text { Log } \\
\text { Likelihood of } \\
\text { Reduced Model }\end{array}$ & Chi-Square & df & Sig. \\
\hline Intercept & $38,851^{\text {a }}$ &, 000 & 0 & \\
\hline Uso do Facebook & 75,096 & 36,245 & 3 &, 000 \\
\hline
\end{tabular}

The chi-square statistic is the difference in -2 log-likelihoods between the final model and a reduced model. The reduced model is formed by omitting an effect from the final model. The null hypothesis is that all parameters of that effect are 0 .

a. This reduced model is equivalent to the final model because omitting the effect does not increase the degrees of freedom.

\section{Parameter Estimates}

\begin{tabular}{|c|c|c|c|c|c|c|}
\hline Argentina $^{a}$ & & $\mathrm{~B}$ & Std. Error & Wald & df & Sig. \\
\hline \multirow[t]{3}{*}{ Amizade } & Intercept & 1,039 & ,125 & 69,438 & 1 &, 000 \\
\hline & [Uso do Facebook=1] & ,664 & ,181 & 13,487 & 1 &, 000 \\
\hline & [Uso do Facebook=2] & $0^{b}$ & . & . & 0 & 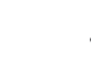 \\
\hline \multirow[t]{3}{*}{ Sociedade } & Intercept & ,676 & ,132 & 26,331 & 1 &, 000 \\
\hline & [Uso do Facebook=1] & 1,064 & ,185 & 32,926 & 1 &, 000 \\
\hline & [Uso do Facebook=2] & $0^{b}$ & . & . & 0 & r. \\
\hline \multirow[t]{3}{*}{ Rivalidade } & Intercept & ,159 &, 146 & 1,188 & 1 & ,276 \\
\hline & [Uso do Facebook=1] & ,890 & ,202 & 19,384 & 1 &, 000 \\
\hline & [Uso do Facebook=2] & $0^{b}$ & . & . & 0 & ra \\
\hline
\end{tabular}




\section{Parameter Estimates}

\begin{tabular}{|c|c|c|c|c|}
\hline \multirow[b]{2}{*}{ Argentina $^{a}$} & & \multirow[b]{2}{*}{$\operatorname{Exp}(B)$} & \multicolumn{2}{|c|}{$\begin{array}{l}\text { 95\% Confidence Interval for Exp } \\
\text { (B) }\end{array}$} \\
\hline & & & Lower Bound & Upper Bound \\
\hline \multirow[t]{3}{*}{ Amizade } & Intercept & & & \\
\hline & [Uso do Facebook=1] & 1,943 & 1,363 & 2,769 \\
\hline & [Uso do Facebook=2] & . & . & . \\
\hline \multirow[t]{3}{*}{ Sociedade } & Intercept & & & \\
\hline & [Uso do Facebook=1] & 2,898 & 2,015 & 4,168 \\
\hline & [Uso do Facebook=2] & . & . & . \\
\hline \multirow[t]{3}{*}{ Rivalidade } & Intercept & & & \\
\hline & [Uso do Facebook=1] & 2,435 & 1,639 & 3,619 \\
\hline & [Uso do Facebook=2] & . & . & . \\
\hline
\end{tabular}


TABELA 21 | REGRESSÃO LOGÍSTICA MULTINOMIAL (CHINA)

Case Processing Summary

\begin{tabular}{|c|c|c|c|}
\hline & & $\mathrm{N}$ & $\begin{array}{c}\text { Marginal } \\
\text { Percentage }\end{array}$ \\
\hline \multirow[t]{4}{*}{ China } & Amizade & 563 & $34,6 \%$ \\
\hline & Sociedade & 709 & $43,6 \%$ \\
\hline & Rivalidade & 122 & $7,5 \%$ \\
\hline & Ameaça & 233 & $14,3 \%$ \\
\hline \multirow[t]{2}{*}{ Uso do Facebook } & Sim & 1032 & $63,4 \%$ \\
\hline & Não & 595 & $36,6 \%$ \\
\hline Valid & & 1627 & $100,0 \%$ \\
\hline Missing & & 222 & \\
\hline Total & & 1849 & \\
\hline Subpopulation & & 2 & \\
\hline
\end{tabular}

Model Fitting Information

\begin{tabular}{lr|r|r|r} 
& $\begin{array}{c}\text { Model Fitting } \\
\text { Criteria } \\
\text { Model }\end{array}$ & \multicolumn{3}{|c}{ Likelihood Ratio Tests } \\
Likelihood & Chi-Square & df & Sig. \\
\hline Intercept Only & 81,340 & & & \\
\hline Final & 38,182 & 43,158 & 3 &, 000 \\
\hline
\end{tabular}

\section{Pseudo R-Square}

\begin{tabular}{l|c} 
Cox and Snell &, 026 \\
\hline Nagelkerke &, 029 \\
\hline McFadden &, 011 \\
\hline
\end{tabular}




\section{Likelihood Ratio Tests}

\begin{tabular}{|c|c|c|c|c|}
\hline \multirow[b]{2}{*}{ Effect } & \multirow{2}{*}{$\begin{array}{l}\text { Model Fitting } \\
\text { Criteria } \\
-2 \text { Log } \\
\text { Likelihood of } \\
\text { Reduced Model }\end{array}$} & \multicolumn{3}{|c|}{ Likelihood Ratio Tests } \\
\hline & & Chi-Square & df & Sig. \\
\hline Intercept & $38,182^{a}$ &, 000 & 0 & . \\
\hline Uso do Facebook & 81,340 & 43,158 & 3 & ,000 \\
\hline
\end{tabular}

The chi-square statistic is the difference in -2 log-likelihoods between the final model and a reduced model. The reduced model is formed by omitting an effect from the final model. The null hypothesis is that all parameters of that effect are 0 .

a. This reduced model is equivalent to the final model because omitting the effect does not increase the degrees of freedom.

\begin{tabular}{|c|c|c|c|c|c|c|}
\hline \multirow[b]{2}{*}{ China $^{a}$} & \multicolumn{6}{|c|}{ Parameter Estimates } \\
\hline & & $\mathrm{B}$ & Std. Error & Wald & df & Sig. \\
\hline \multirow[t]{3}{*}{ Amizade } & Intercept &, 558 & ,113 & 24,401 & 1 &, 000 \\
\hline & [Uso do Facebook=1] &, 593 &, 157 & 14,223 & 1 & ,000 \\
\hline & [Uso do Facebook=2] & $0^{b}$ & . & . & 0 & . \\
\hline \multirow[t]{3}{*}{ Sociedade } & Intercept &, 525 & ,114 & 21,333 & 1 &, 000 \\
\hline & [Uso do Facebook=1] &, 991 & ,155 & 40,859 & 1 &, 000 \\
\hline & [Uso do Facebook=2] & $0^{b}$ & . & . & 0 & . \\
\hline \multirow[t]{3}{*}{ Rivalidade } & Intercept &,- 920 &, 169 & 29,682 & 1 &, 000 \\
\hline & [Uso do Facebook=1] &, 510 &, 227 & 5,074 & 1 &, 024 \\
\hline & [Uso do Facebook=2] & $0^{b}$ & & . & 0 & . \\
\hline
\end{tabular}




\section{Parameter Estimates}

\begin{tabular}{|c|c|c|c|c|}
\hline \multirow[b]{2}{*}{ China $^{a}$} & & \multirow[b]{2}{*}{$\operatorname{Exp}(B)$} & \multicolumn{2}{|c|}{$\begin{array}{l}95 \% \text { Confidence Interval for Exp } \\
\text { (B) }\end{array}$} \\
\hline & & & Lower Bound & Upper Bound \\
\hline \multirow[t]{3}{*}{ Amizade } & Intercept & & & \\
\hline & [Uso do Facebook=1] & 1,810 & 1,330 & 2,464 \\
\hline & [Uso do Facebook=2] & . & . & . \\
\hline \multirow[t]{3}{*}{ Sociedade } & Intercept & & & \\
\hline & [Uso do Facebook=1] & 2,693 & 1,988 & 3,649 \\
\hline & [Uso do Facebook=2] & . & . & . \\
\hline \multirow[t]{3}{*}{ Rivalidade } & Intercept & & & \\
\hline & [Uso do Facebook=1] & 1,666 & 1,069 & 2,597 \\
\hline & [Uso do Facebook=2] & . & . & \\
\hline
\end{tabular}

TABELA 22 | REGRESSÃO LOGÍSTICA MULTINOMIAL (CUBA)

Case Processing Summary

\begin{tabular}{llr|r} 
& & & \multicolumn{1}{c}{$\begin{array}{c}\text { Marginal } \\
\text { Percentage }\end{array}$} \\
\hline Cuba & Amizade & 440 & $27,9 \%$ \\
\cline { 2 - 4 } & Sociedade & 475 & $30,1 \%$ \\
\cline { 2 - 4 } & Rivalidade & 268 & $17,0 \%$ \\
\cline { 2 - 4 } & Ameaça & 396 & $25,1 \%$ \\
\hline Uso do Facebook & Sim & 1000 & $63,3 \%$ \\
\cline { 2 - 4 } & Não & 579 & $36,7 \%$ \\
\hline Valid & & 1579 & $100,0 \%$ \\
\hline Missing & & 270 & \\
\hline Total & & 1849 & \\
\hline Subpopulation & & 2 & \\
\hline
\end{tabular}




\section{Model Fitting Information}

\begin{tabular}{l|r|r|r|r} 
& $\begin{array}{c}\text { Model Fitting } \\
\text { Criteria } \\
\text { Model }\end{array}$ & \multicolumn{2}{|l}{ Likelihood Ratio Tests } \\
\hline $\begin{array}{l}\text { Likelihood } \\
\text { Intercept Only }\end{array}$ & Chi-Square & df & Sig. \\
\hline Final & 62,269 & & & \\
\hline
\end{tabular}

Pseudo R-Square

\begin{tabular}{l|l} 
Cox and Snell &, 014 \\
\hline Nagelkerke &, 015 \\
\hline McFadden &, 005 \\
\hline
\end{tabular}

\section{Likelihood Ratio Tests}

\begin{tabular}{lr|r|r|r} 
& $\begin{array}{c}\text { Model Fitting } \\
\text { Criteria } \\
\text { Effect }\end{array}$ & \multicolumn{2}{|l}{ Likelihood Ratio Tests } \\
$\begin{array}{l}\text { Likelihood of } \\
\text { Reduced Model }\end{array}$ & Chi-Square & df & Sig. \\
\hline Intercept & $39,514^{a}$ &, 000 & 0 & . \\
\hline Uso do Facebook & 62,269 & 22,756 & 3 &, 000 \\
\hline
\end{tabular}

The chi-square statistic is the difference in -2 log-likelihoods between the final model and a reduced model. The reduced model is formed by omitting an effect from the final model. The null hypothesis is that all parameters of that effect are 0 .

a. This reduced model is equivalent to the final model because omitting the effect does not increase the degrees of freedom. 


\section{Parameter Estimates}

\begin{tabular}{|c|c|c|c|c|c|c|}
\hline Cuba $^{a}$ & & $\mathrm{~B}$ & Std. Error & Wald & $\mathrm{df}$ & Sig. \\
\hline \multirow[t]{3}{*}{ Amizade } & Intercept &,- 058 & , 108 & ,289 & 1 &, 591 \\
\hline & [Uso do Facebook=1] & ,279 & ,141 & 3,928 & 1 &, 047 \\
\hline & [Uso do Facebook=2] & $0^{\mathrm{b}}$ & . & . & 0 & . \\
\hline \multirow[t]{3}{*}{ Sociedade } & Intercept &,- 233 & ,113 & 4,272 & 1 &, 039 \\
\hline & [Uso do Facebook=1] & ,660 & 142 & 21,446 & 1 & , 000 \\
\hline & [Uso do Facebook=2] & $0^{\mathrm{b}}$ & . & . & 0 & . \\
\hline \multirow[t]{3}{*}{ Rivalidade } & Intercept &,- 660 & ,128 & 26,420 & 1 &, 000 \\
\hline & [Uso do Facebook=1] & ,446 & ,164 & 7,434 & 1 & ,006 \\
\hline & [Uso do Facebook=2] & $0^{b}$ & & & 0 & \\
\hline
\end{tabular}

\section{Parameter Estimates}

\begin{tabular}{|c|c|c|c|c|}
\hline \multirow[b]{2}{*}{ Cuba $^{a}$} & & \multirow[b]{2}{*}{$\operatorname{Exp}(B)$} & \multicolumn{2}{|c|}{$\begin{array}{l}95 \% \text { Confidence Interval for Exp } \\
\text { (B) }\end{array}$} \\
\hline & & & Lower Bound & Upper Bound \\
\hline \multirow[t]{3}{*}{ Amizade } & Intercept & & & \\
\hline & [Uso do Facebook=1] & 1,322 & 1,003 & 1,742 \\
\hline & [Uso do Facebook=2] & . & . & . \\
\hline \multirow[t]{3}{*}{ Sociedade } & Intercept & & & \\
\hline & [Uso do Facebook=1] & 1,934 & 1,463 & 2,557 \\
\hline & [Uso do Facebook=2] & . & . & . \\
\hline \multirow[t]{3}{*}{ Rivalidade } & Intercept & & & \\
\hline & [Uso do Facebook=1] & 1,562 & 1,134 & 2,152 \\
\hline & [Uso do Facebook=2] & . & . & . \\
\hline
\end{tabular}


TABELA 23 | REGRESSÃO LOGÍSTICA MULTINOMIAL (ESTADOS UNIDOS)

Case Processing Summary

\begin{tabular}{llr|r} 
& & & \multicolumn{1}{c}{$\begin{array}{c}\text { Marginal } \\
\text { Percentage }\end{array}$} \\
\hline Estados Unidos & Amizade & 652 & $38,8 \%$ \\
\cline { 2 - 4 } & Sociedade & 663 & $39,4 \%$ \\
\cline { 2 - 4 } & Rivalidade & 119 & $7,1 \%$ \\
\cline { 2 - 4 } & Ameaça & 248 & $14,7 \%$ \\
\hline Uso do Facebook & Sim & 1071 & $63,7 \%$ \\
\cline { 2 - 4 } & Não & 611 & $36,3 \%$ \\
\hline Valid & & 1682 & $100,0 \%$ \\
\hline Missing & & 167 & \\
\hline Total & & 1849 & \\
\hline Subpopulation & & 2 & \\
\hline
\end{tabular}

\section{Model Fitting Information}

\begin{tabular}{lr|r|r|r} 
& $\begin{array}{c}\text { Model Fitting } \\
\text { Criteria } \\
\text { Model }\end{array}$ & \multicolumn{3}{|l}{ Likelihood Ratio Tests } \\
Likelihood & Chi-Square & df & Sig. \\
\hline Intercept Only & 62,426 & & & \\
\hline Final & 38,395 & 24,030 & 3 &, 000 \\
\hline
\end{tabular}

\section{Pseudo R-Square}

\begin{tabular}{l|l} 
Cox and Snell &, 014 \\
\hline Nagelkerke &, 016 \\
\hline McFadden &, 006 \\
\hline
\end{tabular}




\section{Likelihood Ratio Tests}

\begin{tabular}{l|r|r|r|r} 
& $\begin{array}{c}\text { Model Fitting } \\
\text { Criteria } \\
\text { Effect }\end{array}$ & \multicolumn{2}{|l}{ Likelihood Ratio Tests } \\
$\begin{array}{l}\text { Likelihood of } \\
\text { Reduced Model }\end{array}$ & Chi-Square & df & Sig. \\
\hline Intercept & $38,395^{\text {a }}$ &, 000 & 0 &. \\
\hline Uso do Facebook & 62,426 & 24,030 & 3 &, 000 \\
\hline
\end{tabular}

The chi-square statistic is the difference in -2 log-likelihoods between the final model and a reduced model. The reduced model is formed by omitting an effect from the final model. The null hypothesis is that all parameters of that effect are 0 .

a. This reduced model is equivalent to the final model because omitting the effect does not increase the degrees of freedom.

\section{Parameter Estimates}

\begin{tabular}{|c|c|c|c|c|c|c|}
\hline \multicolumn{2}{|c|}{ Estados Unidos $^{a}$} & $\mathrm{~B}$ & Std. Error & Wald & df & Sig. \\
\hline \multirow[t]{3}{*}{ Amizade } & Intercept &, 654 & ,114 & 32,915 & 1 &, 000 \\
\hline & [Uso do Facebook=1] & ,528 & ,152 & 12,123 & 1 &, 000 \\
\hline & [Uso do Facebook=2] & $0^{b}$ & . & . & 0 & $\cdot$ \\
\hline \multirow[t]{3}{*}{ Sociedade } & Intercept & ,599 &, 115 & 27,107 & 1 &, 000 \\
\hline & [Uso do Facebook=1] & ,635 & ,152 & 17,454 & 1 &, 000 \\
\hline & [Uso do Facebook=2] & $0^{b}$ & . & . & 0 & . \\
\hline \multirow[t]{3}{*}{ Rivalidade } & Intercept &,- 737 &, 162 & 20,561 & 1 & ,000 \\
\hline & [Uso do Facebook=1] & ,005 & ,223 &, 000 & 1 & ,983 \\
\hline & [Uso do Facebook=2] & $0^{b}$ & . & . & 0 & . \\
\hline
\end{tabular}




\section{Parameter Estimates}

\begin{tabular}{|c|c|c|c|c|}
\hline \multirow{2}{*}{\multicolumn{2}{|c|}{ Estados Unidos $^{a}$}} & \multirow{3}{*}{$\operatorname{Exp}(B)$} & \multicolumn{2}{|c|}{$\begin{array}{l}\text { 95\% Confidence Interval for Exp } \\
\text { (B) }\end{array}$} \\
\hline & & & Lower Bound & Upper Bound \\
\hline \multirow[t]{3}{*}{ Amizade } & Intercept & & & \\
\hline & [Uso do Facebook=1] & 1,695 & 1,259 & 2,281 \\
\hline & [Uso do Facebook=2] & . & . & . \\
\hline \multirow[t]{3}{*}{ Sociedade } & Intercept & & & \\
\hline & [Uso do Facebook=1] & 1,887 & 1,401 & 2,542 \\
\hline & [Uso do Facebook=2] & . & . & . \\
\hline \multirow[t]{3}{*}{ Rivalidade } & Intercept & & & \\
\hline & [Uso do Facebook=1] & 1,005 & ,648 & 1,557 \\
\hline & [Uso do Facebook=2] & . & . & . \\
\hline
\end{tabular}

TABELA 24 | REGRESSÃO LOGÍSTICA MULTINOMIAL (ÍNDIA)

Case Processing Summary

\begin{tabular}{llr|r} 
& & & \multicolumn{1}{c}{$\begin{array}{c}\text { Marginal } \\
\text { Percentage }\end{array}$} \\
\hline \multirow{2}{*}{ Índia } & Amizade & 654 & $42,9 \%$ \\
\cline { 2 - 4 } & Sociedade & 600 & $39,4 \%$ \\
\cline { 2 - 4 } & Rivalidade & 112 & $7,3 \%$ \\
\cline { 2 - 4 } & Ameaça & 158 & $10,4 \%$ \\
\hline Uso do Facebook & Sim & 959 & $62,9 \%$ \\
\cline { 2 - 4 } & Não & 565 & $37,1 \%$ \\
\hline Valid & & 1524 & $100,0 \%$ \\
\hline Missing & & 325 & \\
\hline Total & & 1849 & \\
\hline Subpopulation & & 2 & \\
\hline
\end{tabular}




\section{Model Fitting Information}

\begin{tabular}{|c|c|c|c|c|}
\hline \multirow[b]{2}{*}{ Model } & \multirow{2}{*}{$\begin{array}{l}\text { Model Fitting } \\
\text { Criteria } \\
-2 \text { Log } \\
\text { Likelihood }\end{array}$} & \multicolumn{3}{|c|}{ Likelihood Ratio Tests } \\
\hline & & Chi-Square & df & Sig. \\
\hline Intercept Only & 82,823 & & & \\
\hline Final & 37,346 & 45,477 & 3 & , 000 \\
\hline
\end{tabular}

\section{Pseudo R-Square}

\begin{tabular}{l|c}
\hline Cox and Snell &, 029 \\
\hline Nagelkerke &, 033 \\
\hline McFadden &, 013 \\
\hline
\end{tabular}

\section{Likelihood Ratio Tests}

\begin{tabular}{l|c|r|r|r} 
& $\begin{array}{c}\text { Model Fitting } \\
\text { Criteria } \\
\text {-2 Log } \\
\text { Likelihood of } \\
\text { Reduced Model }\end{array}$ & Chi-Square & df & Sig. \\
\hline Intercept & $37,346^{\text {a }}$ &, 000 & 0 & \\
\hline Uso do Facebook & 82,823 & 45,477 & 3 &, 000 \\
\hline
\end{tabular}

The chi-square statistic is the difference in -2 log-likelihoods between the final model and a reduced model. The reduced model is formed by omitting an effect from the final model. The null hypothesis is that all parameters of that effect are 0 .

a. This reduced model is equivalent to the final model because omitting the effect does not increase the degrees of freedom. 


\section{Parameter Estimates}

\begin{tabular}{|c|c|c|c|c|c|c|}
\hline Índia $^{a}$ & & $\mathrm{~B}$ & Std. Error & Wald & df & Sig. \\
\hline \multirow[t]{3}{*}{ Amizade } & Intercept & 1,095 &, 125 & 77,224 & 1 &, 000 \\
\hline & [Uso do Facebook=1] & ,613 & ,179 & 11,752 & 1 & ,001 \\
\hline & [Uso do Facebook=2] & $0^{b}$ & . & . & 0 & \\
\hline \multirow[t]{3}{*}{ Sociedade } & Intercept & ,681 & ,132 & 26,520 & 1 &, 000 \\
\hline & [Uso do Facebook=1] & 1,106 & ,184 & 36,249 & 1 &, 000 \\
\hline & [Uso do Facebook=2] & $0^{b}$ & . & . & 0 & . \\
\hline \multirow[t]{3}{*}{ Rivalidade } & Intercept &,- 503 & ,176 & 8,202 & 1 & ,004 \\
\hline & [Uso do Facebook=1] & ,321 & ,248 & 1,676 & 1 & , 196 \\
\hline & [Uso do Facebook=2] & $0^{\mathrm{b}}$ & . & . & 0 & \\
\hline
\end{tabular}

\section{Parameter Estimates}

\begin{tabular}{|c|c|c|c|c|}
\hline \multirow[b]{2}{*}{ Índia $^{a}$} & & \multirow[b]{2}{*}{$\operatorname{Exp}(B)$} & \multicolumn{2}{|c|}{$\begin{array}{l}\text { 95\% Confidence Interval for Exp } \\
\text { (B) }\end{array}$} \\
\hline & & & Lower Bound & Upper Bound \\
\hline \multirow[t]{3}{*}{ Amizade } & Intercept & & & \\
\hline & [Uso do Facebook=1] & 1,845 & 1,300 & 2,619 \\
\hline & [Uso do Facebook=2] & . & . & . \\
\hline \multirow[t]{3}{*}{ Sociedade } & Intercept & & & \\
\hline & [Uso do Facebook=1] & 3,021 & 2,108 & 4,330 \\
\hline & [Uso do Facebook=2] & . & . & . \\
\hline \multirow[t]{3}{*}{ Rivalidade } & Intercept & & & \\
\hline & [Uso do Facebook=1] & 1,378 & ,848 & 2,240 \\
\hline & [Uso do Facebook=2] & . & . & . \\
\hline
\end{tabular}


TABELA 25 | REGRESSÃO LOGÍSTICA MULTINOMIAL (JAPÃO)

Case Processing Summary

\begin{tabular}{llr|r} 
& & $\mathrm{N}$ & \multicolumn{1}{c}{$\begin{array}{c}\text { Marginal } \\
\text { Percentage }\end{array}$} \\
\hline \multirow{2}{*}{ Japão } & Amizade & 678 & $41,5 \%$ \\
\cline { 2 - 4 } & Sociedade & 707 & $43,2 \%$ \\
\cline { 2 - 4 } & Rivalidade & 82 & $5,0 \%$ \\
\cline { 2 - 4 } & Ameaça & 168 & $10,3 \%$ \\
\hline \multirow{2}{*}{ Uso do Facebook } & Sim & 1027 & $62,8 \%$ \\
\cline { 2 - 4 } & Não & 608 & $37,2 \%$ \\
\hline Valid & & 1635 & $100,0 \%$ \\
\hline Missing & & 214 & \\
\hline Total & & 1849 & \\
\hline Subpopulation & & 2 & \\
\hline
\end{tabular}

Model Fitting Information

\begin{tabular}{lr|r|r|r} 
& $\begin{array}{c}\text { Model Fitting } \\
\text { Criteria } \\
\text {-2 Log }\end{array}$ & \multicolumn{3}{|c}{ Likelihood Ratio Tests } \\
Model & Likelihood & Chi-Square & df & Sig. \\
\hline Intercept Only & 61,709 & & & \\
\hline Final & 37,161 & 24,547 & 3 &, 000 \\
\hline
\end{tabular}

\section{Pseudo R-Square}

\begin{tabular}{l|r} 
Cox and Snell &, 015 \\
\hline Nagelkerke &, 017 \\
\hline McFadden &, 007 \\
\hline
\end{tabular}




\section{Likelihood Ratio Tests}

\begin{tabular}{|c|c|c|c|c|}
\hline & $\begin{array}{l}\text { Model Fitting } \\
\text { Criteria }\end{array}$ & \multicolumn{3}{|c|}{ Likelihood Ratio Tests } \\
\hline Effect & $\begin{array}{c}-2 \text { Log } \\
\text { Likelihood of } \\
\text { Reduced Model }\end{array}$ & Chi-Square & df & Sig. \\
\hline Intercept & $37,161^{a}$ &, 000 & 0 & . \\
\hline Uso do Facebook & 61,709 & 24,547 & 3 & ,000 \\
\hline
\end{tabular}

The chi-square statistic is the difference in -2 log-likelihoods between the final model and a reduced model. The reduced model is formed by omitting an effect from the final model. The null hypothesis is that all parameters of that effect are 0 .

a. This reduced model is equivalent to the final model because omitting the effect does not increase the degrees of freedom.

\begin{tabular}{|c|c|c|c|c|c|c|}
\hline \multicolumn{7}{|c|}{ Parameter Estimates } \\
\hline \multicolumn{2}{|l|}{ Japão $^{a}$} & B & Std. Error & Wald & df & Sig. \\
\hline \multirow[t]{3}{*}{ Amizade } & Intercept & 1,110 &, 124 & 79,724 & 1 &, 000 \\
\hline & [Uso do Facebook=1] &, 516 &, 173 & 8,866 & 1 &, 003 \\
\hline & [Uso do Facebook=2] & $0^{b}$ & . & . & 0 & . \\
\hline \multirow[t]{3}{*}{ Sociedade } & Intercept & ,962 & ,127 & 57,550 & 1 &, 000 \\
\hline & [Uso do Facebook=1] & ,809 & ,174 & 21,595 & 1 &, 000 \\
\hline & [Uso do Facebook=2] & $0^{b}$ & . & . & 0 & \\
\hline \multirow[t]{3}{*}{ Rivalidade } & Intercept &,- 871 & ,199 & 19,244 & 1 &, 000 \\
\hline & [Uso do Facebook=1] & ,293 & ,271 & 1,169 & 1 & ,280 \\
\hline & [Uso do Facebook=2] & $0^{b}$ & . & . & 0 & 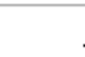 \\
\hline
\end{tabular}




\section{Parameter Estimates}

\begin{tabular}{|c|c|c|c|c|}
\hline \multirow[b]{2}{*}{ Japão $^{a}$} & & \multirow[b]{2}{*}{$\operatorname{Exp}(B)$} & \multicolumn{2}{|c|}{$\begin{array}{l}\text { 95\% Confidence Interval for Exp } \\
\text { (B) }\end{array}$} \\
\hline & & & Lower Bound & Upper Bound \\
\hline \multirow[t]{3}{*}{ Amizade } & Intercept & & & \\
\hline & [Uso do Facebook=1] & 1,676 & 1,193 & 2,354 \\
\hline & [Uso do Facebook=2] & . & . & . \\
\hline \multirow[t]{3}{*}{ Sociedade } & Intercept & & & \\
\hline & [Uso do Facebook=1] & 2,247 & 1,597 & 3,161 \\
\hline & [Uso do Facebook=2] & . & . & . \\
\hline \multirow[t]{3}{*}{ Rivalidade } & Intercept & & & \\
\hline & [Uso do Facebook=1] & 1,340 & ,788 & 2,279 \\
\hline & [Uso do Facebook=2] & . & . & \\
\hline
\end{tabular}

\section{TABELA 26 | REGRESSÃO LOGÍSTICA MULTINOMIAL (MÉXICO)}

\section{Case Processing Summary}

\begin{tabular}{llr|r} 
& & & \multicolumn{1}{c}{ Marginal } \\
\hline \multirow{2}{*}{ México } & Amizade & 659 & Percentage \\
\cline { 2 - 4 } & Sociedade & 604 & $41,8 \%$ \\
\cline { 2 - 4 } & Rivalidade & 135 & $38,3 \%$ \\
\cline { 2 - 4 } & Ameaça & 178 & $11,3 \%$ \\
\hline Uso do Facebook & Sim & 990 & $62,8 \%$ \\
\cline { 2 - 4 } & Não & 586 & $37,2 \%$ \\
\hline Valid & & 1576 & $100,0 \%$ \\
\hline Missing & & 273 & \\
\hline Total & & 1849 & \\
\hline Subpopulation & & 2 & \\
\hline
\end{tabular}




\section{Model Fitting Information}

\begin{tabular}{lr|r|r|r} 
& $\begin{array}{c}\text { Model Fitting } \\
\text { Criteria } \\
-2 \text { Log } \\
\text { Likelihood }\end{array}$ & \multicolumn{3}{|c}{ Likelihood Ratio Tests } \\
Model & 71,953 & & & \\
\hline Intercept Only & 37,888 & 34,065 & 3 &, 000 \\
\hline Final & & & df & Sig. \\
\hline
\end{tabular}

\section{Pseudo R-Square}

\begin{tabular}{lr} 
Cox and Snell &, 021 \\
\hline Nagelkerke &, 024 \\
\hline McFadden &, 009 \\
\hline
\end{tabular}

\section{Likelihood Ratio Tests}

\begin{tabular}{|c|c|c|c|c|}
\hline \multirow[b]{2}{*}{ Effect } & $\begin{array}{l}\text { Model Fitting } \\
\text { Criteria }\end{array}$ & \multicolumn{3}{|c|}{ Likelihood Ratio Tests } \\
\hline & $\begin{array}{c}-2 \text { Log } \\
\text { Likelihood of } \\
\text { Reduced Model }\end{array}$ & Chi-Square & df & Sig \\
\hline Intercept & $37,888^{a}$ & ,000 & 0 & \\
\hline Uso do Facebook & 71,953 & 34,065 & 3 &, 000 \\
\hline
\end{tabular}

a. This reduced model is equivalent to the final model because omitting the effect does not increase the degrees of freedom. 


\section{Parameter Estimates}

\begin{tabular}{|c|c|c|c|c|c|c|}
\hline México $^{a}$ & & B & Std. Error & Wald & df & Sig. \\
\hline \multirow[t]{3}{*}{ Amizade } & Intercept & 892 & 119 & 56,436 & 1 &, 000 \\
\hline & [Uso do Facebook=1] & ,780 & 171 & 20,722 & 1 & ,000 \\
\hline & [Uso do Facebook=2] & $0^{\mathrm{b}}$ & . & . & 0 & \\
\hline \multirow[t]{3}{*}{ Sociedade } & Intercept & ,652 & ,123 & 27,980 & 1 &, 000 \\
\hline & [Uso do Facebook=1] & 1,012 & 175 & 33,626 & 1 & ,000 \\
\hline & [Uso do Facebook=2] & $0^{\mathrm{b}}$ & . & . & 0 & . \\
\hline \multirow[t]{3}{*}{ Rivalidade } & Intercept &,- 693 & 173 & 16,015 & 1 & ,000 \\
\hline & [Uso do Facebook=1] & ,779 & 234 & 11,120 & 1 & ,001 \\
\hline & [Uso do Facebook=2] & $0^{\mathrm{b}}$ & . & . & 0 & \\
\hline
\end{tabular}

\section{Parameter Estimates}

\begin{tabular}{|c|c|c|c|c|}
\hline \multirow[b]{2}{*}{ México $^{a}$} & & \multirow[b]{2}{*}{$\operatorname{Exp}(B)$} & \multicolumn{2}{|c|}{$\begin{array}{l}95 \% \text { Confidence Interval for Exp } \\
\text { (B) }\end{array}$} \\
\hline & & & Lower Bound & Upper Bound \\
\hline \multirow[t]{3}{*}{ Amizade } & Intercept & & & \\
\hline & [Uso do Facebook=1] & 2,181 & 1,559 & 3,050 \\
\hline & [Uso do Facebook=2] & . & . & . \\
\hline \multirow[t]{3}{*}{ Sociedade } & Intercept & & & \\
\hline & [Uso do Facebook=1] & 2,751 & 1,954 & 3,873 \\
\hline & [Uso do Facebook=2] & . & . & . \\
\hline \multirow[t]{3}{*}{ Rivalidade } & Intercept & & & \\
\hline & [Uso do Facebook=1] & 2,179 & 1,379 & 3,445 \\
\hline & [Uso do Facebook=2] & . & . & . \\
\hline
\end{tabular}


TABELA 27 | REGRESSÃo LOGíSTICA MULTINOMIAL (RÚSSIA)

\begin{tabular}{|c|c|c|c|}
\hline \multicolumn{4}{|c|}{ Case Processing Summary } \\
\hline & & $\mathrm{N}$ & $\begin{array}{c}\text { Marginal } \\
\text { Percentage }\end{array}$ \\
\hline \multirow[t]{4}{*}{ Rússia } & Amizade & 456 & $29,4 \%$ \\
\hline & Sociedade & 570 & $36,8 \%$ \\
\hline & Rivalidade & 166 & $10,7 \%$ \\
\hline & Ameaça & 359 & $23,1 \%$ \\
\hline \multirow[t]{2}{*}{ Uso do Facebook } & Sim & 975 & $62,9 \%$ \\
\hline & Não & 576 & $37,1 \%$ \\
\hline Valid & & 1551 & $100,0 \%$ \\
\hline Missing & & 298 & \\
\hline Total & & 1849 & \\
\hline Subpopulation & & 2 & \\
\hline
\end{tabular}

\section{Model Fitting Information}

\begin{tabular}{lr|r|r|r} 
& $\begin{array}{c}\text { Model Fitting } \\
\text { Criteria } \\
-2 \text { Log } \\
\text { Likelihood }\end{array}$ & \multicolumn{2}{|c}{ Likelihood Ratio Tests } \\
Model & 89,887 & & & \\
\hline Intercept Only & 38,871 & 51,016 & 3 &, 000 \\
\hline Final & & df & Sig. \\
\hline
\end{tabular}

\section{Pseudo R-Square}

\begin{tabular}{l|r} 
Cox and Snell &, 032 \\
\hline Nagelkerke &, 035 \\
\hline McFadden &, 013 \\
\hline
\end{tabular}




\section{Likelihood Ratio Tests}

\begin{tabular}{l|r|r|r|r} 
& $\begin{array}{c}\text { Model Fitting } \\
\text { Criteria } \\
\text { Effect }\end{array}$ & \multicolumn{2}{|c}{ Likelihood Ratio Tests } \\
$\begin{array}{l}\text { Likelihood of } \\
\text { Reduced Model }\end{array}$ & Chi-Square & df & Sig. \\
\hline Intercept & $38,871^{\text {a }}$ &, 000 & 0 & \\
\hline Uso do Facebook & 89,887 & 51,016 & 3 &, 000 \\
\hline
\end{tabular}

The chi-square statistic is the difference in -2 log-likelihoods between the final model and a reduced model. The reduced model is formed by omitting an effect from the final model. The null hypothesis is that all parameters of that effect are 0 .

a. This reduced model is equivalent to the final model because omitting the effect does not increase the degrees of freedom.

\begin{tabular}{|c|c|c|c|c|c|c|}
\hline \multirow[b]{2}{*}{ Rússia $^{a}$} & \multicolumn{6}{|c|}{ Parameter Estimates } \\
\hline & & B & Std. Error & Wald & df & Sig. \\
\hline \multirow[t]{3}{*}{ Amizade } & Intercept &, 023 & , 107 &, 046 & 1 & 830 \\
\hline & [Uso do Facebook=1] &, 381 & ,143 & 7,099 & 1 & ,008 \\
\hline & [Uso do Facebook=2] & $0^{b}$ & . & . & 0 & . \\
\hline \multirow[t]{3}{*}{ Sociedade } & Intercept &,- 124 &, 111 & 1,233 & 1 & ,267 \\
\hline & [Uso do Facebook=1] &, 928 & ,142 & 42,774 & 1 & ,000 \\
\hline & [Uso do Facebook=2] & $0^{\mathrm{b}}$ & & . & 0 & . \\
\hline \multirow[t]{3}{*}{ Rivalidade } & Intercept &,- 817 & ,138 & 35,163 & 1 &, 000 \\
\hline & [Uso do Facebook=1] &, 085 & , 188 & ,206 & 1 & ,650 \\
\hline & [Uso do Facebook=2] & $0^{b}$ & & . & 0 & . \\
\hline
\end{tabular}




\section{Parameter Estimates}

\begin{tabular}{|c|c|c|c|c|}
\hline \multirow[b]{2}{*}{ Rússia $^{a}$} & & \multirow[b]{2}{*}{$\operatorname{Exp}(B)$} & \multicolumn{2}{|c|}{$\begin{array}{l}\text { 95\% Confidence Interval for Exp } \\
\text { (B) }\end{array}$} \\
\hline & & & Lower Bound & Upper Bound \\
\hline \multirow[t]{3}{*}{ Amizade } & Intercept & & & \\
\hline & [Uso do Facebook=1] & 1,463 & 1,106 & 1,936 \\
\hline & [Uso do Facebook=2] & . & . & \\
\hline \multirow[t]{3}{*}{ Sociedade } & Intercept & & & \\
\hline & [Uso do Facebook=1] & 2,529 & 1,915 & 3,340 \\
\hline & [Uso do Facebook=2] & . & . & \\
\hline \multirow[t]{3}{*}{ Rivalidade } & Intercept & & & \\
\hline & [Uso do Facebook=1] & 1,089 &, 753 & 1,575 \\
\hline & [Uso do Facebook=2] & . & . & \\
\hline
\end{tabular}

\section{TABELA 28 | REGRESSÃO LOGÍSTICA MULTINOMIAL (VENEZUELA)}

\section{Case Processing Summary}

\begin{tabular}{llr|r} 
& & & \multicolumn{1}{c}{ Marginal } \\
& & $\mathrm{N}$ & Percentage \\
\hline Venezuela & Amizade & 453 & $28,2 \%$ \\
\cline { 2 - 4 } & Sociedade & 427 & $26,5 \%$ \\
\cline { 2 - 4 } & Rivalidade & 271 & $16,8 \%$ \\
\cline { 2 - 4 } & Ameaça & 458 & $28,5 \%$ \\
\hline Uso do Facebook & Sim & 1011 & $62,8 \%$ \\
\cline { 2 - 4 } & Não & 598 & $37,2 \%$ \\
\hline Valid & & 1609 & $100,0 \%$ \\
\hline Missing & & 240 & \\
\hline Total & & 1849 & \\
\hline Subpopulation & & 2 & \\
\hline
\end{tabular}




\section{Model Fitting Information}

\begin{tabular}{l|c|c|c|c|} 
& $\begin{array}{c}\text { Model Fitting } \\
\text { Criteria } \\
\text {-2 Log }\end{array}$ & \multicolumn{2}{|c}{ Likelihood Ratio Tests } \\
Model & Likelihood & Chi-Square & df & Sig. \\
\hline Intercept Only & 66,240 & & & \\
\hline Final & 39,634 & 26,606 & 3 &, 000 \\
\hline
\end{tabular}

\section{Pseudo R-Square}

\begin{tabular}{lr} 
Cox and Snell &, 016 \\
\hline Nagelkerke &, 018 \\
\hline McFadden &, 006 \\
\hline
\end{tabular}

\section{Likelihood Ratio Tests}

\begin{tabular}{|c|c|c|c|c|}
\hline & $\begin{array}{l}\text { Model Fitting } \\
\text { Criteria }\end{array}$ & \multicolumn{3}{|c|}{ Likelihood Ratio Tests } \\
\hline Effect & $\begin{array}{c}-2 \text { Log } \\
\text { Likelihood of } \\
\text { Reduced Model }\end{array}$ & Chi-Square & df & Sig. \\
\hline Intercept & $39,634^{a}$ &, 000 & 0 & \\
\hline Uso do Facebook & 66,240 & 26,606 & 3 &, 000 \\
\hline
\end{tabular}

The chi-square statistic is the difference in -2 log-likelihoods between the final model and a reduced model. The reduced model is formed by omitting an effect from the final model. The null hypothesis is that all parameters of that effect are 0.

a. This reduced model is equivalent to the final model because omitting the effect does not increase the degrees of freedom. 


\section{Parameter Estimates}

\begin{tabular}{|c|c|c|c|c|c|c|}
\hline Venezuela $^{a}$ & & $\mathrm{~B}$ & Std. Error & Wald & $\mathrm{df}$ & Sig. \\
\hline \multirow[t]{3}{*}{ Amizade } & Intercept &,- 166 &, 104 & 2,557 & 1 & , 110 \\
\hline & [Uso do Facebook=1] & ,263 & ,135 & 3,791 & 1 & ,052 \\
\hline & [Uso do Facebook=2] & $0^{b}$ & . & . & 0 & . \\
\hline \multirow[t]{3}{*}{ Sociedade } & Intercept &,- 534 & ,115 & 21,400 & 1 & ,000 \\
\hline & [Uso do Facebook=1] &, 723 &, 143 & 25,496 & 1 &, 000 \\
\hline & [Uso do Facebook=2] & $0^{b}$ & . & . & 0 & . \\
\hline \multirow[t]{3}{*}{ Rivalidade } & Intercept &,- 669 & ,121 & 30,761 & 1 &, 000 \\
\hline & [Uso do Facebook=1] & ,246 & ,156 & 2,466 & 1 & ,116 \\
\hline & [Uso do Facebook=2] & $0^{b}$ & . & . & 0 & \\
\hline
\end{tabular}

\section{Parameter Estimates}

\begin{tabular}{|c|c|c|c|c|}
\hline \multirow[b]{2}{*}{ Venezuela $^{a}$} & & \multirow[b]{2}{*}{$\operatorname{Exp}(B)$} & \multicolumn{2}{|c|}{$\begin{array}{l}\text { 95\% Confidence Interval for Exp } \\
\text { (B) }\end{array}$} \\
\hline & & & Lower Bound & Upper Bound \\
\hline \multirow[t]{3}{*}{ Amizade } & Intercept & & & \\
\hline & [Uso do Facebook=1] & 1,301 & ,998 & 1,694 \\
\hline & [Uso do Facebook=2] & . & . & . \\
\hline \multirow[t]{3}{*}{ Sociedade } & Intercept & & & \\
\hline & [Uso do Facebook=1] & 2,060 & 1,556 & 2,728 \\
\hline & [Uso do Facebook=2] & . & . & . \\
\hline \multirow[t]{3}{*}{ Rivalidade } & Intercept & & & \\
\hline & [Uso do Facebook=1] & 1,278 & ,941 & 1,737 \\
\hline & [Uso do Facebook=2] & . & . & \\
\hline
\end{tabular}


FIGURA 18 | REDE BILATERAL BRASIL - ÁFRICA DO SUL

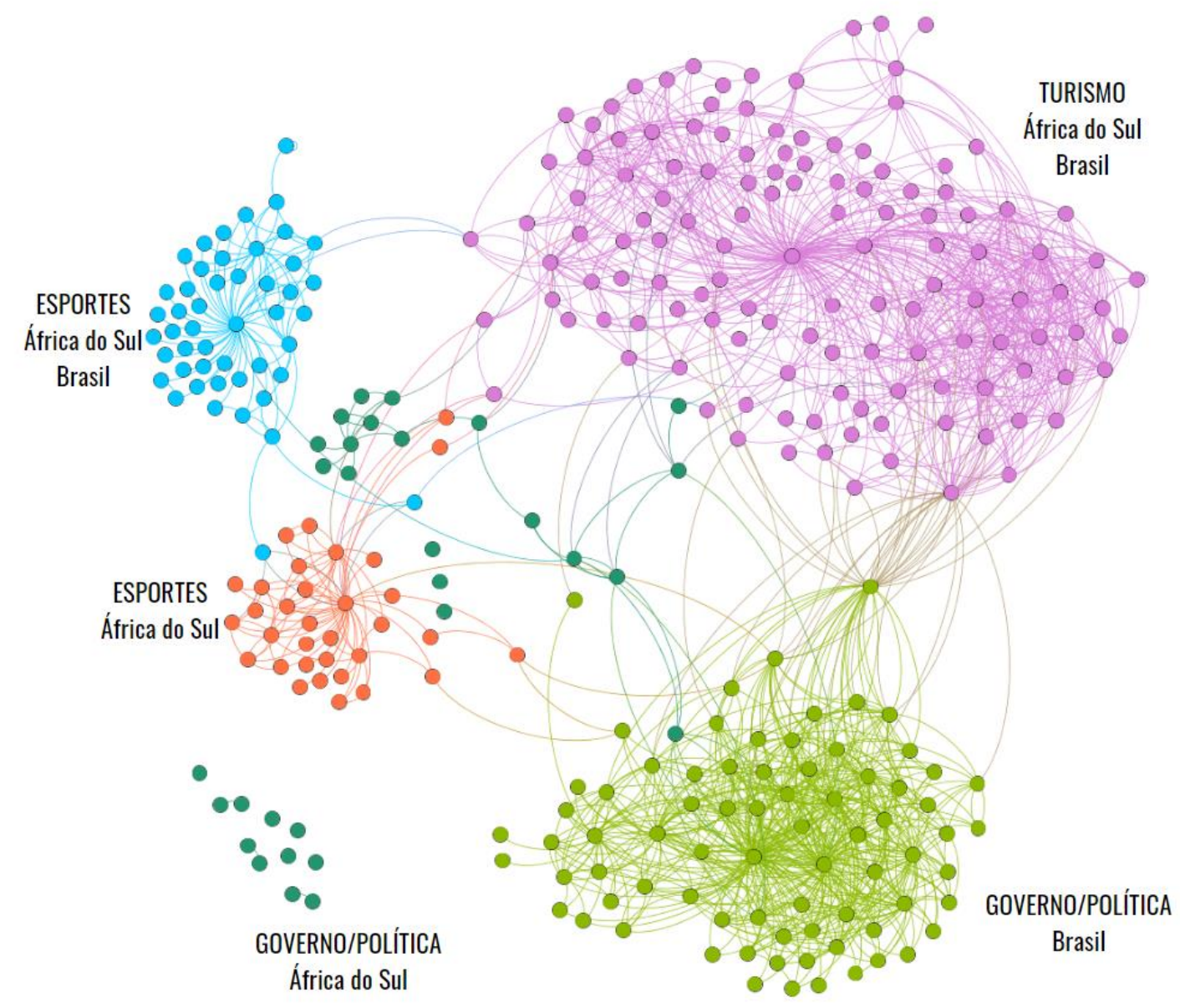


FIGURA 19 | REDE BILATERAL BRASIL - ARGENTINA

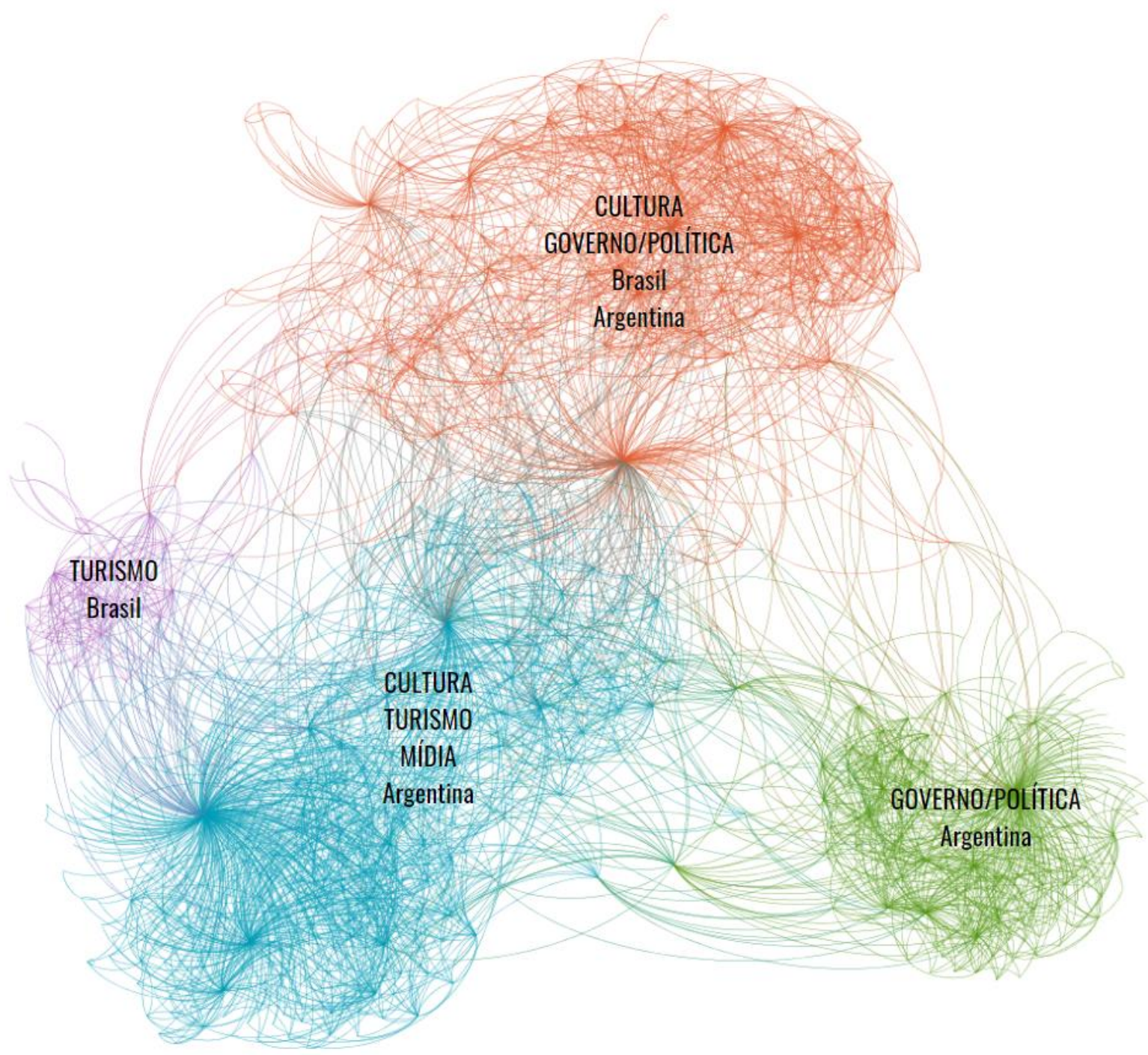


FIGURA 20 | REDE BILATERAL BRASIL-CHINA

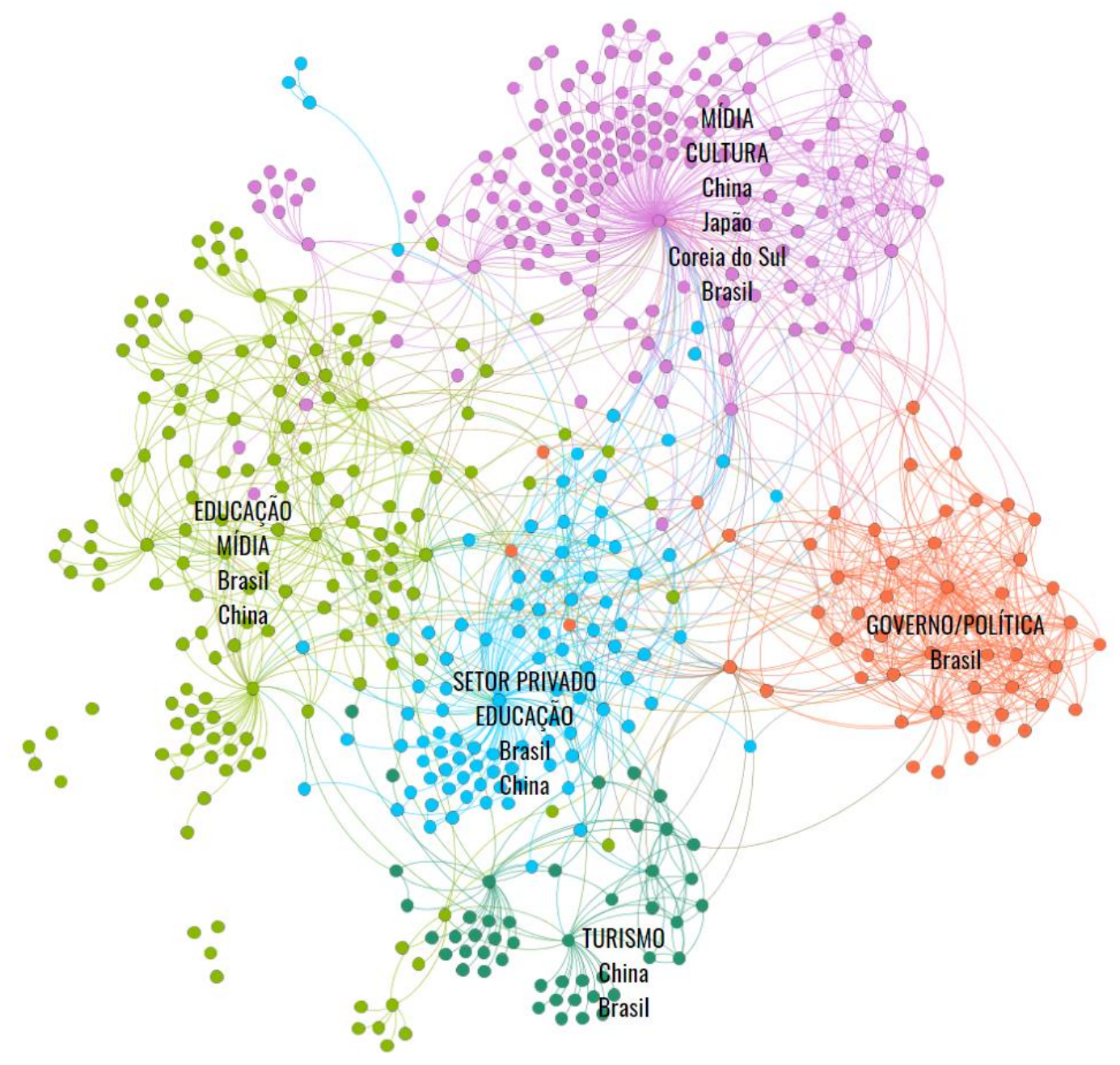


FIGURA 21 | REDE BILATERAL BRASIL - CUBA

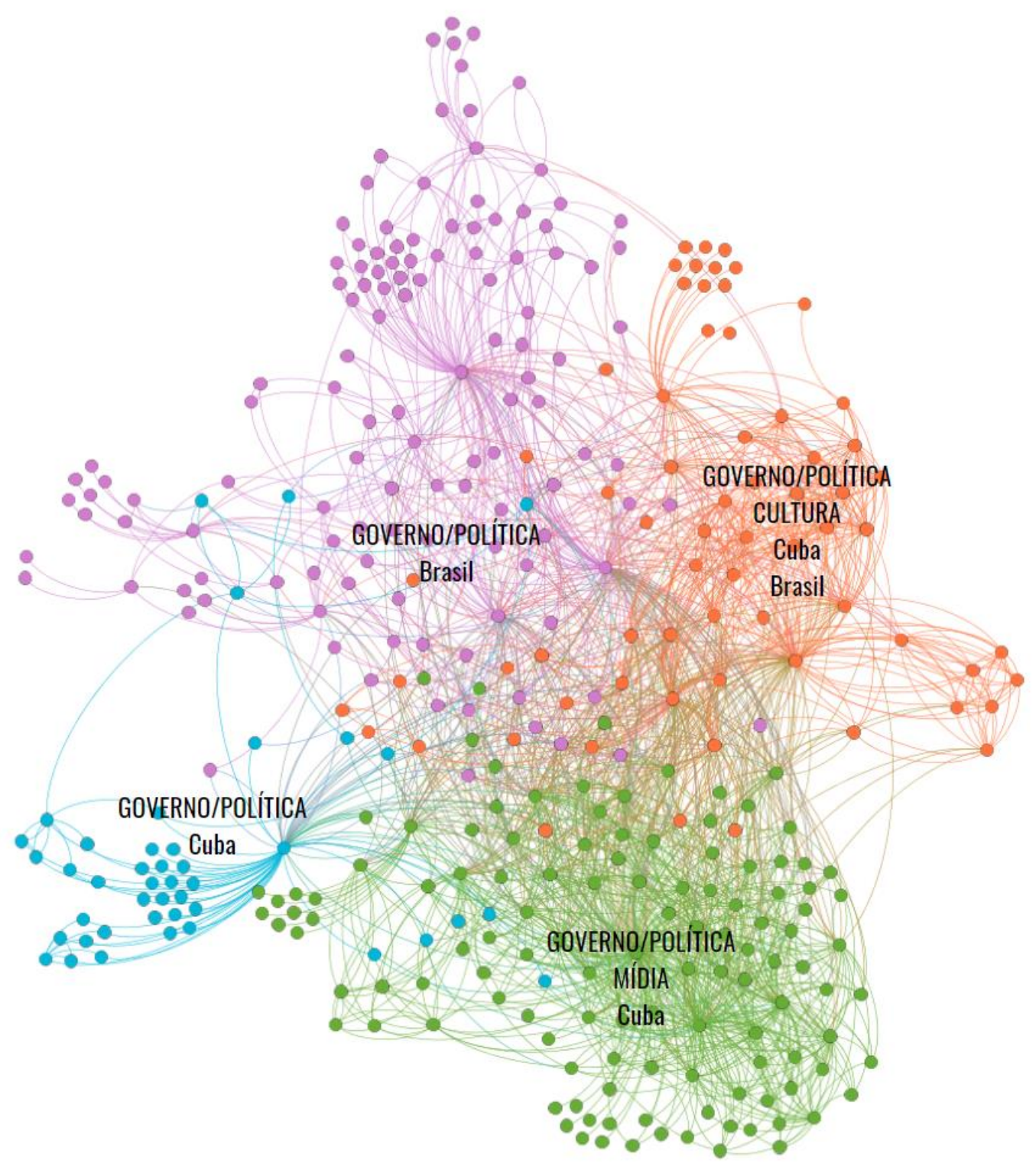




\section{FIGURA 22 | REDE BILATERAL BRASIL - ESTADOS UNIDOS}

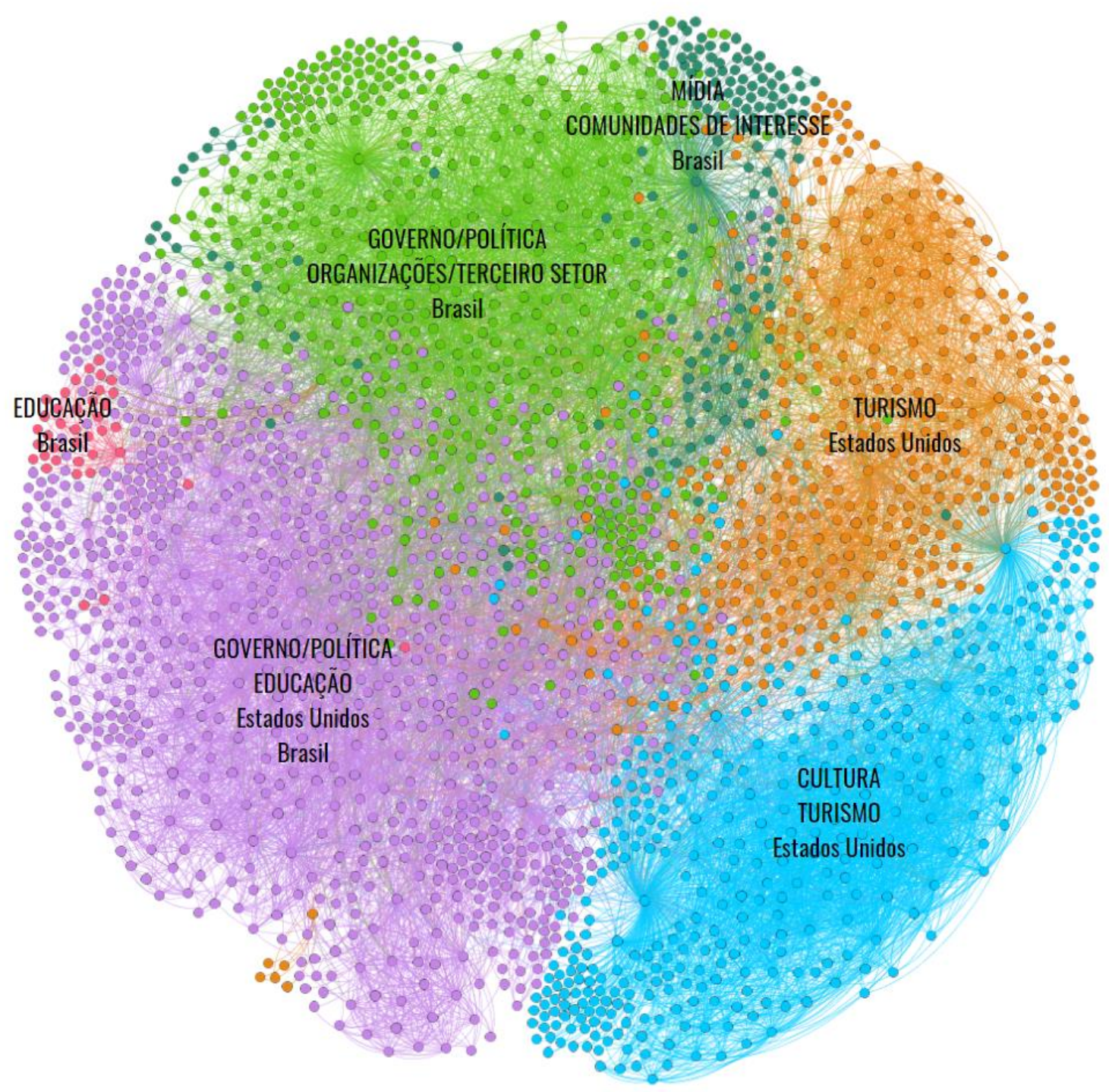


FIGURA 23 | REDE BILATERAL BRASIL - ÍNDIA

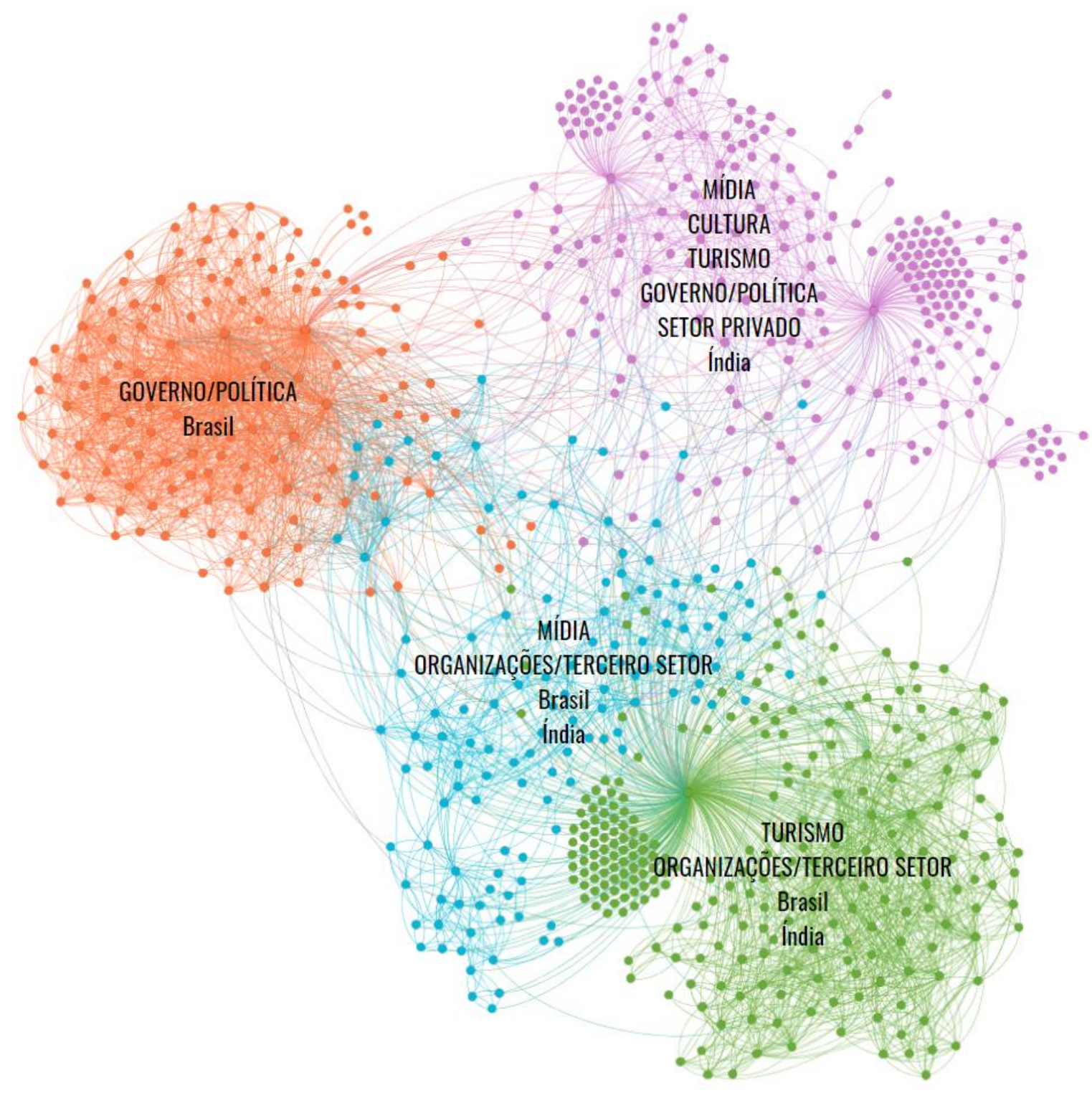


FIGURA 24 | REDE BILATERAL BRASIL - JAPÃO

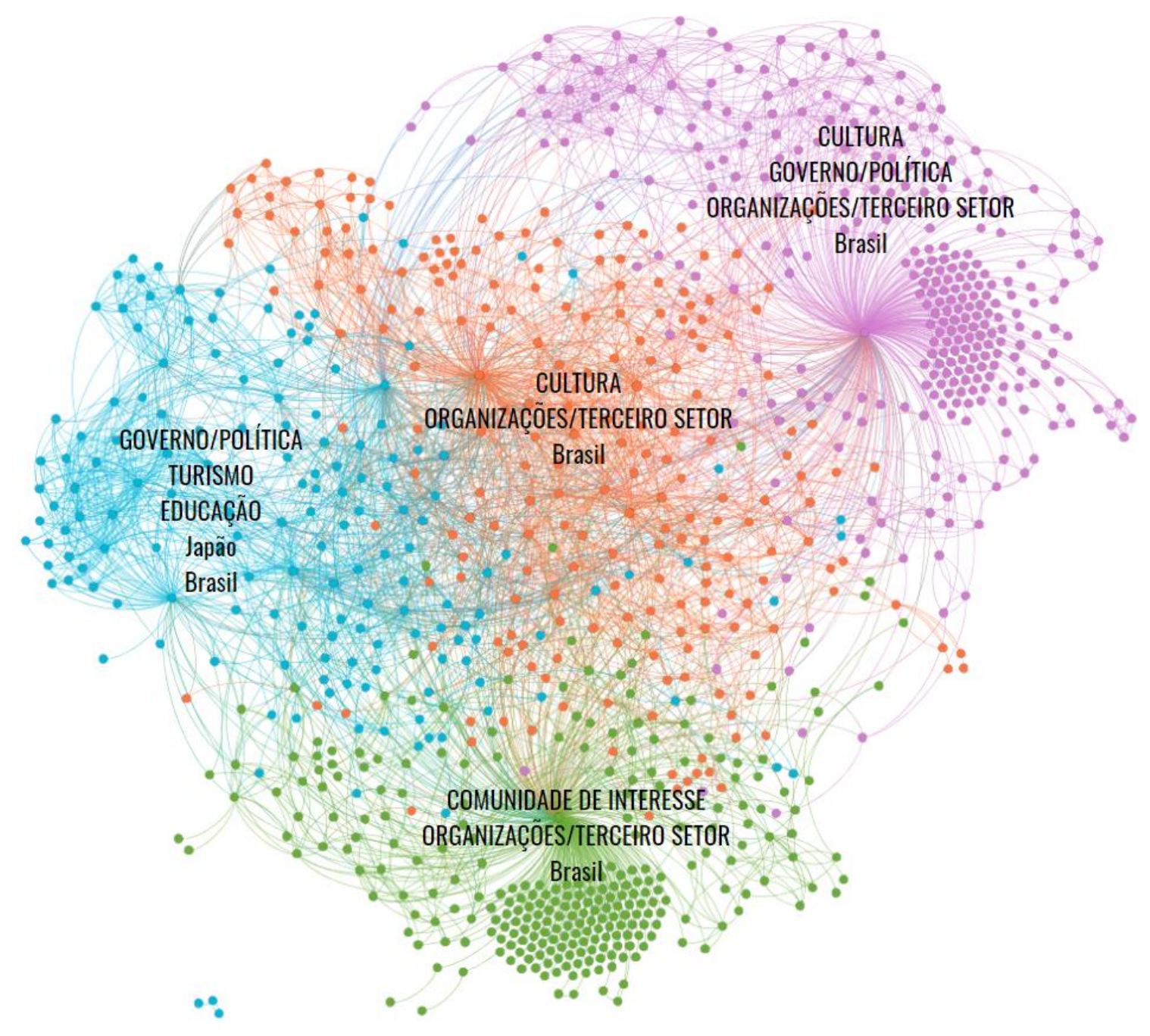


FIGURA 25 | REDE BILATERAL BRASIL-MÉXICO

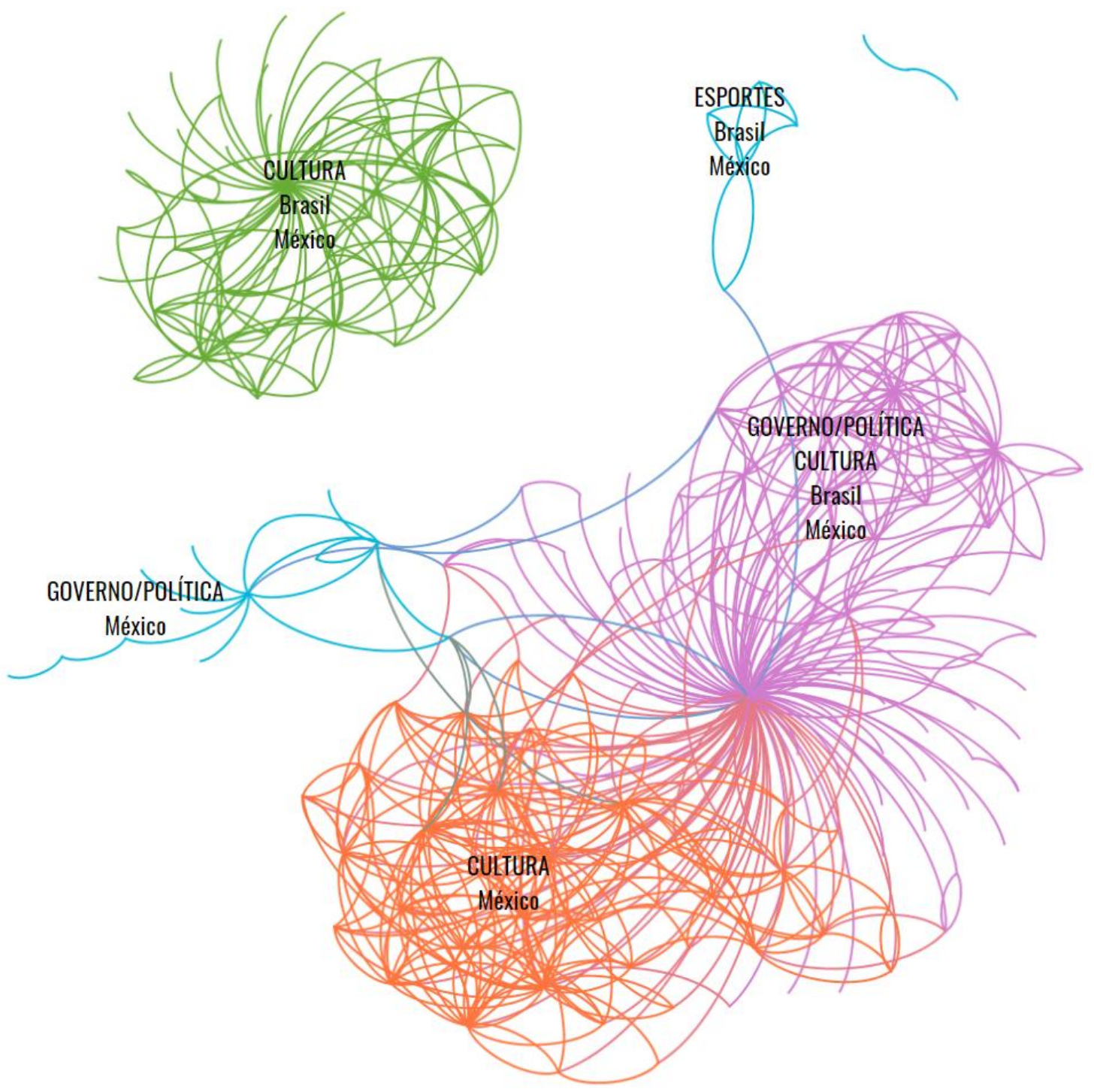


FIGURA 26 | REDE BILATERAL BRASIL - RÚSSIA

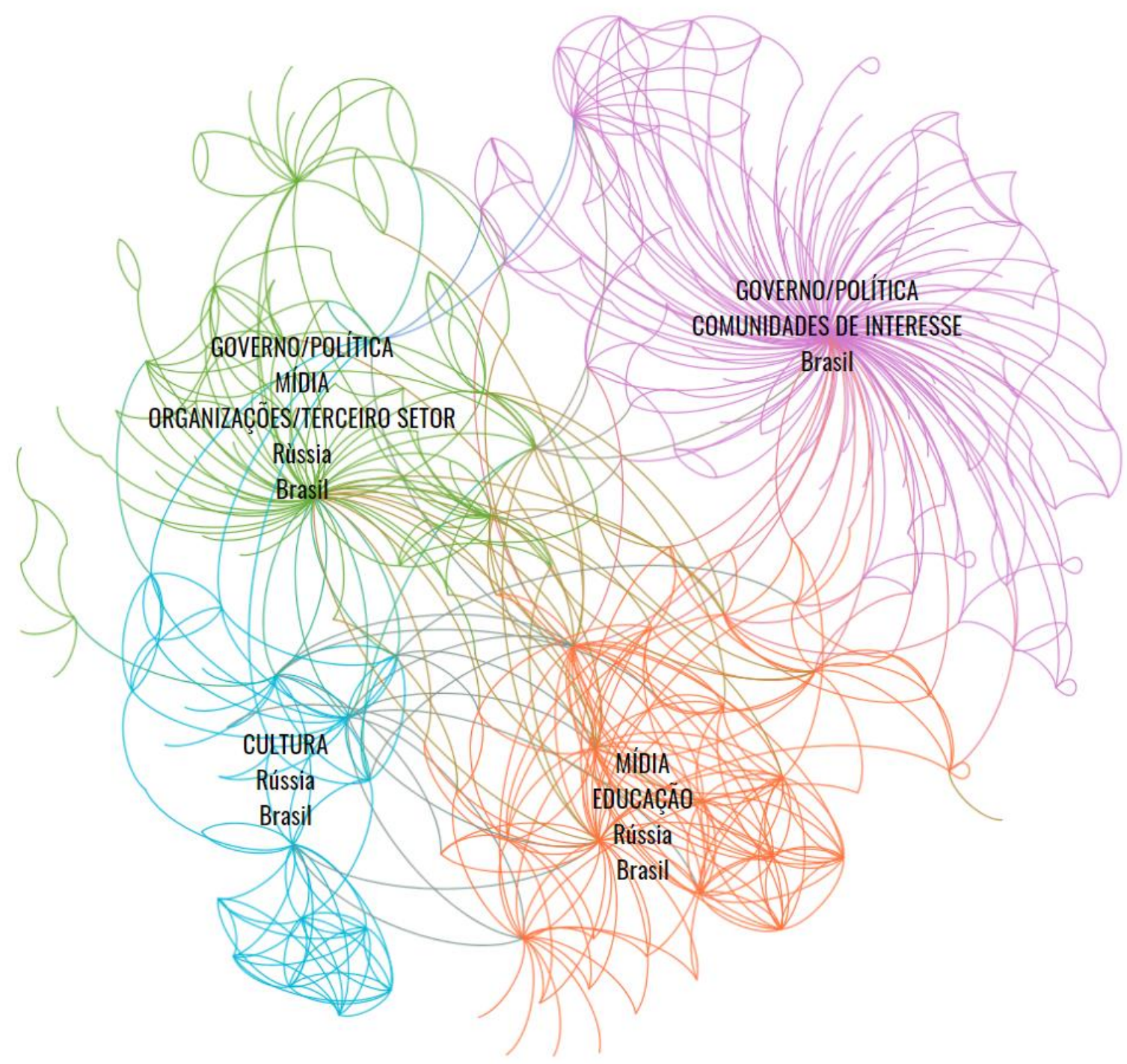


FIGURA 27 | REDE BILATERAL BRASIL - VENEZUELA

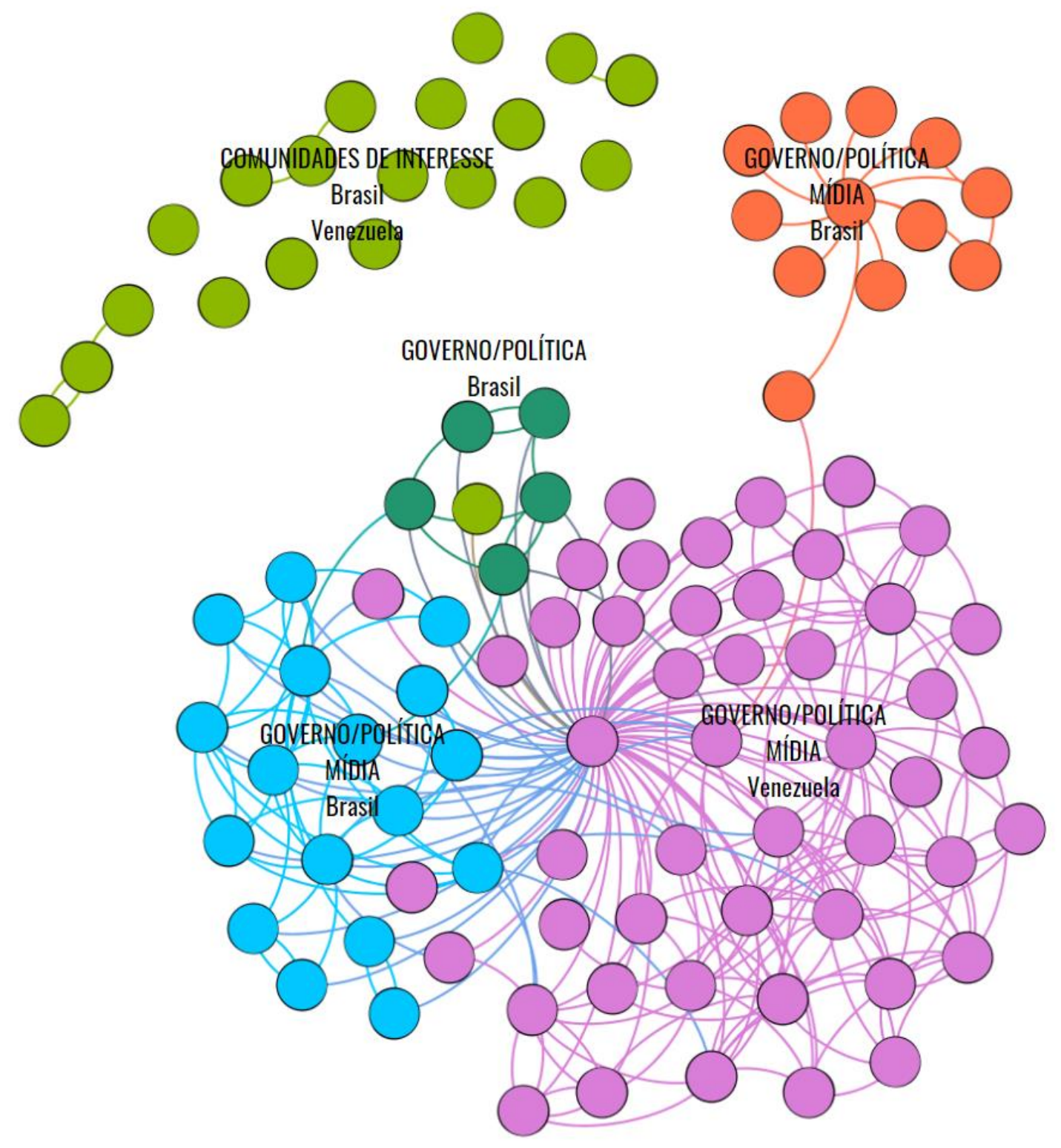




\section{CONSIDERAÇÕES FINAIS}

A história dos estudos sobre opinião pública e política externa pode ser lida como uma história sobre as distâncias. Nos marcos iniciais desses estudos (Almond, 1960; Converse, 1964), o público é tido como ignorante, incoerente e volátil em temas internacionais - ou seja, muito distante. Os massivos protestos contra a Guerra do Vietnã ao final dos anos 1960, apresentaram um novo cenário, no qual se via um público politicamente e pessoalmente envolvido em uma guerra em outro continente. A distância não poderia ser tão grande assim: a coerência e estabilidade dos valores pessoais poderia, em algumas ocasiões, aproximar parte do público aos temas distantes.

Se a distância em algumas ocasiões pode ser encurtada, isso não significa que ela deixe de existir: há um alto custo de participação na construção de opiniões políticas sofisticadas (Popkin, 1994), de modo que percorrer esse longo caminho desacompanhado seria uma decisão irracional (Powlick, 1998). Os atalhos cognitivos são as estradas construídas por outros em quem confiamos, para chegarmos de forma mais rápida e segura a uma opinião política sofisticada. Parte importante do debate sobre os atalhos cognitivos é a respeito de quais são essas estradas.

Em um mundo offline, não havia tanta diversidade das rotas possíveis: imprensa, governo, partidos políticos, valores pessoais e os discursos das elites. Essas diversas rotas poderiam inclusive ser coerentes entre si, de modo que diferenças de opiniões entre atores independentes - como governos e imprensa - estivessem mais alinhadas do que desalinhadas ao longo das décadas (Zaller, 1992).

Conforme discutido anteriormente, a diversificação de atores nas relações internacionais, o advento da internet e o advento das redes sociais constrói novas vias para os atalhos cognitivos. Eu defendo que, no mundo online, as redes sociais assumem o papel de principal atalho cognitivo para os públicos na década de 2010, 
lugar de poder ocupado pela imprensa offline no Século XX. Além disso, tais atalhos podem ser crescentemente customizados pela via dos algoritmos, que resultam em diferentes clusters, próximos ou distantes entre si em diferentes redes.

Tais mudanças significativas não ocorrem em um vácuo político: elas ganham terreno em um momento no qual os tempos de prosperidade econômica e dos arranjos políticos que a sustentavam se encontram mais distantes; e no qual sucessivas crises e divisionismos se acumulam nos países capitalistas centrais e nos países emergentes.

A escolha do marco cronológico de 2010 a 2020 nesta investigação visa aprofundar as consequências dessas mudanças para o público brasileiro, por meio dos possíveis caminhos que podem ser tomados para a aproximação com países estrangeiros e dos efeitos que os novos atalhos cognitivos podem apresentar nos públicos.

No primeiro capítulo, verificamos que o crescimento do acesso à internet, smartphones e redes sociais foi acompanhado por um aumento da polarização na política doméstica, mas que isso não causou alterações no interesse em notícias internacionais. Nas três rodadas de As Américas e O Mundo, observamos posicionamentos que se mantiveram estáveis e outros alterados na polarização. No entanto, conforme sinalizado por Page e Shapiro (1988), os picos de mudança em opiniões sobre temas externos não significam necessariamente uma alteração perene na orientação do público, mas uma reação a uma mudança repentina de cenário externo, fator próprio das relações internacionais.

No segundo capítulo, identificamos dez clusters principais em 15 redes bilaterais das Américas, 23 da Europa, 6 da África e 15 da Ásia, Oriente Médio e Oceania. Entre as 59 redes bilaterais, encontramos grande diversidade nos clusters hegemônicos: Governo/Política e Mídia, em conjunto, são os principais clusters em 21 redes, menos da metade do total. Além disso, redes bilaterais com países 
importantes não estão incluídas neste grupo. Estados Unidos (Educação), Japão (Cultura), França (Cultura) e Alemanha (Setor Privado) são alguns exemplos. Também identificamos diferenças significativas entre as redes bilaterais com base em suas métricas: França, Estados Unidos, Austrália e Espanha têm portes de redes bem distintos das restantes; Alemanha, Hungria e Israel, apesar de menores na comparação com as quatro primeiras, são significativamente mais conectadas em relação às 52 redes restantes.

Por fim, no terceiro capítulo, foram realizados dez estudos de caso comparando as redes bilaterais no Facebook e as opiniões do público em As Américas e O Mundo acerca de Argentina, África do Sul, China, Cuba, Estados Unidos, Índia, Japão, México, Rússia e Venezuela. Confirmamos para todos os dez países a hipótese de que o uso do Facebook por um respondente altera positivamente a relação declarada de Amizade e Sociedade na comparação com Ameaça. Quando consideramos a relação de Rivalidade, a alteração é significativa para metade do grupo: Argentina, México, China, Cuba e Índia. Também foi confirmada a hipótese de que a imagem positiva ou negativa de um país junto ao público varia em função do volume (nós) e conectividade (arestas) de suas respectivas redes. Além disso, observamos que o porte das redes não está necessariamente associado a tipos específicos de clusters.

A partir dos findings da investigação, temos alguns caminhos para analisar a dinâmica dos atalhos cognitivos, das redes sociais e dos diferentes cenários internacionais de polarizações. A primeira alternativa diz respeito ao público: a atitude da opinião pública para temas domésticos é fundamentalmente diferente da atitude para temas internacionais (Stimson, 2004). Ou seja, o mesmo público usuário de redes sociais e polarizado na política doméstica - pode ter imagens mais positivas de países estrangeiros em relação aos não-usuários por: a) se posicionar mais próximo a eles pelas estradas dos atalhos cognitivos das redes sociais; $b$ ) não associar outros países ao cenário de polarização doméstica. 
A diversidade de perfis das redes bilaterais exploradas neste trabalho indica algumas possibilidades de investigação. Um exemplo seria o estudo mais detalhado de cada uma das redes em contraste com as estratégias de diplomacia digital e das próprias linhas de relações bilaterais definidas pelas chancelarias. A possibilidade de métricas mais diversas nas redes, para além das variáveis já conhecidas em pesquisas de opinião clássicas, possibilita a produção de análises que explorem mais a fundo esta nova conjuntura.

Outro caminho que podemos percorrer é o de que a polarização política doméstica ou externa tem diferentes níveis de sofisticação entre o público, tese já sinalizada por autores como Almond e Deutsch. O público, portanto, poderia ser alheio aos pormenores de alinhamentos e desalinhamentos internos às elites polarizadas. Por exemplo, o uso de Cuba e da Venezuela como maus exemplos políticos pela nova direita no Brasil ao longo da década não altera o fato de que um usuário do Facebook tenha maior probabilidade de ter uma imagem positiva de ambos os países na comparação com um não-usuário, ainda que esse usuário esteja em tese mais exposto a um discurso negativo sobre eles por parte de seu próprio político preferencial nas redes sociais.

Apesar disso, é sabido que o uso das redes sociais para fins eleitorais no plano doméstico ou para influenciar as relações internacionais tem se mostrado eficaz, como demonstraram os casos das eleições dos Estados Unidos de 2016, nos planos doméstico e externo; e as eleições no Brasil em 2018. Porém, a estratégia de uso dessas ferramentas guarda em seu interior algumas fragilidades: a fragilidade das interações caírem, remediadas pelo uso de boots (perfis falsos) e pelas constantes declarações polêmicas; e a fragilidade de eventuais incoerências e ilegalidades da estratégia política serem expostas a qualquer momento, por meio dos vazamentos de dados. Aliás, muitas das grandes crises políticas da década de 2010 foram crises geradas pelos vazamentos de dados online. 
Esse cenário nos leva a mais uma rota de análise: os dados são o ativo mais valioso no Século XXI e aqueles que buscam poder, buscam o controle dos dados (Susskind, 2018). A implicação disto é que os governos e grandes corporações buscarão exercer maior influência nas redes de atalhos cognitivos, para que seja assegurado um alinhamento entre a práxis política e informações disponíveis aos públicos. Esses alinhamentos, bem afinados entre governos e mídias na Guerra Fria (Zaller, 2000), se perderam em meio a diversificação de atores, vazamentos de dados e crises institucionais.

A recuperação desses alinhamentos será parte fundamental da estratégia dos diferentes atores políticos no cenário internacional do Século XXI. Porém, esse novo cenário levanta questões complexas. Quais serão os custos de tais alinhamentos para a democracia liberal? A diversificação de atores nas redes de atalhos cognitivos será totalmente instrumentalizada pelas grandes potências e por oligopólios de empresas de dados?

$\mathrm{Na}$ ocasião da conclusão desta investigação, as licitações da internet $5 \mathrm{G}$ estão no centro de uma guerra econômica entre as duas maiores potências mundiais: Estados Unidos e China. No início de uma nova década, os dados online passarão a ser uma ferramenta indispensável de hard power? A internet e os dados serão variáveis cada vez mais importantes no posicionamento de países no sistema internacional e, em caso de fragmentação da internet em estruturas independentes, podem definir as esferas de influência nas quais diferentes países serão posicionados.

Nesse sentido, estudos comparativos de uso de redes sociais tendem a se tornar mais raros, caso a proibição de redes sociais externas às esferas de influência de cada país se torne um padrão. A tentativa de proibição do uso do aplicativo chinês TikTok nos EUA por Trump, durante a campanha eleitoral, pode ser um aperitivo do que poderia ocorrer em caso de fragmentação da internet mundial no futuro. 
As duas primeiras décadas do século XXI são um período de transição tecnológica muito importante em diferentes planos domésticos e no plano internacional. As mudanças nas concepções de poder, influência e discurso político causadas pelo crescente uso da internet pela sociedade civil nos computadores pessoais e nos smartphones ainda têm um amplo campo de investigação a ser explorado. 


\section{REFERÊNCIAS BIBLIOGRÁFICAS}

ALDRICH JH, GELPI C, FEAVER P, REIFLER J, SHARP KT. Foreign policy and the electoral connection. Annu.Rev.Polit.Sci.9:477-502. 2006

ALDRICH JH, SULLIVAN JL, BORGIDA E. Foreign affairs and issue voting: Do presidential candidates waltz before a blind audience? Am.Polit.Sci.Rev.83(1):12341. 1989

ALMEIDA, M; CARNEIRO, L; SÁ, F; FERNANDES, I; ONUKI, J. O Brasil, As Américas e $O$ Mundo segundo a opinião do público e dos líderes. IRI/USP, CEBRAP: 2017

ALMEIDA, M; CARNEIRO, L; ONUKI, J. O Brasil, As Américas e O Mundo segundo a opinião do público e dos líderes. IRI/USP, CEBRAP: 2011

ALMEIDA, M; ONUKI, J; CARNEIRO, L. O Brasil, as Américas e o Mundo. São Paulo: Imprensa Oficial, 2012

ALMOND, G. The American People and The Foreign Policy. New York: Harcourt, Brace and Company, 1950

ALMOND, G; VERBA, S. The Civic Culture: Political Attitudes and Democracy in Five Nations. Sage, 1989

BAUM MA. Soft News Goes to War: Public Opinion and American Foreign Policy in the New Media Age. Princeton,NJ:Princeton Univ.Press. 2003.

BAUM, M. POTTER, P. The Relationships Between Mass Media, Public Opinion, and Foreign Policy: Toward a Theoretical Synthesis. Annu. Rev. Polit. Sci. 11:3965. 2008.

BAKSHY, E. et al (2012). The Role of Social Networks in Information Diffusion. WWW'12 - Proceedings of the 21st Annual Conference on World Wide Web. 10.1145/2187836.2187907.

BARBERÁ, P.; RIVERO, G. (2014) Understanding the political representativeness of Twitter users. Social Science Computer Review. December/2014 BARNETT, G. A. and SUNG, E. (2005). Culture and the Structure of the International Hyperlink Network. Journal of Computer-Mediated Communication, 11: 217-238. 
BENNETT, W. The Persian Gulf War's Impact on Americans' Political Information. Political Behavior. 16(2):179-201 (1994)

BERINSKY A. Assuming the costs of war: events, elites, and American public support for military conflict. J.Polit.69: Inpress. 2007

BISBEE, J. \& LARSON, J.M. (2017) Testing Social Science Network Theories with Online Network Data: An Evaluation of External Validity. American Political Science Review, 1-20.

BLAU, P. (1977) A Macrosociological Theory of Social Structure. The American Journal of Sociology, Vol. 83, No. 1 (Jul.), pp. 26-54

BOND, R. et al. (2012) A 61-million-person experiment in social influence and political mobilization. Nature, Sep.2012

BORGATTI, S. et al. (2009). Network Analysis in the Social Sciences. Science (New York, N.Y.). 323. 892-5. 10.1126/science.1165821

BOURDIEU, P. L'opinion publique n'existe pas. Les temps modernes, 318. Jan, 1973

BURSON-MARSTELLER. Twitplomacy Study 2012-2017. Disponível em $<$ www.twitplomacy.com>. Acessado em abril/2017

BURSON-MARSTELLER. World Leaders on Facebook 2016-2017. Disponível em $<$ www.twitplomacy.com>Acessado em abril/2017

BURSON-MARSTELLER. International Organizations on Twitter. Disponível em $<$ www.twitplomacy.com>Acessado em abril/2017

CASPARY, W. The Mood Theory: A Study of Public Opinion and Foreign Policy. American Political Science Review. 64: 536-547 (1970)

CASTILLO, R, MALDONADO, G, SCHIAVON, J. To Know or Not To Know? Realist and Liberal Theories on Foreign Affairs and Latin America. Latin American Policy. 6.1, 2-18

CATTENBERG, G; MORENO, A. The individual bases of political trust: trends in new and established democracies. International Journal of Public Opinion Research. v. 18 n. 1,2005

COHEN, BC. The Press and Foreign Policy. Princeton,NJ:Princeton Univ.Press, 1963 
COHEN, BC. Democracies and Foreign Policy: Public Participation in the United States and the Netherlands. Madison: Univ. Wisc. Press, 1995

CONVERSE, P. The nature of belief systems in mass public. Critical Review: 18.13, 1-74, 1964.

DA EMPOLI, G. Os Engenheiros do Caos. São Paulo: Vestígio, 2019

DALTON, R. Citizen Politics: Public Opinion and Political Parties in advanced industrial societies. In: Critical Citizens: Global Support for Democratic Governance. Oxford: Oxford University Press, 1999.

DRUCKMAN JN. The implications of framing effects for citizen competence. Polit.Behav. 23:225-56. 2001.

DEUTSCH, K. The analysis of international relations. New Jersey: Prentice Hall, 1978

EASLEY, D. \& KLEINBERG, J. (201) Networks, Crowds, and Markets: Reasoning About a Highly Connected World. Cambridge: Cambridge University Press.

Freedom of the Net 2019.

FREEDOM HOUSE. Freedom of the Net: The Rise of Digital Authoritarism. 2018. https://freedomhouse.org/report/freedom-net/freedom-net-2018. Acessado em novembro/2019

GARCíA, M. et al. (2016) Identifying the new influencers in the Internet Era: Social Media and Social Network Analysis. Revista Española de Investigaciones Sociológicas, 153: 23-40.

GRANOVETTER, M. (1973). The strength of weak ties. American Journal of Sociology, 78.

GOEL, S., MASON, W., and WATTS, D. Real and Perceived Attitude Agreement in Social Networks. Journal of Personality and Social Psychology 99, no. 4 (2010) 611 GOLDER, S. A., \& MACY, M. W. (2014) Digital footprints - Opportunities and challenges for online social research. Annual Review of Sociology HABERMAS, J. (2014) Mudança estrutural da esfera pública: investigações sobre uma categoria da sociedade burguesa. São Paulo: Editora Unesp. 
HAFNER-BURTON, E. \& KAHLER, M. \& MONTGOMERY, A. (2009). Network Analysis For International Relations. International Organization. 63. 559-592. 10.1017/S0020818309090195.

HOSTI, O. Public Opinion and Foreign Policy: Challenges to the Almond-Lippmann Consensus. International Studies Quarterly, Vol. 36, No. 4 (Dec., 1992), pp. 439-46 HUBERMAN B. et al. (2004) Status as a valued resource. Soc. Psychol. Q. 67(1):103

HUNTINGTON, S. 1994. A terceira onda: a democratização no final do século XX. São Paulo: Ática.

HURWITZ, J. and PEFFlEY, M., 1987. How Are Foreign Policy Attitudes Structured? A Hierarchical Model. The American Political Science Review, 81(4), pp. 1099-1120.

INGLEHART, R., 1988. The Renaissance of Political Culture. The American Political Science Review, 82(4), pp. 1203-1230.

INGLEHART, R.; CATTENBERG, G. Trends in political action: The developmental trend and the post-honeymoon decline. International Journal of Comparative Sociology, v.

43, 2003.

KEY, VO. Public Opinion and American Democracy. NewYork: Knopf, 1961 KLEINBERG, J. (1998). Authoritative sources in a hyperlinked environment. Proc. 9th ACM-SIAM Symposium on Discrete Algorithms.

KROSNICK JA, KINDER DR. Altering the foundations of support for the president through priming. Am. Polit. Sci.Rev. 84:497-512. 1990.

LATINOBARÓMETRO. Informe Latinobarómetro. Santiago de Chile: Latinobarómetro, 2013.

LAZER, D. et al (2009). Computational Social Science. Science 6 February: 323 (5915), 721-723. [DOI:10.1126/science.1167742]

LIPPMAN, W. Public Opinion. London: Collier-Macmillan, 1965.

LIVINGSTON S, BENNETT L. Gatekeeping, indexing, and live-event news: Is technology altering the construction of news? Polit.Commun.20:363-80. 2003 
MALINI F., ANTOUN, H. Monitoramento, vazamentos e anonimato nas revoluções democráticas das redes sociais da internet. Revista Fronteiras - Estudos Midiáticos. 14(2): 68-76 maio/agosto 2012

MARRES, N., R. ROGERS (2005). Recipe for Tracing Issues and Their Publics on the Web.' In Making Things Public: Atmospheres of Democracy, edited by B. Latour and P. Weibel, 922-35. Cambridge, MA: MIT Press.

MARIN, A. WELLMAN, B. (2010) Social Network Analysis: An Introduction. In: Handbook of Social Network Analysis. London: Sage.

MERAZ, S.; PAPACHARISSI, Z. Networked Gatekeeping and Networked Framing on \#egypt. The International Journal of Press/Politics.1-29. 2013 MILGRAM, S. (1967). The small world problem. Psychology Today 2, 60-67. MOISÉS, J. A desconfiança nas instituições democráticas. Opinião Pública, v. XI, n. $1,2005$.

MOISÉS, J; CARNEIRO, G. Democracia, desconfiança política e insatisfação com o regime: o caso do Brasil. Opinião Pública, v. 14, n. 1, jun.2008 MORENO J. (1934). Who Shall Survive? .Beacon House, Beacon, NY.

MORGENTHAU, H. Politics among the nations: the struggle for power and peace. Knopf: New York, 1948

NEUMAN R, JUST MR, CRIGLER AN. Common Knowledge: News and the Construction of Political Meaning. Chicago: Univ. Chicago Press. 1992.

POPKIN, S. (1993). Information Shortcuts and the reasoning voter. In Democracy and the Media: A Comparative Perspective, pp 241-65. Cambridge, UK: Cambridge University Press.

POPKIN, SL. The Reasoning Voter: Communication and Persuasion in Presidential Campaigns. Chicago: Univ. Chicago Press. 1994.

POWLICK PJ. The sources of public opinion for American foreign-policy officials. Int. Stud.Q.39:427-51.1995

POWLICK P, KATZ AZ. Defining the American public opinion/foreign policy nexus. Int. Stud.Q.42:29-61. 1998.

RECUERO, R. et al Hashtags Functions in the Protests Across Brazil. SAGE Open. April-June 2015: 1-14 
REED, N. (1989) The strength of strong ties: social networks and intergroup conflict in organizations. Academy of Management Journal, Vol. 32, No. 2.

RISSE-KAPPEN, T. Public Opinion, Domestic Structure, and Foreign Policy in Liberal Democracies. Cambridge: World Politics, 1991.

ROGERS, R. (2012) Mapping and the Politics of Web Space. Theory, Culture \& Society 29(4/5) 1-27

ROSENAU, J. Public Opinion and Foreign Policy.New York: Random House, 1961

ROSENAU, J. Domestic Sources of Foreign Policy. New York: Free Press, 1967.

SCHMITT-BECK R. Mass communication, personal communication and vote choice: the filter hypothesis of media influence in comparative perspective. $\mathrm{Br}$.J. Polit. Sci. 33:233-5. 2003

SIMMEL, G. (1955) Conflict and The web of group-affiliations. New York: Free Press.

SINCLAIR, B. (2016) Network Structure and Social Outcomes: Network Analysis for Social Science in Computational Social Science. Cambridge: Cambridge University Press.

STIMSON, J. Tides of Consent. 1, 1-20 Cambridge: Cambridge University Press, 2004

SHAPIRO, R.Y. and PAGE, B.I., 1988. Foreign Policy and the Rational Public. The Journal of Conflict Resolution, 32(2), pp. 211-247

SOUZA, A. A Agenda Internacional do Brasil: a política externa brasileira de FHC a Lula. Rio de Janeiro, Elsevier, 2009.

SUSSKIND, J. Future Politics. Oxford: Oxford University Press, 2018

TICKNER, A.; CEPEDA, C; ROUVINSKI, V; MILANESE, J. Colombia, Las Américas

y El Mundo: Opinión Pública y Política Exterior. Universidad de los Andes: Bogotá, 2015

TUFEKCI, Z. (2014) Big Questions for Social Media Big Data: Representativeness, Validity and Other Methodological Pitfalls. Proceedings of the 8th International Conference on Weblogs and Social Media, ICWSM. 
ZALLER J, CHIU D. Government's little helper: U.S. press coverage of foreign policy crises, 1946-1999. In Decisionmaking in a Glass House, ed. BL Nacos, RY Shapiro, P Isernia, pp.61-84. New York:Rowman \& Littlefield. 2000.

ZALLER J. The Nature and Origins of Mass Opinion. NewYork: Cambridge Univ.Press, 1992

ZALLER J. A new standard of news quality: burglar alarms for the monitorial citizen. Polit. Commun.20:109-30, 2003

WASSERMAN, S.; FAUST, K. (1994) Social Network Analysis: Methods and Applications. 1.ed. Cambridge: Cambridge University Press.

WEBER, M. \& MONGE, P. R. (2011). The flow of digital news in a network of sources, authorities, and hubs. Journal of Communication, 61, 1062-1081

WHITE, D.M. (1964). "The 'Gatekeeper': A Case Study In the Selection of News In: Lewis A. Dexter / David M. White: People, Society and Mass Communications. London S. 160 - 172.

WORLD BANK. World Bank Database. <https://data.worldbank.org/> Acessado em julho/2019 


\section{APPENDIX}

\section{AMÉRICAS | MÉTRICAS GERAIS DAS REDES BILATERAIS}

\begin{tabular}{|c|c|c|c|c|c|c|}
\hline & NÓS & NÓS FORTES & ARESTAS & GRAU MÉDIO & $\begin{array}{l}\text { COMP. MÉD. } \\
\text { CAM. }\end{array}$ & DIÂMETRO \\
\hline ARGENTINA & 735 & 377 & 4124 & 5.611 & 2.638 & 13 \\
\hline BOLÍVIA & 110 & 98 & 191 & 1.736 & 2.638 & 7 \\
\hline CHILE & 534 & 344 & 1860 & 3.483 & 4.759 & 13 \\
\hline CANADÁ & 548 & 254 & 2745 & 5,009 & 4,453 & 14 \\
\hline COLÔMBIA & 604 & 378 & 2353 & 3.896 & 6.317 & 16 \\
\hline CUBA & 357 & 180 & 1945 & 5.448 & 3.653 & 9 \\
\hline EQUADOR & 323 & 140 & 2018 & 6.248 & 4.502 & 13 \\
\hline EUA & 2229 & 886 & 14693 & 6,592 & 5,406 & 19 \\
\hline HAITI & 252 & 138 & 1327 & 5.66 & 3.51 & 8 \\
\hline MÉXICO & 185 & 109 & 616 & 3.33 & 3.046 & 9 \\
\hline PARAGUAI & 366 & 188 & 2065 & 5.642 & 3.679 & 9 \\
\hline PERU & 217 & 88 & 1303 & 6.005 & 3.798 & 11 \\
\hline R DOMINIC. & 43 & 20 & 162 & 3.767 & 2.125 & 4 \\
\hline URUGUAI & 284 & 178 & 904 & 3.183 & 3.856 & 9 \\
\hline VENEZUELA & 103 & 78 & 286 & 2.777 & 2.69 & 10 \\
\hline
\end{tabular}

\section{ÁFRICA | MÉTRICAS GERAIS DAS REDES BILATERAIS}

\begin{tabular}{ccccccc}
\hline & NÓS & NÓS FORTES & ARESTAS & GRAU MÉDIO & $\begin{array}{c}\text { COMP. MÉD. } \\
\text { CAM. }\end{array}$ & DIÂMETRO \\
$\begin{array}{c}\text { ÁFRICA DO } \\
\text { SUL }\end{array}$ & 316 & 156 & 1626 & 5.146 & 4.326 & 14 \\
ANGOLA & 541 & 424 & 1422 & 2.628 & 4.448 & 14 \\
CABO VERDE & 82 & 40 & 292 & 3.561 & 4.129 & 11 \\
EGITO & 314 & 268 & 628 & 2 & 3.958 & 8 \\
MARROCOS & 182 & 160 & 250 & 1.374 & 2.957 & 6 \\
MOÇAMBIQUE & 1368 & 546 & 15492 & 8.536 & 4.676 & 13 \\
\hline
\end{tabular}




\section{EUROPA | MÉTRICAS GERAIS DAS REDES BILATERAIS}

\begin{tabular}{ccccccc}
\hline & NÓS & NÓS FORTES & ARESTAS & GRAU MÉDIO & $\begin{array}{c}\text { COMP. MÉD. } \\
\text { CAM. }\end{array}$ & DIÂMETRO \\
ALEMANHA & 1166 & 547 & 7688 & 6,593 & 4.174 & 13 \\
ÁUSTRIA & 158 & 73 & 588 & 3.722 & 3.3 & 7 \\
BÉLGICA & 627 & 307 & 3493 & 5.571 & 3.999 & 10 \\
CROÁCIA & 231 & 107 & 1130 & 4.892 & 4.254 & 11 \\
DINAMARCA & 282 & 139 & 1277 & 4.528 & 3.711 & 9 \\
ESPANHA & 1763 & 747 & 15828 & 8.978 & 4.146 & 13 \\
FINLÂNDIA & 359 & 183 & 3222 & 8.975 & 3.308 & 8 \\
FRANÇA & 2635 & 1143 & 26454 & 10.039 & 4.031 & 11 \\
GRÉCIA & 202 & 96 & 939 & 4.649 & 3.841 & 9 \\
HOLANDA & 604 & 246 & 3627 & 6.005 & 3.863 & 9 \\
HUNGRIA & 1233 & 629 & 6500 & 5.272 & 4.794 & 12 \\
IRLANDA & 503 & 214 & 3234 & 6.429 & 3.881 & 9 \\
ITÁLIA & 1088 & 669 & 4695 & 4.315 & 5.045 & 17 \\
NORUEGA & 440 & 218 & 2025 & 4.602 & 4.735 & 12 \\
POLÔNIA & 829 & 486 & 3300 & 3.981 & 4.719 & 13 \\
PORTUGAL & 587 & 294 & 3719 & 6.336 & 4.212 & 12 \\
REINO UNIDO & 758 & 306 & 4158 & 5.485 & 4.328 & 11 \\
REPÚBLICA & 153 & 107 & 349 & 2.281 & 3.814 & 12 \\
TCHECA & 282 & 225 & 731 & 2.592 & 2.264 & 6 \\
ROMÉNIA & 247 & 186 & 654 & 2,648 & 3.514 & 10 \\
RÚSSIA & 241 & 1429 & 3,780 & 3.584 & 10 \\
SUÉCIA & 378 & 137 & 727 & 3.203 & 3.996 & 14 \\
SUÍÇA & 227 & 151 & 1305 & 5.138 & 3.893 & 12 \\
UCRÂNIA & 254 & & & & \\
\hline
\end{tabular}




\section{ÁSIA/ORIENTE MÉDIO/OCEANIA | MÉTRICAS GERAIS DAS REDES BILATERAIS}

\begin{tabular}{ccccccc}
\hline & NÓS & NÓS FORTES & ARESTAS & GRAU MÉDIO & $\begin{array}{c}\text { COMP. MÉD. } \\
\text { CAM. }\end{array}$ & DIÂMETRO \\
ARMÊNIA & 121 & 72 & 349 & 2.884 & 3.425 & 9 \\
AUSTRÁLIA & 1825 & 511 & 20528 & 11,248 & 4.069 & 12 \\
CHINA & 519 & 382 & 1521 & 2,931 & 6.067 & 15 \\
COREIA DO & 134 & 103 & 351 & 2,619 & 3.239 & 8 \\
$\begin{array}{c}\text { SUL } \\
\text { EMIRADOS }\end{array}$ & 309 & 199 & 1053 & 3,408 & 4.541 & 12 \\
ARABES & 121 & 56 & 766 & 6,331 & 2.503 & 6 \\
FILIPINAS & 777 & 420 & 4019 & 5,172 & 6.164 & 14 \\
ÍNDIA & 299 & 7741 & 11,434 & 3.559 & 10 \\
ISRAEL & 677 & 531 & 3735 & 3,907 & 4.556 & 13 \\
JAPÃO & 956 & 269 & 3719 & 6,713 & 4.11 & 12 \\
LíBANO & 554 & 235 & 5638 & 8,921 & 3.763 & 8 \\
NOVA & 632 & 428 & 3818 & 5,340 & 4.553 & 11 \\
ZELÂNDIA & 715 & 169 & 724 & 2,732 & 4.973 & 15 \\
PALESTINA & 265 & 529 & 2643 & 3.363 & 5.605 & 14 \\
TAILÂNDIA & 786 & 260 & 1453 & 3.855 & 3.452 & 12 \\
TURQUIA & 778 & & & & & 8 \\
VIETNÃ & 376 & & & & \\
\hline
\end{tabular}




\section{CLASSIFICAÇÕES DE FANPAGES POR CLUSTERS}

CULTURA | Actor, Art, Art Gallery, Artist, Art Museum, Arts \& Crafts Store, Arts \& Entertainment, Arts \& Humanities Website, Album, Auditorium, Author, Band, Book, Book \& Magazine Distributor, Book Genre, Book \& Magazines, Book Series, Bookstore, Civilization Museum, Comedian, Comedy Club, Concert Tour, Contemporary Art Museum, Cultural Center, Dance \& Night Club, Dance Studio, Dancer, Dance School, Dance Studio, Drive-In Movie Theater, Entertainment Website, Festival, Film Director, History Museum, Jazz \& Blues Club, Karaoke, Live Music Venue, Literary Arts, Literary Editor, Modern Art Museum, Movie, Movie Character, Movie Theater, Museum, Museum/Art Gallery, Music, Musical Genre, Musical Instrument, Musical Instrument Store, Music Award, Music Chart, Musician, Musician/Band, Music Production Studio, Music Video, Opera House, Orchestra, Playlist, Record Label, Performance \& Event Venue, Performance Art, Performance Art Theatre, Performing Arts, Society \& Culture Website, Song, Theatrical Play, Theatrical Productions, Visual Arts, Writer

MíDIA | Advertising/Marketing, Advertising Agency, App Pages, Blogger, Broadcasting \& Media Production Company, Business \& Economy Website, Camera/Photo, Canal, Computers \& Internet Website, Entertainment Website, Event Videographer, Health \& Wellness Website, Home \& Garden Website, Journalist, Magazine, Marketing Agency, Marketing Consultant, Market Research Consultant, Media, Media/News Company, Media Agency, Movie/Television Studio, News \& Media Website, Newspaper, News Personality, Personal Blog, Personal Website, Photographer, Photographer Videography, Photography Videography, Podcast, Podcast Producer, Public Figure, Public Relations Agency, Publisher, Radio Station, Recreation \& Sports Website, Reference Website, Social Media Agency, Television Service Provider, TV, TV/Movie Award, TV Channel, TV Network, TV Show, Video, Video Creator, Video Game, Teens \& Kids Website, Website

GOVERNO/POLÍTICA | Armed Forces, City Hall, Consulate \& Embassy, County, 
Courthouse, Government Building, Government Official, Government Organization, Government Website, Lobbyist, Military Base, Monarch, Passport \& Visa Service, Political Candidate, Political Ideology, Political Organization, Political Party, Politician, Public \& Government Service, Public Service, Public Utility Company, State, State/Province/Region

ORGANIZAÇÕES/TERCEIRO SETOR | Animal Shelter, Baptist Church, Buddhist Temple, Catholic Church, Charity Organization, Child Protective Service, Christian Church, Church, Community Center, Community Organization, Country Club / Clubhouse, Disability Service, Environmental Conservation Organization, Environmental Service, Halfway House, Lutheran Church, Mosque, Nondenominational Church, Non-Governmental Organization (NGO), Nonprofit Organization, Organization, Private Members Club, Religious Center, Religious Place of Worship, Religious Organization, Retirement \& Assisted Living Facility, Senior Center, Social Club, Social Service, Sorority \& Fraternity, Synagogue, Youth Organization

TURISMO | Airline Company, Airline Industry Service, Airport, Airport Terminal, Amusement \& Theme Park, Aquarium, Beach, Beach Resort, Bed and Breakfast, Boat Rental, Boat Tour Agency, Bus Tour Agency, Bus Line, Casino, Circus, City, Country, Cruise Agency, Cruise Line, Currency Exchange, Eco Tour Agency, Highway, Historical Place, Hospitality Service, Hostel, Hot Air Balloon Tour Agency, Hotel, Hotel \& Lodging, Hotel Resort, Hotel Services Company, Inn, Island, Landmark \& Historical Place, Local \& Travel Website, Lodge, Monument, Mountain, National Park, Nature Preserve, Neighborhood, Park, Port, Railway Station, Railroad Company, Recreational Vehicle Dealership, Recreation Center, Region, Regional Website, Reservoir, Sightseeing Tour Agency, Ski Resort, State Park Tour Agency, Tour Guide, Tourist Information Center, Train Station, Transportation Service, Travel \& Transportation, Travel Agency, Travel Company, Travel Service, Vacation Home Rental, Water Park, Wildlife Sanctuary, Zoo 
EDUCAÇÃO | Art School, Aviation School, Academic Camp, Campus Building, Child Care Service, College \& University, Community College, Computer Training School, Concentration or Major, Cooking School, Culinary School, Degree, Education, Educational Consultant, Educational Research Center, Education Company, Education Website, Elementary School, Exchange Program, Field of Study, High School, Junior High School, Language, Language School, Library, Medical Research Center, Medical School, Music Lessons \& Instruction School, Middle School, Preschool, Private School, Public School, School, Science, Science Website, Scientist, Science Technology \& Engineering, Science Museum, Speciality School, Teacher, Tutor/Teacher, University Status

SETOR PRIVADO | Accessories, Accountant, Aerospace Company, Agriculture, Agriculture Company, Apartment \& Condo Building, Appliances, Automotive, Aircraft \& Boat; Automotive Repair Shop, Automotive Manufacturer, Automotive Wholesaler, Baby \& Children's Clothing Store, Baby Goods/Kids Goods, Bags/Luggage, Bank, Barber Shop, Biotechnology Company, Brand, Brokerage Firm, Business Center, Business Consultant, Business Service, Cabin, Car Dealership, Career Counselor, Cargo \& Freight Company, Car Rental, Cars, Chemical Company, Chiropractor, Clothing (Brand), Clothing Store, Collectibles Store, Commercial \& Industrial, Commercial \& Industrial Equipment Supplier, Commercial Bank, Company, Computer Company, Consulting Agency, Convention Center, Corporate Office, Cosmetics Store, Counselor, Criminal Lawyer, Day Care, Defense, Dentist \& Dental Office, Doctor, Electronics Store, Employment Agency, Endocrinologist, Energy Company, Engineering Service, Entrepreneur, Escape Game Room, Fashion Designer, Finance Company, Financial Consultant, Financial Planner, Financial Service, Footwear Store, Franchising Service, Forestry Service, Furniture Store, General Dentist, Gift Shop, Glass Manufacturer, Graphic Designer, Hair Salon, Health/Beauty, Healthcare Administrator, Health Spa, Home Decor, Home Improvement, Home Window Service, Hospital, Household Supplies, Immigration Lawyer, Industrial Company, Information Technology Company, Insurance Broker, Insurance Company, Internet Company, Internet Marketing Service, Investing 
Service, Jewelry/Watches, Jewelry \& Watches Store, Laser Hair Removal Service, Lawyer \& Law Firm, Legal, Legal Service, Loan Service, Local Business, Local Service, Medical \& Health, Medical Center, Medical Company, Medical Equipment Supplier, Medical Lab, Men's Clothing Store, Mental Health Service, Mobile Phone Shop, Motor Vehicle Company, Occupational Safety and Health Service, Office Supplies, Patio/Garden, Petroleum Service, Pet Supplies, Phone/Tablet, Plastic Surgeon, Post Office, Printing Service, Product/Service, Professional Service, Psychotherapist, Real Estate, Real Estate Agent, Real Estate Investment Firm, Retail Company, Robotics Company, Screen Printing \& Embroidery, Shopping \& Retail, Tattoo \& Piercing Shop, Textile Company, Thrift \& Consignment Store, Translator, Web Designer

COMUNIDADES DE INTERESSE | Cause, Community, Event, Interest, Event Planner, Flea Market, Home, Just for Fun

ESPORTES | Amateur Sports Team, Athlete, Baseball Field, Bicycle Shop, Coach, Fitness Boot Camp, Football Stadium, Golf Course \& Country Club, Gym/Physical Fitness Center, Fitness Model, Hiking Trail, Magician, Martial Arts School, Miniature Golf Course, Mountain Biking Shop, Outdoor \& Sporting Goods Company, Paddleboarding Center, Personal Coach, Professional Sports Team, Rafting/Kayaking Center, Recreation \& Sports Website, Recreation Center, Recreation Spot, Rock Climbing Gym, Scuba Diving Center, School Sports Team, Ski \& Snowboard School, Skydiving Center, Soccer Field, Sport, Sporting Goods Store, Sports, Sports \& Fitness Instruction, Sports \& Recreation, Sports \& Recreation Venue, Sports Club, Sports Event, Sports League, Sports Promoter, Sports Team, Sportswear Store, Stadium Arena \& Sports Venue, Surfing Sport, Tennis Court

GASTRONOMIA | African Restaurant, American Restaurant, Arabian Restaurant, Argentinian Restaurant, Asian Restaurant, Australian Restaurant, Bakery, Bar, Bar \& Grill, Barbecue Restaurant, Beer Bar, Beer Garden, Belgian Restaurant, Brazilian 
Restaurant, Breakfast \& Brunch Restaurant, Brewery, Buffet Restaurant, Bunsik Restaurant, Burger Restaurant, Cafe, Cafeteria, Canadian Restaurant, Candy Store, Cantonese Restaurant, Caterer, Chef, Chicken Joint, Chilean Restaurant, Chocolate Shop, Cocktail Bar, Coffee Shop, Comfort Food Restaurant, Cuisine, Cupcake Shop, Deli, Dessert Shop, Diner, Dive Bar, Eastern European Restaurant, Farmers Market, Family Style Restaurant, Fast Food Restaurant, Fish Market, Fondue Restaurant, Food \& Beverage, Food \& Beverage Company, Food Delivery Service, Foodservice Distributor, Food Stand, Food Tour Agency, Food Truck, French Restaurant, Fruit \& Vegetable Store, Gastropub, German Restaurant, Grocery Store, Health Food Restaurant, Hungarian Restaurant, Hot Dog Joint, Hot Pot Restaurant, Ice Cream Shop, Indonesian Restaurant, Indian Restaurant Internet Cafe, Italian Restaurant, Japanese Restaurant, Kitchen/Cooking, Korean Restaurant, Latin American Restaurant, Lebanese Restaurant, Meat Wholesaler, Mediterranean Restaurant, Mexican 